Quim. Nova, Vol. 34, No. 6, 1014-1020, 2011

\title{
CHEMICAL MODIFICATIONS OF A NATURAL XANTHONE AND ANTIMICROBIAL ACTIVITY AGAINST MULTIDRUG RESISTANT Staphylococcus aureus AND CYTOTOXICITY AGAINST HUMAN TUMOR CELL LINES
}

\author{
Ana Camila Micheletti, Neli Kika Honda, Dênis Pires de Lima e Adilson Beatriz* \\ Departamento de Química, Centro de Ciências Exatas e Tecnologia, Universidade Federal de Mato Grosso do Sul, Av. Senador \\ Filinto Müller, 1555, 79074-460 Campo Grande - MS, Brasil \\ Maria Rita Sant'ana e Nadia Cristina Pereira Carvalho \\ Seção de Análises Clínicas, Universidade Federal de Mato Grosso do Sul, Av. Senador Filinto Muller, s/n, 79080-190 Campo \\ Grande - MS, Brasil \\ Maria de Fatima Cepa Matos, Lyara Meira Marinho Queiróz e Danielle Bogo \\ Departamento de Farmácia-Bioquímica, Universidade Federal de Mato Grosso do Sul, CP 549, 79080-190 Campo Grande - MS, \\ Brasil \\ José Roberto Zorzatto \\ Faculdade de Computação, Universidade Federal de Mato Grosso do Sul, CP 549,79080-190 Campo Grande - MS, Brasil
}

Recebido em 19/10/10; aceito em 19/1/11; publicado na web em 29/3/11

\begin{abstract}
A series of $15 \omega$-aminoalkoxylxanthones containing methyl, ethyl, propyl, tert-butylamino and piperidinyl moieties were synthesized from a natural xanthone isolated from a lichen species. These compounds were tested for their in vitro antibacterial properties against Gram-positive and Gram-negative bacteria and cytotoxicity against a number of human tumor cell lines was too evaluated. The newly synthesized derivatives revealed selective activity against Staphylococcus aureus (Gram-positive), and the most promising results are for a multidrug resistant strain, for which six of these compounds showed good activity (MICs $4 \mu \mathrm{g} / \mathrm{mL}$ ). Many derivatives inhibited tumor cells growth and most compounds were active on multiple lines.
\end{abstract}

Keywords: xanthone; antimicrobial activity; cytotoxic activity.

\section{INTRODUCTION}

Nature continues to be a rich source of structurally diverse small organic molecules, and natural products play a significant role in the discovery and development of new drugs for the treatment of human diseases. Over $60 \%$ of approved drugs are either natural products, derivatives or based on their structures. Seventyeight percent of antibacterials and $74 \%$ of antitumor compounds are related to natural products, and almost half of the best-selling pharmaceuticals are natural or are related to them. ${ }^{1}$ Natural products can be highly functionalized and possess multi-functional groups with well-balanced polarity and hydrophobicity, frequently with high oxygen content. Therefore, when it's necessary chemical and biological methods are often applied to modify these natural products to optimize their desired activity and physical properties before they can be further developed as a therapeutic agent. ${ }^{2}$

Lichens are one important source of biologically active natural compounds. They are spread world-wide and live in symbiotic relationship with fungi (mycobiont), algae (phycobiont) and/or cyanobacteria (photobiont) ${ }^{3}$ and have been used in folk medicine for centuries, as traditional medicines. ${ }^{4}$ Many different secondary metabolites have been isolated from lichens including aliphatic, cycloaliphatic, aromatic and terpenic components that are unique with respect to those found in higher plants. ${ }^{5}$ Screening of lichen extracts has revealed the frequent occurrence of metabolites with antibiotic, antimycobacterial, antiviral, antitumor, analgesic, antiallergic and antipiretic properties, and also substances that inhibit plant growth as well as several enzymes. ${ }^{4,6}$

Xanthone compounds represent a class of these lichen substances, but they are widely distributed in nature, ${ }^{2}$ and can also be isolated from higher plants and microorganisms. ${ }^{7}$ In recent years, xanthones and xanthone derivatives have been reported to have significant pharmacological activities based on their diverse structures. ${ }^{8-20}$ Their interesting structural scaffold and the significant biological activities have led many scientists to isolate, modify or synthesize different xanthones for the development of prospective new drug candidates. ${ }^{7}$

Many xanthones bearing nitrogenated side chains connected to the phenolic core in different positions by $\mathrm{C}, \mathrm{O}$ or $\mathrm{N}$ atoms have been synthesized during the last 10 years, and this group of molecules have showed interesting biological effects ${ }^{14,18,21-25}$ including antibacterial ${ }^{26}$ and cytotoxic activities..$^{27,28}$

Based on this information and as a part of our efforts to enhance biological activities of lichen substances, we have decided to synthesize five series (dimethyl, diethyl, dipropyl, t-butylamine and piperidinyl) of ( $\omega$-aminoalkoxyl)-xanthone derivatives from lichexanthone (1), a naturally occurring xanthone isolated from the lichen Parmotrema lichexanthonicum, and evaluate their cytotoxic acitvity against human tumor cell lines and their antimicrobial activity against selected bacterial strains, including multidrug resistant Staphylococcus aureus, aiming to establish a relationship between side chains characteristics and biological activity. 


\section{EXPERIMENTAL}

\section{General}

Silica gel (Carlo Erba 70-270 mesh) was used for column chromatography. All solvents and chemicals were analytical grade. NMR spectra were taken in a Bruker DPX-300 spectrometer (solvent is indicated for each compound; $\mathrm{C}$ and $\mathrm{H}$ atoms from side chains were consecutively numbered from 10 (for the group attached to oxygen) to 17. Mass spectra (EI, $70 \mathrm{eV}$ ) were run on a Shimadzu CGMS QP2010 Plus gas chromatography mass spectrometer, in direct injection mode, and melting points were recorded in a Uniscience do Brasil apparatus, model 498.

\section{Isolation and synthesis}

Isolation and demethylation (Scheme 1) of lichexanthone (1) were carried out as a previous described procedure. ${ }^{29}$

\section{General procedure for $\omega$-bromoalkoxylxanthones (3), (4) and (5)}

$\omega$-bromoalkoxylxanthones $(\mathbf{3}),(\mathbf{4})$ and (5) were prepared by treatment of (2) (50 mg, $0.2 \mathrm{mmol}$ ) with $0.5 \mathrm{~mL}$ of 1,3-dibromopropane, 1,4-dibromobutane or 1,5-dibromopentane, according to the method described by Sousa et al..$^{30}$ Chromatographic column separations (hexane/ethyl acetate 2\% (v/v) as eluent) gave desired compounds in good yields (Scheme 1).

\section{3,6-bis(3-bromopropoxy)-1-hydroxy-8-methyl-9H-xanthen-9-one} (3)

Yield 65\%; Mp: 139-140 ${ }^{\circ} \mathrm{C}$ (from $\mathrm{CHCl}_{3}$ ); ${ }^{1} \mathrm{H} \mathrm{NMR}(300 \mathrm{MHz}$; $\left.\mathrm{CDCl}_{3}\right): \delta=2.35(\mathrm{H}-11, \mathrm{~m}, 4 \mathrm{H}), 2.81\left(\mathrm{CH}_{3}-\mathrm{Ph}, \mathrm{s}, 3 \mathrm{H}\right), 3.60(\mathrm{H}-12$, $\mathrm{m}, 4 \mathrm{H}), 4.17$ (H-10, m, 4H), $6.26(\mathrm{H}-2$, br s, 1H), 6.29 (H-4, br s, $1 \mathrm{H}), 6.63(\mathrm{H}-7$, br s, $1 \mathrm{H}), 6.65(\mathrm{H}-5$, br s, $1 \mathrm{H}), 13.33(\mathrm{OH}, \mathrm{s}, 1 \mathrm{H}) ;{ }^{13} \mathrm{C}$ NMR (75 MHz; $\left.\mathrm{CDCl}_{3}\right): \delta=23.4\left(\mathrm{CH}_{3}-\mathrm{Ph}\right) ; 29.6(\mathrm{C}-11) ; 32.0(\mathrm{C}-12)$; 65.7 (C-10); 92.4 (C-4); 97.2 (C-2); 99.0 (C-5); 104.2 (C-9a); 113.1 (C-8a); 115.7 (C-7); 143.5 (C-8); 156.9 (C-4a); 159.3 (C-10a); 162.8 (C-6); 163.7 (C-1); 164.8 (C-3); 182.3 (C-9); MS (EI) m/z (\%): 498 (22) $[\mathrm{M}-2]^{+}, 500(42)[(\mathrm{M}-2)+2]^{+}, 502(22)[(\mathrm{M}-2)+4]^{+}, 421$ (97), 419 (100), 391 (22), 229 (21).

3,6-bis(3-bromobutoxy)-1-hydroxy-8-methyl-9H-xanthen-9-one (4)

Yield 67.7\%; Mp: $117-118{ }^{\circ} \mathrm{C}$ (from $\mathrm{CHCl}_{3}$ ); ${ }^{1} \mathrm{H}$ NMR $(300$ $\left.\mathrm{MHz} ; \mathrm{CDCl}_{3}\right): \delta=2.00(\mathrm{H}-11, \mathrm{H}-12, \mathrm{~m}, 8 \mathrm{H}), 2.77\left(\mathrm{CH}_{3}-\mathrm{Ph}, \mathrm{s}, 3 \mathrm{H}\right)$, $3.47(\mathrm{H}-13,2 \mathrm{t}, J=6.2 \mathrm{~Hz}, 4 \mathrm{H}), 4.02(\mathrm{H}-10, \mathrm{~m}, 4 \mathrm{H}), 6.21(\mathrm{H}-2, \mathrm{~d}, J$ $=2.2 \mathrm{~Hz}, 1 \mathrm{H}), 6.23(\mathrm{H}-4, \mathrm{~d}, J=2.2 \mathrm{~Hz}, 1 \mathrm{H}), 6.57(\mathrm{H}-5, \mathrm{H}-7$, br s, $2 \mathrm{H}), 13.31(\mathrm{OH}, \mathrm{s}, 1 \mathrm{H}) ;{ }^{13} \mathrm{C} \mathrm{NMR}\left(75 \mathrm{MHz} ; \mathrm{CDCl}_{3}\right): \delta=23.4\left(\mathrm{CH}_{3}\right.$ $\mathrm{Ph}$ ); 27.6 (C-11); 29.3 (C-12); 33.2 (C-13); 67.3 (C-10); 92.4 (C-4); 97.1 (C-2); 98.9 (C-5); 104.1 (C-9a); 113.0 (C-8a); 115.7 (C-7); 143.5 (C-8); 156.9 (C-4a); 159.4 (C-10a); 163.0 (C-6); 163.7 (C-1); 165.1 (C-3); 182.3 (C-9); MS (EI) $m / z$ (\%): 526 (19) $[\mathrm{M}-2]^{+}, 528$ (37) $[(\mathrm{M}-2)+2]^{+}, 530(19)[(\mathrm{M}-2)+4]^{+}, 447(80), 449(80), 395$ (33), 394 (46), 393 (35), 393 (35), 259 (22), 229 (30), 136 (38), 135 (41), 55 (100).

\section{3,6-bis(3-bromopentoxy)-1-hydroxy-8-methyl-9H-xanthen-9-one} (5)

Yield 77.4\%; Mp: 89-90 ${ }^{\circ} \mathrm{C}$ (from $\mathrm{CHCl}_{3}$ ); ${ }^{1} \mathrm{H} \mathrm{NMR}(300 \mathrm{MHz}$; $\left.\mathrm{CDCl}_{3}\right): \delta=1.61(\mathrm{H}-12, \mathrm{~m}, 4 \mathrm{H}), 1.79(\mathrm{H}-13, \mathrm{~m}, 4 \mathrm{H}), 1.89(\mathrm{H}-11, \mathrm{~m}$, $4 \mathrm{H}), 2.71\left(\mathrm{CH}_{3}-\mathrm{Ph}, \mathrm{s}, 3 \mathrm{H}\right), 3.42(\mathrm{H}-14,2 \mathrm{t}, J=6.6 \mathrm{~Hz}, 4 \mathrm{H}), 3.94(\mathrm{H}-$ 10, m, 4H), 6.15 (H-2, H-4, br s, 2H), 6.48 (H-5, H-7, s, 2H), 13.27 $(1 \mathrm{H}, \mathrm{s}, \mathrm{OH}) ;{ }^{13} \mathrm{C}$ NMR $\left(75 \mathrm{MHz} ; \mathrm{CDCl}_{3}\right): \delta=23.4\left(\mathrm{CH}_{3}-\mathrm{Ph}\right) ; 24.7$ (C-12); 28.2 (C-11); 32.4 (C-13); 33.6 (C-14); 68.0 (C-10); 92.2 (C-
4); 97.0 (C-2); 98.7 (C-5); 103.8 (C-9a); 112.6 (C-8a); 115.6 (C-7); 143.1 (C-8); 156.7 (C-4a); 159.1 (C-10a); 163.0 (C-6); 163.5 (C-1); 165.9 (C-3); 182.1 (C-9); MS (EI) $\mathrm{m} / z$ (\%): 554 (19) [M - 2] $]^{+}, 556$ (37) $[(\mathrm{M}-2)+2]^{+}, 558(19)[(\mathrm{M}-2)+4]^{+}, 477(100), 475(99), 408$ (79), 406 (75), 380 (30), 378 (30), 258 (40), 229 (43), 69 (87).

\section{General procedure for the synthesis of ( $\omega$-aminoalkoxyl)-} xanthone derivatives $(6)-(20)$

Each haloalkanolic derivative [20 mg, (3) - $0.04 \mathrm{mmol}$, (4) - 0.038 $\mathrm{mmol},(\mathbf{5})-0.036 \mathrm{mmol}$ ] was stirred with $0.5 \mathrm{~mL}$ of the corresponding amine (dimethyl, diethyl, dipropyl, $t$-butylamine or piperidine) in acetone for about $48 \mathrm{~h}$ at room temperature. After solvent evaporation, the mixture was dissolved in an $\mathrm{HCl}$ aqueous solution (3\%) and shaken out with ethyl acetate. The $\mathrm{pH}$ of the aqueous layer was raised to 10 with aqueous $\mathrm{KOH}$ and then it was shaken out again with ethyl acetate. The organic layer was separated and dried over $\mathrm{Na}_{2} \mathrm{SO}_{4}$ and the residue after the evaporation of the solvent could be characterized as the desired compound. In this way the $\omega$-aminoalkoxylxanthones (6) - (20) were obtained.

3,6-bis[3-(dimethylamino)propoxy]-1-hydroxy-8-methyl-9Hxanthen-9-one $(6)^{29}$

Yield $98 \%$.

3,6-bis[4-(dimethylamino)butoxy]-1-hydroxy-8-methyl-9Hxanthen-9-one (7)

Yield 98\%; Mp: 80-82 ${ }^{\circ} \mathrm{C}$ (dec.) (from $\left.\mathrm{MeOH}\right) ;{ }^{1} \mathrm{H}$ NMR (300 MHz; methanol-d $\left.{ }_{4}\right): \delta=1.70(\mathrm{H}-12$, br s, $4 \mathrm{H}), 1.82(\mathrm{H}-11$, br s, $4 \mathrm{H})$, $2.28(\mathrm{H}-14, \mathrm{~s}, 12 \mathrm{H}), 2.42(\mathrm{H}-13, \mathrm{t}, J=5.9 \mathrm{~Hz}, 4 \mathrm{H}), 2.79\left(\mathrm{CH}_{3}-\mathrm{Ph}\right.$, s, $3 \mathrm{H}), 4.09(\mathrm{H}-10, \mathrm{~m}, 4 \mathrm{H}), 6.24(\mathrm{H}-3$, br s, $1 \mathrm{H}), 6.39$ (H-4, br s, 1H), $6.70(\mathrm{H}-7$, br s, $1 \mathrm{H}), 6.77$ (H-5, br s, $1 \mathrm{H}) ;{ }^{13} \mathrm{C} \mathrm{NMR}(75 \mathrm{MHz}$; DMSO-d $)_{6}$ : $\delta=23.0(\mathrm{C}-12) ; 23.5\left(\mathrm{CH}_{3}-\mathrm{Ph}\right) ; 26.3(\mathrm{C}-11) ; 45.2(\mathrm{C}-14)$; 58.6 (C-13); 68.3 (C-10); 92.3 (C-4); 97.3 (C-2); 99.3 (C-5); 103.2 (C-9a); 111.9 (C-8a); 116.0 (C-7); 142.7 (C-8); 156.6 (C-4a); 158.9 (C-10a); 163.3 (C-1 and C-6); 165.2 (C-3); 181.7 (C-9); MS (EI) $\mathrm{m} / \mathrm{z}$ (\%): 456 (16) [M]+, 441 (6), 357 (14), 100 (34), 58 (100).

\section{3,6-bis\{[5-(dimethylamino)pentyl]oxy\}-1-hydroxy-8-methyl-9H-} xanthen-9-one (8)

Yield 99\%; Mp: 65-67 ${ }^{\circ} \mathrm{C}$ (dec.) (from $\left.\mathrm{MeOH}\right) ;{ }^{1} \mathrm{H}$ NMR (300 $\left.\mathrm{MHz} ; \mathrm{CDCl}_{3}\right): \delta=1.50(\mathrm{H}-12, \mathrm{H}-13$, br s, $8 \mathrm{H}), 1.82(\mathrm{H}-11, \mathrm{~m}, 4 \mathrm{H})$, $2.21(\mathrm{H}-15, \mathrm{~s}, 12 \mathrm{H}), 2.28(\mathrm{H}-14, \mathrm{t}, J=7.1 \mathrm{~Hz}, 4 \mathrm{H}), 2.79\left(\mathrm{CH}_{3}-\mathrm{Ph}, \mathrm{s}\right.$, $3 \mathrm{H}), 3,99(\mathrm{H}-10, \mathrm{~m}, 4 \mathrm{H}), 6.23(\mathrm{H}-2$, br s, 1H), $6.25(\mathrm{H}-4$, br s, $1 \mathrm{H})$, $6.60\left(\mathrm{H}-5, \mathrm{H}-7\right.$, br s, 2H), $13.35(\mathrm{OH}$, br s, $1 \mathrm{H}) ;{ }^{13} \mathrm{C}$ NMR $(75 \mathrm{MHz}$; $\left.\mathrm{CDCl}_{3}\right): \delta=23.4\left(\mathrm{CH}_{3}-\mathrm{Ph}\right) ; 23.9(\mathrm{C}-12) ; 27.3(\mathrm{C}-13) ; 28.9(\mathrm{C}-11) ; 45.4$ (C-15); 59.6 (C-14); 68.3 (C-10); 92.4 (C-4); 97.1 (C-2); 98.8 (C-5); 103.9 (C-9a); 112.8 (C-8a); 115.8 (C-7); 143.3 (C-8); 156.9 (C-4a); 159.4 (C-10a); 163.2 (C-6); 163.6 (C-1); 165.3 (C-3); 182.3 (C-9); MS (EI) $m / z$ (\%): 484 (1) [M], 469 (2), 384 (2), 114 (45), 58 (100).

\section{3,6-bis[3-(diethylamino)propoxy]-1-hydroxy-8-methyl-9H- xanthen-9-one (9)}

Yield 97\%; gum; ${ }^{1} \mathrm{H}$ NMR $\left(300 \mathrm{MHz}\right.$; acetone- $\left.\mathrm{d}_{6}\right): \delta=0.99(\mathrm{H}-15$, $\mathrm{t}, J=7.2 \mathrm{~Hz}, 12 \mathrm{H}), 1.92(\mathrm{H}-11, \mathrm{~m}, 4 \mathrm{H}), 2.51(\mathrm{H}-13, \mathrm{~m}, 8 \mathrm{H}), 2.59$ (H-12, 2t, $J=6.7 \mathrm{~Hz}, 4 \mathrm{H}), 2.77\left(\mathrm{CH}_{3}-\mathrm{Ph}, \mathrm{s}, 3 \mathrm{H}\right), 4.18(\mathrm{H}-10, \mathrm{~m}, 4 \mathrm{H})$, 6.24 (H-2, br s, 1H), 6.36 (H-4, br s, 1H), $6.72(\mathrm{H}-7$, br s, 1H), 6.76 (H-5, br s, 1H); ${ }^{13} \mathrm{C}$ NMR (75 MHz; methanol-d $\left.\mathrm{d}_{4}\right): \delta=11.5$ (C-14); $23.6\left(\mathrm{CH}_{3}-\mathrm{Ph}\right) ; 26.9$ (C-11); 47.8 (C-13); 50.2 (C-12); 67.9 (C-10); 93.2 (C-4); 98.2 (C-2); 99.9 (C-5); 104.8 (C-9a); 113.5 (C-8a); 116.7 (C-7); 144.2 (C-8); 158.2 (C-4a); 160.5 (C-10a); 164.5 (C-6); 164.6 (C-1); 166.6 (C-3); 183.2 (C-9); MS (EI) m/z (\%): 484 (10) [M] $]^{+}$, 469 (9), 455 (13), 113 (20), 86 (100), 72 (23). 
3,6-bis[4-(diethylamino)butoxy]-1-hydroxy-8-methyl-9H-xanthen9-one (10)

Yield 94\%; Mp: 61-62 ${ }^{\circ} \mathrm{C}$ (from MeOH); ${ }^{1} \mathrm{H}$ NMR $(300 \mathrm{MHz}$; methanol- $\left.\mathrm{d}_{4}\right): \delta=1.07(\mathrm{H}-15, \mathrm{t}, J=7.3 \mathrm{~Hz}, 12 \mathrm{H}), 1.68(\mathrm{H}-12, \mathrm{~m}$, $4 \mathrm{H}), 1.78(\mathrm{H}-11, \mathrm{~m}, 4 \mathrm{H}), 2.59(\mathrm{H}-13, \mathrm{H}-14, \mathrm{~m}, 12 \mathrm{H}), 2.71\left(\mathrm{CH}_{3}-\mathrm{Ph}\right.$, s, $3 \mathrm{H}), 4.03(\mathrm{H}-10, \mathrm{~m}, 4 \mathrm{H}), 6.15(\mathrm{H}-2$, br s, 1H), $6.26(\mathrm{H}-4$, br s, 1H), 6.57 (H-7, br s, 1H), $6.61(\mathrm{H}-5$, br s, $1 \mathrm{H}) ;{ }^{13} \mathrm{C} \mathrm{NMR}(75 \mathrm{MHz}$; methanol-d $\left.\mathrm{d}_{4}\right): \delta=11.2(\mathrm{C}-15) ; 23.6\left(\mathrm{CH}_{3}-\mathrm{Ph}\right) ; 23.7(\mathrm{C}-12) ; 28.2(\mathrm{C}-$ 11); 47.7 (C-14); 53.4 (C-13); 69.4 (C-10); 93.2 (C-4); 96,1 (C-2); 100.0 (C-5); 104.8 (C-9a); 113.5 (C-8a); 116.8 (C-7); 144.3 (C-8); 158.2 (C-4a); 160.6 (C-10a); 164.5 (C-6); 164.8 (C-1); 166.7 (C-3); 183.3 (C-9); MS (EI) m/z (\%): 512 (2) [M] $]^{+}, 497$ (3), 483 (8), 128 (13), 86 (100).

\section{3,6-bis\{[5-(diethylamino)pentyl]oxy\}-1-hydroxy-8-methyl-9H-} xanthen-9-one (11)

Yield 98\%; Mp: 75-76 ${ }^{\circ} \mathrm{C}$ (dec) (from $\left.\mathrm{MeOH}\right) ;{ }^{1} \mathrm{H}$ NMR (300 $\left.\mathrm{MHz} ; \mathrm{CDCl}_{3}\right): \delta=1.00(\mathrm{H}-16, \mathrm{t}, J=7.2 \mathrm{~Hz}, 12 \mathrm{H}), 1.48(\mathrm{H}-12, \mathrm{H}-13$, $\mathrm{m}, 8 \mathrm{H}), 1.81(\mathrm{H}-11, \mathrm{~m}, 4 \mathrm{H}), 2.43(\mathrm{H}-14, \mathrm{t}, J=7.2 \mathrm{~Hz}, 4 \mathrm{H}), 2.52$ $(\mathrm{H}-15, \mathrm{q}, J=7.1 \mathrm{~Hz}, 8 \mathrm{H}), 2.80\left(\mathrm{CH}_{3}-\mathrm{Ph}, \mathrm{s}, 3 \mathrm{H}\right), 4.61(\mathrm{H}-10, \mathrm{~m}$, $4 \mathrm{H}), 6.25(\mathrm{H}-2$, br s, $1 \mathrm{H}), 6.27(\mathrm{H}-4$, br s, $1 \mathrm{H}), 6.62(\mathrm{H}-5, \mathrm{H}-7,1 \mathrm{H})$, $13.36(\mathrm{OH}, \mathrm{s}, 1 \mathrm{H}) ;{ }^{13} \mathrm{C}$ NMR $\left(75 \mathrm{MHz} ; \mathrm{CDCl}_{3}\right): \delta=11.6(\mathrm{C}-16)$; $23.4\left(\mathrm{CH}_{3}-\mathrm{Ph}\right) ; 24.1$ (C-12); 26.8 (C-13); 29.0 (C-11); 46.9 (C-15); 52.8 (C-14); 68.4 (C-10); 92.4 (C-4); 97.2 (C-2); 98.9 (C-5); 103.9 (C-9a); 112.8 (C-8a); 115.8 (C-7); 143.3 (C-8); 156.9 (C-4a); 159.4 (C-10a); 163.3 (C-6); 163.7 (C-1); 165.3 (C-3); 182.3 (C-9); MS (EI) $\mathrm{m} / \mathrm{z}(\%): 540$ (1) $[\mathrm{M}]^{+}, 525$ (4), 511 (10), 412 (6), 142 (19), $85(100)$

\section{3,6-bis[3-(dipropylamino)propoxy]-1-hydroxy-8-methyl-9H-} xanthen-9-one (12)

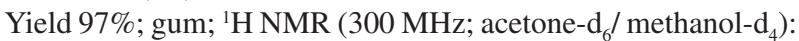
$\delta=0.86(\mathrm{H}-15, \mathrm{t}, J=7.3 \mathrm{~Hz}, 12 \mathrm{H}), 1.43(\mathrm{H}-14, \mathrm{~m}, 8 \mathrm{H}), 1.92(\mathrm{H}-11$, m, 4H), $2.37(\mathrm{H}-13, \mathrm{t}, J=7.2 \mathrm{~Hz}, 8 \mathrm{H}), 2.59(\mathrm{H}-12,2 \mathrm{t}, J=6.6 \mathrm{~Hz}$, $4 \mathrm{H}), 2.80\left(\mathrm{CH}_{3}-\mathrm{Ph}, \mathrm{s}, 3 \mathrm{H}\right), 4.21(\mathrm{H}-10, \mathrm{~m}, 4 \mathrm{H}), 6.27(\mathrm{H}-2, \mathrm{~d}, J=$ $2.1 \mathrm{~Hz}, 1 \mathrm{H}), 6.42(\mathrm{H}-4, \mathrm{~d}, J=2.1 \mathrm{~Hz}, 1 \mathrm{H}), 6.77(\mathrm{H}-7$, br s, $1 \mathrm{H}), 6.82$

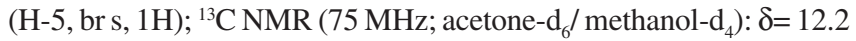
(C-15); 21.2 (C-14); $23.4\left(\mathrm{CH}_{3}-\mathrm{Ph}\right) ; 27.8$ (C-11); 51.0 (C-12); 57.0 (C-13); 67.6 (C-10); 93.0 (C-4); 97.9 (C-2); 99.8 (C-5); 104.4 (C-9a); 113.2 (C-8a); 116.8 (C-7); 144.0 (C-8); 157.9 (C-4a); 160.3 (C-10a); 164.3 (C-6); 164.7 (C-1); 166.6 (C-3); 183.1 (C-9); MS (EI) $\mathrm{m} / \mathrm{z}(\%)$ : $541(2)[\mathrm{M}+1]^{+}, 540(1)[\mathrm{M}]^{+}, 512$ (34), 241 (4), 114 (60), 86 (100).

\section{3,6-bis[4-(dipropylamino)butoxy]-1-hydroxy-8-methyl-9H-} xanthen-9-one (13)

Yield 98\%; Mp: 70-72 ${ }^{\circ} \mathrm{C}$ (from $\mathrm{MeOH}$ ); ${ }^{1} \mathrm{H}$ NMR (300 MHz; $\left.\mathrm{CDCl}_{3}\right): \delta=0.85(\mathrm{H}-16, \mathrm{t}, J=7.3 \mathrm{~Hz}, 12 \mathrm{H}), 1.43(\mathrm{H}-15, \mathrm{~m}, 8 \mathrm{H}), 1.59$ $(\mathrm{H}-12, \mathrm{~m}, 4 \mathrm{H}), 1.80$ (H-11, m, 4H), 2.35 (H-14, t, $J=7.3 \mathrm{~Hz}, 8 \mathrm{H})$, $2.45(\mathrm{H}-13, \mathrm{t}, J=7.2 \mathrm{~Hz}, 4 \mathrm{H}), 2.80\left(\mathrm{CH}_{3}-\mathrm{Ph}, \mathrm{s}, 3 \mathrm{H}\right), 4.01(\mathrm{H}-10$, $\mathrm{m}, 4 \mathrm{H}), 6.24(\mathrm{H}-2$, br s, 1H), $6.26(\mathrm{H}-4$, br s, 1H), 6.61 (H-7, H-5, br s, $2 \mathrm{H}) ;{ }^{13} \mathrm{C} \mathrm{NMR}\left(75 \mathrm{MHz} ; \mathrm{CDCl}_{3}\right): \delta=12.0(\mathrm{C}-16) ; 20.2(\mathrm{C}-15)$; $23.4\left(\mathrm{CH}_{3}-\mathrm{Ph}\right) ; 23.7$ (C-12); 27.0 (C-11); 53.8 (C-14); 56.2 (C-13); 68.4 (C-10); 92.4 (C-4); 97.1 (C-2); 98.9 (C-5); 104.0 (C-9a); 112.7 (C-8a); 115.8 (C-7); 143.3 (C-8); 156.9 (C-4a); 159.4 (C-10a); 163.3 (C-6); 163.6 (C-1); 165.3 (C-3); 182.3 (C-9); MS (EI) m/z (\%): 568 (2) $[\mathrm{M}]^{+}, 553$ (0.3), 539 (45), 525. (1), 156 (19), 128 (32), 114 (100).

\section{3,6-bis\{[5-(dipropylamino)pentyl]oxy\}-1-hydroxy-8-methyl-9H- xanthen-9-one (14)}

Yield 96\%; Mp: 65-66 ${ }^{\circ} \mathrm{C}$ (from $\mathrm{MeOH}$ ); ${ }^{1} \mathrm{H}$ NMR (300 MHz; $\left.\mathrm{CDCl}_{3}\right): \delta=0.85(\mathrm{H}-17, \mathrm{t}, J=7 \mathrm{~Hz}, 12 \mathrm{H}), 1.44(\mathrm{H}-12, \mathrm{H}-13, \mathrm{H}-16$, $\mathrm{m}, 16 \mathrm{H}), 1.81(\mathrm{H}-11, \mathrm{~m}, 4 \mathrm{H}), 2.35(\mathrm{H}-15, \mathrm{t}, J=7.6 \mathrm{~Hz}, 8 \mathrm{H}), 2.41$ (H-14, br s, 4H), $2.81\left(\mathrm{CH}_{3}-\mathrm{Ph}, \mathrm{s}, 3 \mathrm{H}\right), 4.00(\mathrm{H}-10, \mathrm{~m}, 4 \mathrm{H}), 6.25(\mathrm{H}-2$, br s, 1H), 6.27 (H-4, br s, 1H), $6.62(\mathrm{H}-5, \mathrm{H}-7$, br s, 2H), $13.36(\mathrm{OH}$, br s, $1 \mathrm{H}) ;{ }^{13} \mathrm{C}$ NMR $\left(75 \mathrm{MHz} ; \mathrm{CDCl}_{3}\right): \delta=12.0(\mathrm{C}-17) ; 20.2(\mathrm{C}-16)$; $23.4\left(\mathrm{CH}_{3}-\mathrm{Ph}\right) ; 24.0$ (C-12); 26.9 (C-13); 29.0 (C-11); 54.0 (C-14); 56.3 (C-15); 68.4 (C-10); 92.4 (C-4); 97.1 (C-2); 98.8 (C-5); 104.0 (C-9a); 112.8 (C-8a); 115.8 (C-7); 143.3 (C-8); 156.9 (C-4a); 159.4 (C-10a); 163.3 (C-6); 163.6 (C-1); 165.3 (C-3); 182.3 (C-9); MS (EI) $\mathrm{m} / \mathrm{z}(\%): 596$ (2) [M] $]^{+}, 567$ (67), 553 (8), 440 (5), 269 (8), 170 (13), 142 (17), 114 (100), 86 (14).

\section{3,6-bis[3-(tert-butylamino)propoxy]-1-hydroxy-8-methyl-9H- xanthen-9-one (15)}

Yield 96\%; Mp: 85-87 ${ }^{\circ} \mathrm{C}$ (dec.) (from $\left.\mathrm{MeOH}\right) ;{ }^{1} \mathrm{H}$ NMR $(300$ MHz; acetone- $\left.\mathrm{d}_{6}\right): \delta=1.07(\mathrm{H}-14, \mathrm{~s}, 18 \mathrm{H}), 1.90(\mathrm{H}-11, \mathrm{~m}, 4 \mathrm{H}), 2.72$ $(\mathrm{H}-12,2 \mathrm{t}, J=6.6 \mathrm{~Hz}, 4 \mathrm{H}), 2.76\left(\mathrm{CH}_{3}-\mathrm{Ph}, \mathrm{s}, 3 \mathrm{H}\right), 4.20(\mathrm{H}-10, \mathrm{~m}, 4 \mathrm{H})$, $6.22(\mathrm{H}-2, \mathrm{~d}, J=2.3 \mathrm{~Hz}, 1 \mathrm{H}), 6.34(\mathrm{H}-4, \mathrm{~d}, J=2.3 \mathrm{~Hz}, 1 \mathrm{H}), 6.70$ (H-7, br s, 1H), 6.73 (H-5, br s, 1H); ${ }^{13} \mathrm{C}$ NMR (75 MHz; methanol$\left.\mathrm{d}_{4}\right): \delta=24.3\left(\mathrm{CH}_{3}-\mathrm{Ph}\right) ; 28.6(\mathrm{C}-15) ; 30.7(\mathrm{C}-11) ; 40.4(\mathrm{C}-13) ; 51.9$ (C-12); 68.9 (C-10); 913.2 (C-4); 98.1 (C-2); 100.0 (C-5); 104.7 (C-9a); 113.5 (C-8a); 116.6 (C-7); 144.1 (C-8); 158.1 (C-4a); 160.2 (C-10a); 164.4 (C-6); 164.5 (C-1); 166.5 (C-3); 183.1 (C-9); MS (EI) $m / z$ (\%): 484 (1) [M] $]^{+}, 469$ (62), 413 (42), 372 (11), 356 (16), 259 (17), 227 (15), 98 (100).

\section{3,6-bis[4-(tert-butylamino)butoxy]-1-hydroxy-8-methyl-9H- xanthen-9-one (16)}

Yield 94\%; Mp: 154- $155{ }^{\circ} \mathrm{C}$ (dec.) (from $\left.\mathrm{MeOH}\right) ;{ }^{1} \mathrm{H}$ NMR (300 MHz; methanol-d $\left.\mathrm{d}_{4}\right): \delta=1.27(\mathrm{H}-15, \mathrm{~s}, 18 \mathrm{H}), 1.79(\mathrm{H}-12, \mathrm{~m}, 4 \mathrm{H}), 1.90$ (H-11, m, 4H), $2.68\left(\mathrm{CH}_{3}-\mathrm{Ph}, \mathrm{s}, 3 \mathrm{H}\right), 2.86(\mathrm{H}-13,2 \mathrm{t}, J=7.4 \mathrm{~Hz}, 4 \mathrm{H})$, 4.05 (H-10, br s, 4H), 6.13 (H-2, br s, 1H), 6.23 (H-4, br s, 1H), 6.53 (H-7, br s, 1H), 6.57 (H-5, br s, $1 \mathrm{H}) ;{ }^{13} \mathrm{C}$ NMR (75 MHz; methanol$\left.\mathrm{d}_{4}\right): \delta=23.6\left(\mathrm{CH}_{3}-\mathrm{Ph}\right) ; 26.3(\mathrm{C}-12) ; 27.3(\mathrm{C}-15) ; 27.5(\mathrm{C}-11) ; 42.8$ (C-14); 54.8 (C-13); 69.2 (C-10); 93.2 (C-4); 98.2 (C-2); 100.0 (C-5); 104.8 (C-9a); 113.5 (C-8a); 116.7 (C-7); 144.3 (C-8); 158.2 (C-4a); 160.5 (C-10a); 164.5 (C-6); 164.6 (C-1); 166.6 (C-3); 183.2 (C-9); MS (EI) $m / z(\%): 512$ (1) [M] $]^{+}, 497$ (17), 370 (9), 259 (9), 112 (100).

\section{3,6-bis\{[5-(tert-butylamino)pentyl]oxy\}-1-hydroxy-8-methyl-9H- xanthen-9-one (17)}

Yield 98\%; Mp: 78-79 ${ }^{\circ} \mathrm{C}$ (from $\left.\mathrm{MeOH}\right) ;{ }^{1} \mathrm{H}$ NMR $(300 \mathrm{MHz}$ DMSO-d $\left.{ }_{6}\right): \delta=1.01(\mathrm{H}-16, \mathrm{~s}, 18 \mathrm{H}), 1.43(\mathrm{H}-12, \mathrm{H}-13$, br s, $8 \mathrm{H}), 1.73$ (H-11, br s, 4H), 2.50 (H-14, br s, 4H), $2.75\left(\mathrm{CH}_{3}-\mathrm{Ph}, \mathrm{s}, 3 \mathrm{H}\right), 4.10$ (H-10, br s, 4H), 6.30 (H-2, br s, 1H), 6.47 (H-4, br s, 1H), 6.81 (H-7, br s, $1 \mathrm{H}), 6.88(\mathrm{H}-5$, br s, $1 \mathrm{H}) ;{ }^{13} \mathrm{C}$ NMR $\left(75 \mathrm{MHz}\right.$; DMSO-d $\left.{ }_{6}\right): \delta=$ $23.4\left(\mathrm{CH}_{3}-\mathrm{Ph}\right) ; 23.8$ (C-12); 28.8 (C-13); 29.0 (C-16); 30.4 (C-11); 42.1 (C-15); 50.4 (C-14); 68.8 (C-10); 92.8 (C-4); 97.6 (C-2); 99.6 (C-5); 103.5 (C-9a); 112.3 (C-8a); 116.4 (C-7); 143.1 (C-8); 156.9 (C-4a); 159.3 (C-10a); 163.3 (C-6); 163.7 (C-1); 165.6 (C-3); 182.1 (C-9); MS (EI) $\mathrm{m} / \mathrm{z}(\%): 540$ (1) [M] $]^{+}, 525$ (52), 483 (30), 469 (41), 142 (51), 126 (100), 86 (49).

\section{1-hydroxy-8-methyl-3,6-bis(3-piperidin-1-ylpropoxy)-9H-xanthen- 9-one (18)}

Yield 93\%; Mp: 98-100 ${ }^{\circ} \mathrm{C}$ (from $\left.\mathrm{MeOH}\right) ;{ }^{1} \mathrm{H} \mathrm{NMR}(300 \mathrm{MHz}$ $\mathrm{CDCl}_{3} /$ methanol-d $\left.\mathrm{d}_{4}\right): \delta=1.37(\mathrm{H}-15, \mathrm{~m}, 4 \mathrm{H}), 1.52(\mathrm{H}-14$, br s, $8 \mathrm{H})$, $1.92(\mathrm{H}-11, \mathrm{~m}, 4 \mathrm{H}), 2.40(\mathrm{H}-12, \mathrm{H}-13, \mathrm{~m}, 12 \mathrm{H}), 2.71\left(\mathrm{CH}_{3}-\mathrm{Ph}, \mathrm{s}\right.$, $3 \mathrm{H}), 3.97(\mathrm{H}-10, \mathrm{~m}, 4 \mathrm{H}), 6.15(\mathrm{H}-2, \mathrm{~d}, J=1.9 \mathrm{~Hz}, 1 \mathrm{H}), 6.21(\mathrm{H}-4$, d, $J=1.9 \mathrm{~Hz}, 1 \mathrm{H}), 6.54(\mathrm{H}-7$, br s, $1 \mathrm{H}), 6.57(\mathrm{H}-5$, br s, $1 \mathrm{H}) ;{ }^{13} \mathrm{C}$ NMR (75 MHz; $\mathrm{CDCl}_{3} /$ methanol-d $\left.)_{4}\right): \delta=23.4\left(\mathrm{CH}_{3}-\mathrm{Ph}\right) ; 24.3(\mathrm{C}-$ 15); 25.8 (C-14); 26.4 (C-11); 54.6 (C-13); 55.7 (C-12); 67.0 (C-10); 92.4 (C-4); 97.2 (C-2); 98.9 (C-5); 104.0 (C-9a); 112.8 (C-8a); 115.8 (C-7); 143.3 (C-8); 156.9 (C-4a); 159.4 (C-10a); 163.2 (C-6); 163.4 (C-1); 165.2 (C-3); 182.3 (C-9); MS (EI) $m / z$ (\%): 508 (4) [M] $]^{+}, 395$ (4), 126 (13), 98 (100). 
1-hydroxy-8-methyl-3,6-bis(4-piperidin-1-ylbutoxy)-9H-xanthen-

9-one (19)

Yield 95\%; Mp: 84-85 ${ }^{\circ} \mathrm{C}$ (dec.) (from $\mathrm{MeOH}$ ); ${ }^{1} \mathrm{H}$ NMR (300 MHz; DMSO-d $\left.)_{6}\right): \delta=1.54(\mathrm{H}-16$, br s, $4 \mathrm{H}), 1.72(\mathrm{H}-15$, br s, $8 \mathrm{H})$, 1.79 (H-11, H-12, br s, 8H), $2.76\left(\mathrm{CH}_{3}-\mathrm{Ph}, \mathrm{s}, 3 \mathrm{H}\right), 3.06(\mathrm{H}-13, \mathrm{H}-14$, br s, 12H), $4.14(\mathrm{H}-10, \mathrm{~m}, 4 \mathrm{H}), 6.34(\mathrm{H}-2$, br s, 1H), $6.50(\mathrm{H}-4$, br s, 1H), $6.83(\mathrm{H}-7$, br s, 1H), $6.92(\mathrm{H}-5$, br s, $1 \mathrm{H}), 13.31(\mathrm{OH}, \mathrm{s}, 1 \mathrm{H})$; ${ }^{13} \mathrm{C}$ NMR (75 MHz; DMSO-d $)$ : $\delta=20.7$ (C-16); $21.9(\mathrm{C}-12) ; 23.1$ (C-15); $23.4\left(\mathrm{CH}_{3}-\mathrm{Ph}\right) ; 26.1$ (C-11); 52.6 (C-14); 56.0 (C-13); 68.2 (C-10); 92.9 (C-4); 97.7 (C-2); 99.8 (C-5); 103.6 (C-9a); 112.4 (C8a); 116.3 (C-7); 143.2 (C-8); 156.9 (C-4a); 159.3 (C-10a); 163.3 (C-6); 163.6 (C-1); 165.5 (C-3); 182.1 (C-9); MS (EI) $\mathrm{m} / \mathrm{z}(\%): 536$ (3) $[\mathrm{M}]^{+}, 397$ (6), 140 (16), 98 (100).

\section{1-hydroxy-8-methyl-3,6-bis[(5-piperidin-1-ylpentyl)oxy]-9H- xanthen-9-one (20)}

Yield 95\%; Mp: 72-74 ${ }^{\circ} \mathrm{C}$ (from $\mathrm{MeOH}$ ); ${ }^{1} \mathrm{H}$ NMR (300 MHz; $\left.\mathrm{CDCl}_{3}\right): \delta=1.41(\mathrm{H}-12, \mathrm{H}-17$, br s, $8 \mathrm{H}), 1.54(\mathrm{H}-13, \mathrm{H}-16, \mathrm{~m}, 12 \mathrm{H})$, 1.79 (H-11, m, 4H), 2.30 (H-14, H-15, m, 12H), $2.77\left(\mathrm{CH}_{3}-\mathrm{Ph}, \mathrm{s}\right.$, 3H), 3.97 (H-10, m, 4H), 6.21 (H-2, br s, 1H), $6.23(\mathrm{H}-4$, br s, 1H), $6.58\left(\mathrm{H}-5, \mathrm{H}-7\right.$, br s, 2H) $13.33(\mathrm{OH}, \mathrm{s}, 1 \mathrm{H}) ;{ }^{13} \mathrm{C} \mathrm{NMR}(75 \mathrm{MHz}$ $\left.\mathrm{CDCl}_{3}\right): \delta=23.3\left(\mathrm{CH}_{3}-\mathrm{Ph}\right) ; 24.1(\mathrm{C}-17) ; 24.4(\mathrm{C}-12) ; 25.9(\mathrm{C}-16)$; 26.8 (C-13); 28.9 (C-11); 54.6 (C-15); 59.3 (C-14); 68.3 (C-10); 92.3 (C-4); 97.1 (C-2); 98.8 (C-5); 103.9 (C-9a); 112.7 (C-8a); 115.7 (C-7); 143.2 (C-8); 156.8 (C-4a); 159.3 (C-10a); 163.2 (C-6); 163.6 (C-1); 165.2 (C-3); 182.2 (C-9); MS (EI) $m / z(\%): 564$ (1) $\left[\mathrm{M}^{+}\right], 424(8)$, 154 (44), 126 (46), 98 (100), 84 (59), 60 (99), 45 (98).

\section{Antibiotic assay}

\section{Microorganisms and media}

The test organisms used in this study were as follows: Escherichia coli ATCC 25922, Staphylococcus aureus ATCC 25923 and clinical isolated S.aureus resistant to ciprofloxacin, chloramphenicol, penicillin, clindamycin, eritromicin, sulphamethoxazol + trimetoprim and oxacillin. All media were purchased from Oxoid.

\section{Disc diffusion method}

Stock solutions $(10 \mathrm{mg} / \mathrm{mL})$ of each substance were prepared in dimethylsulfoxide (DMSO). The inoculum was an overnight culture of each bacterial species in Mueller-Hinton agar diluted in saline sterile solution $(0.45 \%)$ to a concentration of approximately $10^{8}$ $\mathrm{CFU} / \mathrm{mL}$. The inoculum was spread on Mueller Hinton agar (MHA) and air-dried at room temperature. A 6-mm sterile paper disc was placed on the agar and $20 \mu \mathrm{L}$ of each solution was poured over a disc, and the plates were incubated at $37^{\circ} \mathrm{C}$ for $24 \mathrm{~h}$. As a control, a disc impregnated with gentamycine $(10 \mu \mathrm{g})$ was used. All disc diffusion tests were performed in triplicate and the antibacterial activity was expressed as the mean of inhibition diameters $(\mathrm{mm})$ produced by the compounds.

\section{Determination of minimum inhibitory concentrations}

The 96-well plates were prepared by dispensing $100 \mu \mathrm{L}$ MuellerHinton broth into each well. A stock solution was prepared at a concentration of $2 \mathrm{mg} / \mathrm{mL}$ and serial dilutions were performed to reach a final concentration within a $1 \mu \mathrm{g} / \mathrm{mL}$ to $1.000 \mu \mathrm{g} / \mathrm{mL}$ range, with a $100 \mu \mathrm{L}$ final volume in each well. For gentamycine, final concentration ranged from 64 to $0.5 \mu \mathrm{g} / \mathrm{mL}$. The inoculum was, again, an overnight culture of each bacterial species in Mueller-Hinton agar diluted in saline sterile solution $(0.45 \%)$ to a concentration of approximately $10^{8} \mathrm{CFU} / \mathrm{mL}$. This solution was diluted $1 / 10$ in saline solution $(0.45 \%)$ and $5 \mu \mathrm{L}\left(10^{4} \mathrm{CFU} / \mathrm{mL}\right)$ were added to each well containing the test samples.
All experiments were performed in triplicate and the microdilution trays were incubated at $36{ }^{\circ} \mathrm{C}$ for $18 \mathrm{~h}$. Then, $20 \mu \mathrm{L}$ of an aqueous solution $(0.5 \%)$ of triphenyltetrazolium chloride (TTC) were added to each well and the trays were again incubated at $36^{\circ} \mathrm{C}$ for $2 \mathrm{~h}$. Afterwards, in those wells where bacterial growth did occur, TTC changed from colorless to red. MIC was defined as the lowest concentration of each substance at which no color change occurred, and was expressed in $\mu \mathrm{g} / \mathrm{mL}$.

\section{Antiproliferative assay}

All compounds were solubilized in DMSO and tested at four concentrations $(0.25,2.5,25$, and $250 \mu \mathrm{g} / \mathrm{mL})$, each in triplicate wells. The final content of DMSO was lower than $0.4 \%$. Doxorubicin, an anticancer drug, was used as positive control for all cell lines tested.

\section{Cell lines and culture}

The human tumoral B16-F10 (murine melanoma) were donated by A. Nomizo from Faculdade de Ciências Farmacêuticas de Ribeirão Preto-USP and MCF-7 (breast), 786-0 (kidney), OVCAR03 (ovarian), NCI-ADR (ovarian expressing the resistance phenotype for adryamycin) and HT-29 (colon) were donated by Prof. Dr. J. E. de Carvalho from Centro Pluridisciplinar de Pesquisas Químicas, Biológicas e Agrícolas, Unicamp.

The cells were maintained in RPMI-1640 medium (Sigma Chemical Co., St. Louis, MO, USA), supplemented with $10 \%$ fetal calf serum, $100 \mathrm{U} / \mathrm{mL}$ penicillin, $0.1 \mathrm{mg} / \mathrm{mL}$ streptomycin and 0.25 $\mu \mathrm{g} / \mathrm{mL}$ amphotericcin (complete medium) at $37^{\circ} \mathrm{C}$ with $5 \% \mathrm{CO}_{2}$.

The adherent cell lines were detached from the culture flasks by adding $0.5 \mathrm{~mL}$ trypsin solution $(0.25 \%+$ EDTA $1 \mathrm{mM})$. Then they were transferred to conical tubes containing complete culture medium and after centrifugation at low speed, the culture medium and trypsin were discarded and cells resuspended in small volume of complete medium. After couting, the cells were plated in 96-well microtiter plates $(100,000$ cells/ $\mathrm{mL})$ with a fixed volume of $100 \mu \mathrm{L}$ per well. The microtiter plates containing cells were pre-incubated for $24 \mathrm{~h}$ at $37{ }^{\circ} \mathrm{C}$ to allow stabilizations prior to addition of testing compounds as well as doxorubicin (DOX) $(100 \mu \mathrm{L})$. The plates were incubated with the test substances for $48 \mathrm{~h}$ at $37{ }^{\circ} \mathrm{C}$ and $5 \% \mathrm{CO}_{2} \cdot{ }^{31,32}$

\section{Sulforhodamine B (SRB) assay}

The SRB assay was done as described by Skehan and coworkers. ${ }^{31}$ Briefly, the cells were fixed with $20 \%$ TCA (sigma) at $4{ }^{\circ} \mathrm{C}(100 \mu \mathrm{L} /$ well) for $30 \mathrm{~min}$. The supernatant was then discarded and the plates were washed five times with tap water. The cells were stained for 30 min with $0.1 \%$ SRB in $1 \%$ acetic acid $(50 \mu \mathrm{L} /$ well $)$ and subsequently washed four times with $1 \%$ acetic acid to remove unbound dye. The plates were air-dried and protein-bound dye was solubilized with $100 \mu \mathrm{L}(10 \mathrm{mM})$ of Trizma buffer (Sigma). The plates were shaken for $15 \mathrm{~min}$ and the resulting optical density was read in a multiwell plate reader at $540 \mathrm{~nm}$.

The growth inhibition - IC (\%) - of each test sample was calculated as Monks et al..$^{32}$ using Excell ${ }^{\circledR}$ program (Microsoft Office package). The dose that inhibits $50 \%$ of cell growth $\left(\mathrm{IC}_{50}\right)$ was determined graphically by the program for graphics and data analysis (Microcal Origin Version 6.0) Excell ${ }^{\circledR}$.

\section{RESULTS AND DISCUSSION}

We obtained five series (dimethyl, diethyl, dipropyl, $t$-butylamine and piperidinyl) groups with spacers of 3, 4 and 5 carbon atoms between $\mathrm{N}$ and $\mathrm{O}$, in order to establish a relationship between the characteristics of side chains and the biological activity. The preparation of 
$\omega$-aminoalkoxylxanthones is illustrated in Scheme 1. Lichexanthone (1) was isolated from the lichen Parmotrema lichexanthonicum, and then was $O$-demethylated by $\mathrm{BBr}_{3}$ to produce norlichexanthone (2) in $60 \%$ yield. ${ }^{29} \omega$-bromoalkoxylxanthones $(3,65 \%),(4,67.7 \%)$ and $(\mathbf{5}, 77.4 \%)$ were obtained by treatment of (2) with an appropriate $1, \omega$-dihaloalkane ${ }^{30}$ and were used to prepare the nitrogenated derivatives $(\mathbf{6})-(\mathbf{2 0})$ by reaction with different amines. This last step was very profitable and it was possible to produce these derivatives in good yields, ranging from 93 to $99 \%$.

The structure of compounds (3) - (20) was established on the basis of NMR and MS techniques. Compounds (3), (4) and (5) showed similar NMR features. Their ${ }^{1} \mathrm{H}$ NMR spectra showed all characteristic signals for the scaffold and, besides them, signals in 3.9, and $3.4 \mathrm{ppm}$, that reffer to methylene groups bearing an oxygen and a bromine atoms, respectively, and others at about $2 \mathrm{ppm}$, for the remaining $\mathrm{CH}_{2}$ groups (1,2 or 3 depending on the lengh of the $\omega$-bromoalkyl chain). Integration areas of these ${ }^{1} \mathrm{H}-\mathrm{NMR}$ signals showed that two alkyl chains were introduced in the hydroxyl groups in positions 3 and 6 of the xanthone core, what was confirmed by 2D-NMR techniques. The hydroxyl group in position 1 does not react under the conditions used because of the intramolecular hydrogen bond established between the hydroxyl $\mathrm{H}$ and the carbonyl oxygen. Actually, it can be confirmed by the presence of a sharp singlet at $13.3 \mathrm{ppm}$ in ${ }^{1} \mathrm{H}$ NMR of (3), (4) and (5) corresponding to this group. ${ }^{13} \mathrm{C}$-NMR spectra of these substances presented scaffold characteristic signals reffering to the $\omega$-bromoalkoxyl chains, including these two methylene groups bearing heteroatoms $\left(68 \mathrm{ppm}\right.$, for the group $\mathrm{CH}_{2}-$ $\mathrm{O}-$, and 33 ppm for $\mathrm{CH}_{2}-\mathrm{Br}$-). Aminoalkanolic derivatives (6) - (20) had ${ }^{1} \mathrm{H}$ and ${ }^{13} \mathrm{C}$ NMR spectra very close to the profile exhibited by starting materials, but with signals at 2.6-2.7 and 50-60 ppm in ${ }^{1} \mathrm{H}$ and ${ }^{13} \mathrm{C}$ NMR spectra, respectively, that can be attributed to $\mathrm{CH}_{2}$ group connected to nitrogen, were the $\mathrm{S}_{N^{2}}$ reaction took place.

All compounds were tested for antibiotic activity against $E$. coli (ATCC 25922), S. aureus (ATCC 25923) and oxacillin resistant $S$. aureus. Inhibition zones and MIC values are summarized in Table 1.

All tested substances were much more active for Gram-positive than Gram-negative bacteria. For E. coli (Gram-negative) the best activity was achieved for compounds $(\mathbf{6})-(9)$, including the three dimethylamino derivatives. For standard and clinical $S$. aureus strains, there is a similar behavior, and the most active compounds are that containing tert-butylamino moieties, and the ones that have 4 or 5 member chains between $\mathrm{N}$ and $\mathrm{O}$ atoms. This pattern was even more evident for the clinical strain, for which the most potent compounds, with MIC value of $4 \mu \mathrm{g} / \mathrm{mL}$, are the three ones with $\mathrm{N}$-tert-butylamino groups $(\mathbf{1 5}-\mathbf{1 7})$, and the ones which have five member chains between those heteroatoms $(\mathbf{8}, \mathbf{1 4}, \mathbf{2 0})$.

Some natural xanthones are described as important anti-staphylococcal agents, including for resistant strains, having MIC values ranging from 8 until $1.95 \mu \mathrm{g} / \mathrm{mL} \cdot .^{10,33-35}$ Thus, some of the semi synthetic $\omega$-aminoalkoxylxanthones presented herein are potential antimicrobials and can be considered relevant specially taking into account the growing problem of resistant $S$. aureus strains.

Studies have reported the synthesis and cytotoxic activity of bromoalkoxyxanthones ${ }^{30}$ and xanthones with nitrogenated side chains ${ }^{27,28}$ including arylhydrazones, ${ }^{36}$ with promising results, showing $\mathrm{IC}_{50}$ values between 2 and $30 \mu \mathrm{M}$.

Aiming at evaluating derivatives for their antutumor potential, cytotoxicity on cell lines of various histological origin $\{\mathrm{B} 16-\mathrm{F} 10$ (murine melanoma), MCF-7 (breast carcinoma), 786-0 (kidney carcinoma), OVCAR03 (ovarian carcinoma), NCI-ADR (ovarian expressing the resistance phenotype for adryamycin) and HT-29 (colon carcinoma) \} was determined. Cell proliferation was determined by spectrophotometric assay using sulforhodamine B as protein-binding dye. Concentrations that elicits $50 \%$ inhibition of cell growth $\left(\mathrm{IC}_{50}\right)$ are summarized in Table 2.

Synthesized substances were in general active against multiple cell lines. For almost all lines, at least $50 \%$ of compounds were active, showing $\mathrm{IC}_{50}$ values below $20 \mu \mathrm{M}$ (about $10 \mu \mathrm{g} / \mathrm{mL}$ for these substances). Compound (15), containing, tert-butylamino moieties was the most active, with $\mathrm{IC}_{50}=4.3,7.6$ and $8.5 \mu \mathrm{M}$ for MCF-7 (breast), 786-0 (kidney) and HT-29 (colon) lines respectively. Compounds (10) and (11), with four or five member chains between $\mathrm{N}$ and $\mathrm{O}$ atoms and diethylamino moieties were more active than DOX over the resistant line NCI-ADR. It is notable a tendency of lower activity for substances with dipropylamino moieties (12-14).

Starting materials, lichexanthone (1) and norlichexanthone (2) were tested before for antibiotic (disc diffusion method) and cytotoxic activities ${ }^{29}$ but they showed low activity against bacterial strains and cells tested. On this basis we can say that the changes made were relevant and useful to achieve this biological profile.<smiles>COc1cc(C)c2c(=O)c3c(O)cc(OC)cc3oc2c1</smiles>

(1)<smiles>Cc1cc(O)cc2oc3cc(O)cc(O)c3c(=O)c12</smiles>

(2) $(60 \%)$

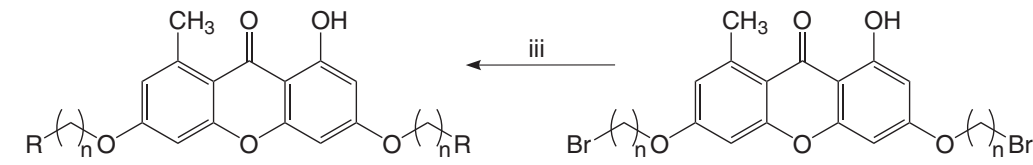

\footnotetext{
R=dimethylamino (6): $n=3(7): n=4(8): n=5$ R=diethylamino (9): $n=3(10): n=4$ (11): $n=5$

R=dipropylamino (12): $n=3$ (13): $n=4$ (14): $n=5$

$R=t$-butylamino (15): $n=3$ (16): $n=4$ (17): $n=5$

$R=$ piperidinyl (18): $n=3$ (19): $n=4$ (20): $n=5$
}

Scheme 1. Reagents and conditions: i) $\mathrm{BBr}_{3}, \mathrm{CH}_{2} \mathrm{Cl}_{2}, \mathrm{~N}_{2}, \mathrm{rt}, 16 \mathrm{~h}$; ii) $\mathrm{K}_{2} \mathrm{CO}_{3}$, acetone, $\mathrm{Br}\left(\mathrm{CH}_{2}\right)_{n} \mathrm{Br}, n=3,4$ or 5 , rt, 24 h; iii) amine (dimethyl, diethyl, dipropyl, $t$-butylamine and piperidine), acetone, $r t, 48 \mathrm{~h}$ 
Table 1. Antimicrobial activity for compounds (3) - (20) and gentamycine (GENTA)

\begin{tabular}{|c|c|c|c|c|c|c|}
\hline \multirow{3}{*}{ Compounds } & \multicolumn{6}{|c|}{ Microorganism } \\
\hline & \multicolumn{2}{|c|}{ S. aureus ATCC (25923) } & \multicolumn{2}{|c|}{ Resistant $S$. aureus } & \multicolumn{2}{|c|}{ E. coli ATCC (25922) } \\
\hline & Inhibition zone (mm) & $\mathrm{MIC}(\mu \mathrm{g} / \mathrm{mL})$ & Inhibition zone (mm) & $\mathrm{MIC}(\mu \mathrm{g} / \mathrm{mL})$ & Inhibition zone (mm) & $\mathrm{MIC}(\mu \mathrm{g} / \mathrm{mL})$ \\
\hline (3) & 0 & NT & 0 & NT & 0 & NT \\
\hline (4) & 0 & NT & 0 & NT & 0 & NT \\
\hline (5) & 0 & NT & 0 & NT & 0 & NT \\
\hline (6) & $20^{[29]}$ & 62.5 & 13 & 125 & $12^{[29]}$ & 31.25 \\
\hline (7) & 15 & 31.25 & 16 & 15.6 & 13 & 31.25 \\
\hline (8) & 14 & 7.8 & 16 & 4 & 0 & 31.25 \\
\hline (9) & 14 & 15.6 & 19 & 31.25 & 12 & 31.25 \\
\hline (10) & 19 & 7.8 & 20 & 7.8 & 10 & 250 \\
\hline (11) & 14 & 15.6 & 16 & 15.6 & 10 & 125 \\
\hline (12) & 18 & 15.6 & 19 & 15.6 & 8 & 125 \\
\hline (13) & 12 & 7.8 & 14 & 15.6 & 0 & 250 \\
\hline (14) & 12 & 7.8 & 15 & 4 & 10 & 250 \\
\hline (15) & 17 & 7.8 & 18 & 4 & 10 & 62.6 \\
\hline (16) & 20 & 2 & 21 & 4 & 10 & 62.5 \\
\hline (17) & 16 & 4 & 17 & 4 & 8 & 250 \\
\hline (18) & 15 & 15.6 & 15 & 31.25 & 20 & 62.5 \\
\hline (19) & 17 & 7.8 & 17 & 15.6 & 8 & 125 \\
\hline (20) & 13 & 4 & 15 & 4 & 12 & 62.5 \\
\hline GENTA & 27 & $<0.5$ & 14 & 64 & 24 & $<0.5$ \\
\hline
\end{tabular}

NT $=$ not tested

Table 2. $\mathrm{IC}_{50}$ values, given in $\mu \mathrm{M}$, for compounds $(\mathbf{3})-(\mathbf{2 0})$ and doxorubicin (DOX) required for inhibiting tumor cell proliferation

\begin{tabular}{|c|c|c|c|c|c|c|}
\hline \multirow{2}{*}{ Compounds } & \multicolumn{6}{|c|}{$\mathrm{IC}_{50}(\mu \mathrm{M})$} \\
\hline & OVCAR & NCI.ADR & MCF-7 & $786-0$ & B16-F10 & HT-29 \\
\hline (3) & $>500$ & $>500$ & $>500$ & $>500$ & $>500$ & $>500$ \\
\hline (4) & $>500$ & $>500$ & $>500$ & 387.6 & $>500$ & $>500$ \\
\hline (5) & $>500$ & $>500$ & $>500$ & 313.3 & $>500$ & $>500$ \\
\hline (6) & NT & NT & 4.7 & 13.3 & 17.5 & 13.8 \\
\hline (7) & 15.5 & 32.0 & 17.3 & 15.1 & 16.4 & 28.5 \\
\hline (8) & 16.5 & 108.1 & 19.4 & 15.5 & 17.1 & 126.3 \\
\hline (9) & NT & 114.8 & 150.1 & 117.4 & 122.8 & 166.5 \\
\hline (10) & NT & 17.7 & 13.8 & 13.5 & 15.8 & 15.8 \\
\hline (11) & NT & 13.5 & 15.2 & 12.2 & 12.8 & 15.0 \\
\hline (12) & NT & NT & 112.4 & 125.4 & 131.8 & NT \\
\hline (13) & $>500$ & 92.3 & 131.2 & 71.4 & 109.7 & $>500$ \\
\hline (14) & 38.2 & 40.1 & 30 & 12.1 & 13.6 & NT \\
\hline (15) & NT & NT & 4.3 & 7.6 & 15.7 & 8.5 \\
\hline (16) & 7.4 & $>500$ & $>500$ & $>500$ & $>500$ & 11.3 \\
\hline (17) & NT & NT & 13.9 & 13.1 & 15.7 & 15.3 \\
\hline (18) & NT & NT & 29.5 & 13.8 & NT & 30.7 \\
\hline (19) & $>500$ & 74.3 & 14.3 & 13.6 & 16.0 & 12.8 \\
\hline (20) & NT & NT & 14.5 & 12.9 & 14.5 & 14.1 \\
\hline DOX & 1.57 & 22.8 & 0.40 & 0.88 & 0.69 & 2.33 \\
\hline
\end{tabular}

NT $=$ not tested 


\section{CONCLUSION}

Many xanthone derivatives were synthesized and described for the first time, including a series of aminoalkanolic derivatives. Promising results were obtained in the evaluation of antimicrobial activity for these compounds, specially related to activity against multidrug resistant $S$. aureus, a growing serious problem worldwide. Good citotoxic activities were achieved as well, confirming the great biological potential of this compound class.

\section{SUPPLEMENTARY MATERIAL}

Available at http://quimicanova.sbq.org.br, in format PDF, with free access.

\section{ACKNOWLEDGEMENTS}

The authors thank FUNDECT/MS for scholarship and financial support, CAPES and PROPP-UFMS, for supporting and infrastructure.

\section{REFERENCES}

1. Demain, A. L.; Med. Res. Rev. 2009, 29, 821

2. Liu, Y.; Ke, Z.; Cui, J.; Chen; W.; Ma, L.; Wan, B.; Bioorg. Med. Chem. 2008, 16, 7185 .

3. Engel, K.; Schmidt, U.; Reuter, J.; Weckesser, S.; Simon-Haarhaus, B.; Schempp, C. M.; J. Photochem. Photobiol., B 2007, 89, 9.

4. Rankovi , B.; Miši , M.; Sukdolak, S.; Microbiology 2007, 76, 723.

5. Russo, A.; Piovano, M.; Lombardo, L.; Garbarino, J.; Cardile, V.; Life Sci. 2008, 83, 468.

6. Rankovi , B.; Miši , M.; Sukdolak, S.; World J. Microbiol. Biotechnol. 2008, 74, 1239.

7. Woo, S.; Jung, J.; Lee, C.; Kwon, Y.; Na, Y.; Bioorg. Med. Chem. Lett. 2007, 17, 1163

8. Pinto, M. M. M.; Sousa, M. E.; Nascimento, M. S. J.; Curr. Med. Chem. 2005, 12, 2517.

9. Azebaze, A. G. B.; Ouahouo, B. M. W.; Vardamides, J. C.; Valentin, A.; Kuete, V.; Acebey, L.; Beng, V. P.; Kkengfack, A.; E.; Meyer, M.; Chem. Nat. Comp. 2008, 44, 582.

10. Chomnawang, M.; T.; Surassmo, S.; Wongsariya, K.; Bunyapraphatsara, N.; Fitoterapia 2009, 80, 102.

11. Ding, L.; Liu, B.; Qi, L.; Zhou, Q.; Hou, Q.; Li, J.; Zhang, Q.; Toxicol. in Vitro 2009, 23, 408.

12. Ha, L. D.; Hansen, P. E.; Vang, O.; Duus, F.; Phan, H. D.; Nguyen, L. D.; Chem. Pharm. Bull. 2009, 57, 830.

13. Chen, L.; Yang, L.; Wang, C.; Food Chem. Toxicol. 2008, 46, 688.

14. Marona, H.; Librowski, T.; Cegla, M.; Erdogan, C.; Sahin, N. Ö.; Acta Pol. Pharm. 2008a, 65, 383.
15. Marona, H.; Szkaradek, N.; Kubacka, M.; Bednarski, M.; Filipek, B.; Cegla, M.; Szneler, E.; Arch. Pharm. Chem. Life Sci. 2008b, 341, 90.

16. Pontius, A.; Krick, A.; Kehraus, S.; Brun, R, König, G. M.; J. Nat. Prod. 2008, 71,1579

17. Zou, J.; Jin, D.; Chen, W.; Wang, J.; Liu, Q.; Zhu, X.; Zhao, W.; J. Nat. Prod. 2005, 68, 1514.

18. Piazzi, L.; Belluti, F.; Bisi, A.; Gobbi, S.; Rizzo, S.; Bartolini, M.; Andrisano, V.; Recanatini, M.; Rampa, A.; Bioorg. Med. Chem. 2007, 15, 575.

19. Urbain, A.; Marston, A.; Grilo, L. S.; Purev, J. B.; Purevsuren, Batsuren, D.; Reist, M.; Carrupt, A.; Hostettman, K.; J. Nat. Prod. 2008, 71, 895.

20. Harkcom, W. T.; Bevan, D. R.; Biochem. Biophys. Res. Commun. 2007, 360,401 .

21. Lin, K.; Fang, S.; Hung, C.; Shieh, B.; Yang, S.; Teng, C.; Lin, C.; Arch. Pharm. Chem. Life Sci. 2009, 342, 19.

22. Marona, H.; Pekala, E.; Antkiewicz-Michaluk, L.; Walczak, M.; Szneler, E.; Bioorg. Med. Chem. 2008c, 16, 7234

23. Marona, H.; Szkaradek, N.; Rapacz, A.; Filipek, B.; Dybala, M.; Siwek, A.; Cegla, M.; Szneler, E.; Bioorg. Med. Chem. 2009a, 17, 1345.

24. Riscoe, M.; Kelly, J. X.; Winter, R.; Curr. Med. Chem. 2005, 12, 2539.

25. Szkaradek, N.; Stachura, K.; Waszkielewicz, A.; M.; Cegla, M.; Szneler, E.; Marona, H.; Acta Pol. Pharm. 2008, 65, 21.

26. Marona, H.; Szkaradek, N.; Karczewska, E.; Trojanowska, D.; Budak, A.; Bober, P.; Przepiórka, W.; Cegla, M.; Szneler, E.; Arch. Pharm. Chem. Life Sci. 2009b, 342, 9.

27. Kolokythas, G.; Kostakis, I. K.; Pouli, N.; Marakos, P.; Skaltsounis, A.; Pratsinis, H.; Bioorg. Med. Chem. Lett. 2002, 12, 1443.

28. Kostakis, I.; Ghirtis, K.; Pouli, N.; Marakos, P.; Skaltsounis, A.; Leonce, S.; Caignard, D. H.; Atassi, G.; Il Farmaco 2000, 55, 455.

29. Micheletti, A. C.; Beatriz, A.; Lima, D. P.; Honda, N. K.; Pessoa, C. O.; Moraes, M. O.; Lotufo, L. V.; Magalhães, H. I. F.; Carvalho, N. C. P.; Quim. Nova 2009, 32, 12.

30. Sousa, E.; Paiva, A.; Nazareth, N.; Gales, L.; Damas, A. M.; Nascimento, M. S. J.; Pinto, M.; Eur. J. Med. Chem. 2009, 44, 3830.

31. Skehan, P.; Storeng. R.; Scudiero, D.; Monks, A.; Mcmahon, J.; Vistica, D.; Warren, J. T.; Bokesch, H.; Kenney, S.; Boyd, M. R.; J. Natl. Cancer Inst. 1990, 82, 1107.

32. Monks, A.; Scudiero, D.; Skehan, P.; Shoemaker, R.; Paull, K.; Vistica, D.; Hose, C.; Langley, J.; Cronise, P.; Vaigro-Wolff, A.; Gray-Groodich, M.; Campbell, H.; Mayo, J.; Boyd, M.; J. Natl. Cancer Inst. 1991, 83, 757.

33. Pinheiro, L.; Nakamura, C. V.; Dias Filho, B. P.; Ferreira, A. G.; Young, M. C. M.; Cortez, D. A. G.; Mem. Inst. Oswaldo Cruz, 2003, 98, 549.

34. Yasunaka, K.; Abe, F.; Nagayama, A.; Okabe, H.; Lozada-Pérez, L.; López-Villafranco, E.; Muniz, E. E.; Aguilar, A.; Reyes-Chilpa, R.; J. Ethnopharmacol. 2005, 97, 293.

35. Vooturi, S. K.; Cheung, C. M.; Rybak, M. J.; Firestine, S. M.; J. Med. Chem. 2009, 52, 5020.

36. Varache-Lembège, M.; Moreau, S.; Larrouture, S.; Montaudon, D.; Robert, J.; Nuhrich, A.; Eur. J. Med. Chem. 2007, 42, 1. 
CHEMICAL MODIFICATIONS OF A NATURAL XANTHONE AND ANTIMICROBIAL ACTIVITY AGAINST MULTIDRUG RESISTANT Staphylococcus aureus AND CYTOTOXICITY AGAINST HUMAN TUMOR CELL LINES

Ana Camila Micheletti, Neli Kika Honda, Dênis Pires de Lima e Adilson Beatriz*

Departamento de Química, Centro de Ciências Exatas e Tecnologia, Universidade Federal de Mato Grosso do Sul, Av. Senador Filinto Müller, 1555, 79074-460 Campo Grande - MS, Brasil

Maria Rita Sant'ana e Nadia Cristina Pereira Carvalho

Seção de Análises Clínicas, Universidade Federal de Mato Grosso do Sul, Av. Senador Filinto Muller, s/n, 79080-190 Campo Grande - MS, Brasil

Maria de Fatima Cepa Matos, Lyara Meira Marinho Queiróz e Danielle Bogo

Departamento de Farmácia-Bioquímica, Universidade Federal de Mato Grosso do Sul, CP 549, 79080-190 Campo Grande - MS, Brasil

José Roberto Zorzatto

Faculdade de Computação, Universidade Federal de Mato Grosso do Sul, CP 549,79080-190 Campo Grande - MS, Brasil

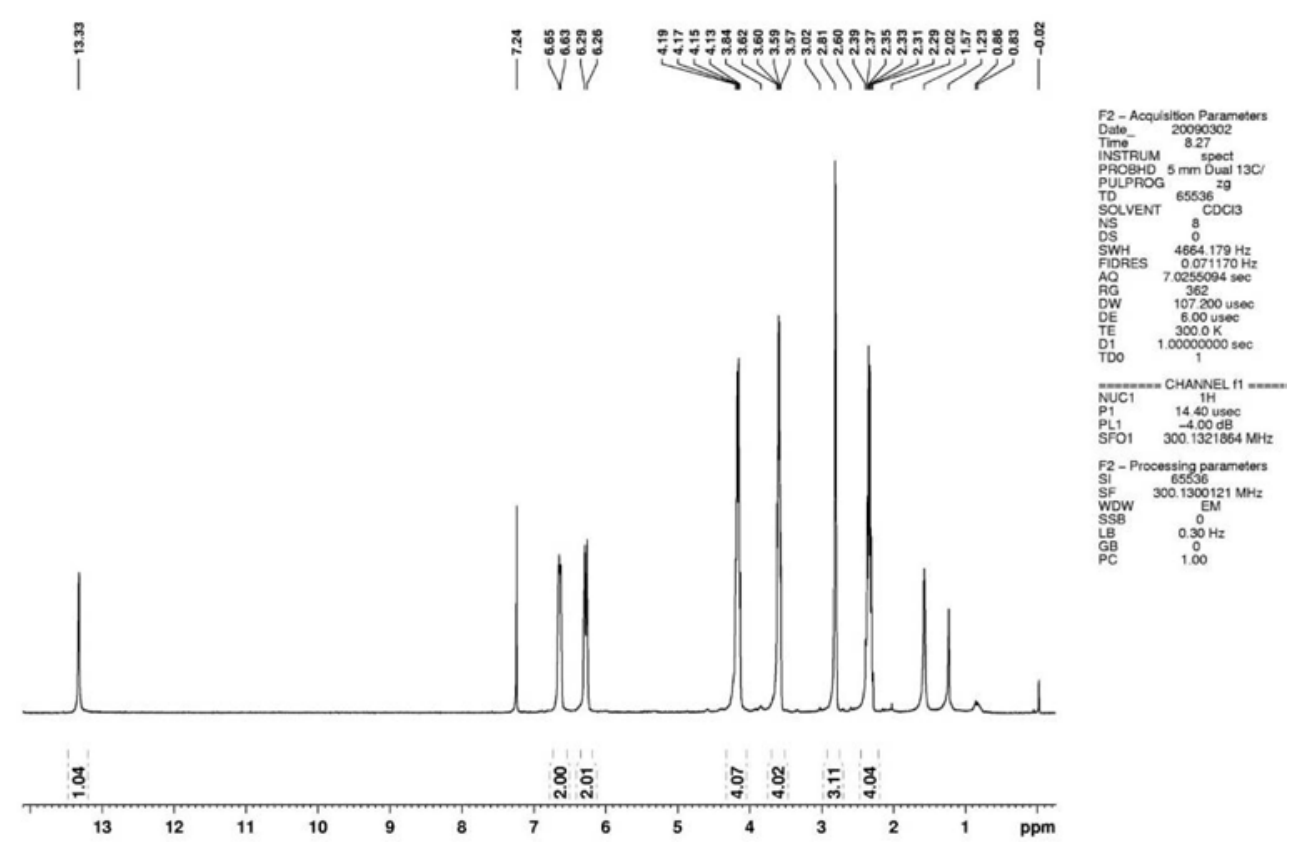

Figure 1S. ${ }^{1} \mathrm{H} \mathrm{NMR}$ spectrum of (3), $300 \mathrm{MHz}, \mathrm{CDCl}_{3}$ 

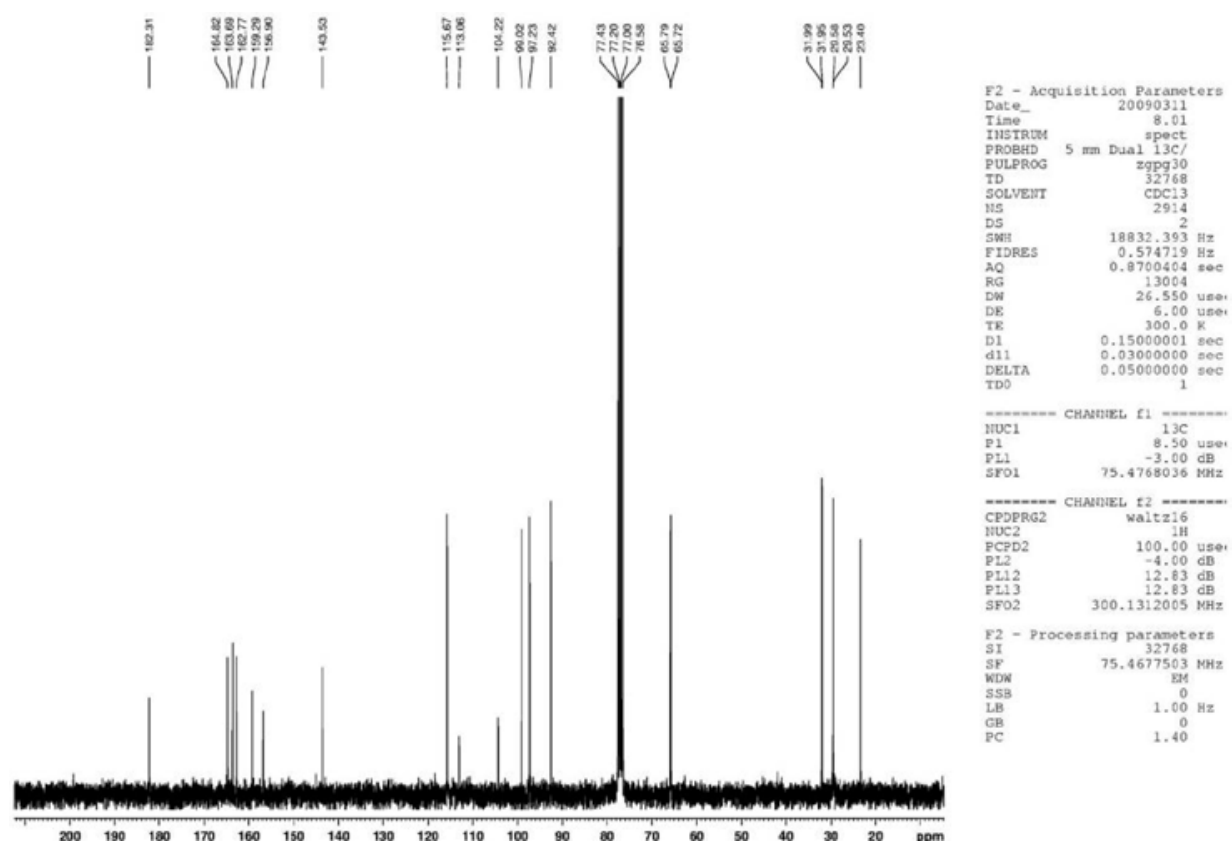

Figure 2S. ${ }^{13} \mathrm{C} \mathrm{NMR}$ spectrum of (3), $75 \mathrm{MHz}, \mathrm{CDCl}_{3}$

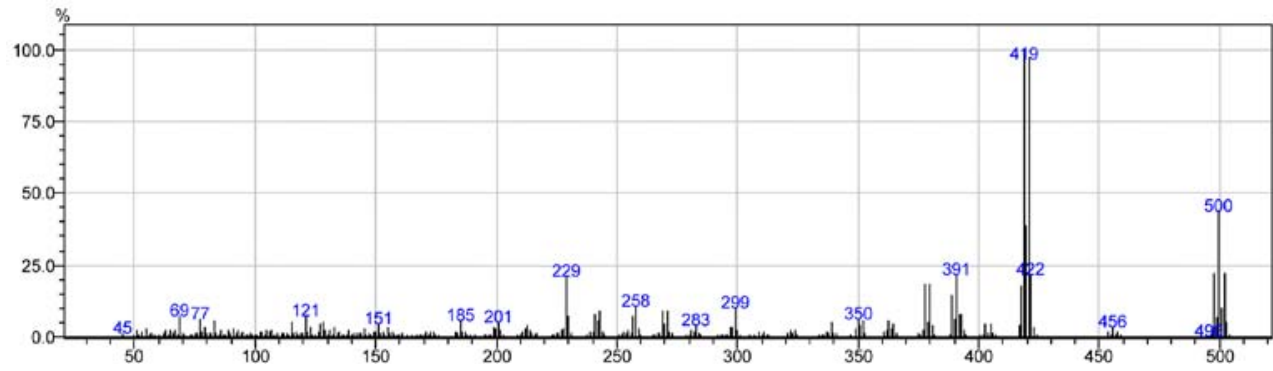

Figure 3S. EI/MS spectrum of (3)

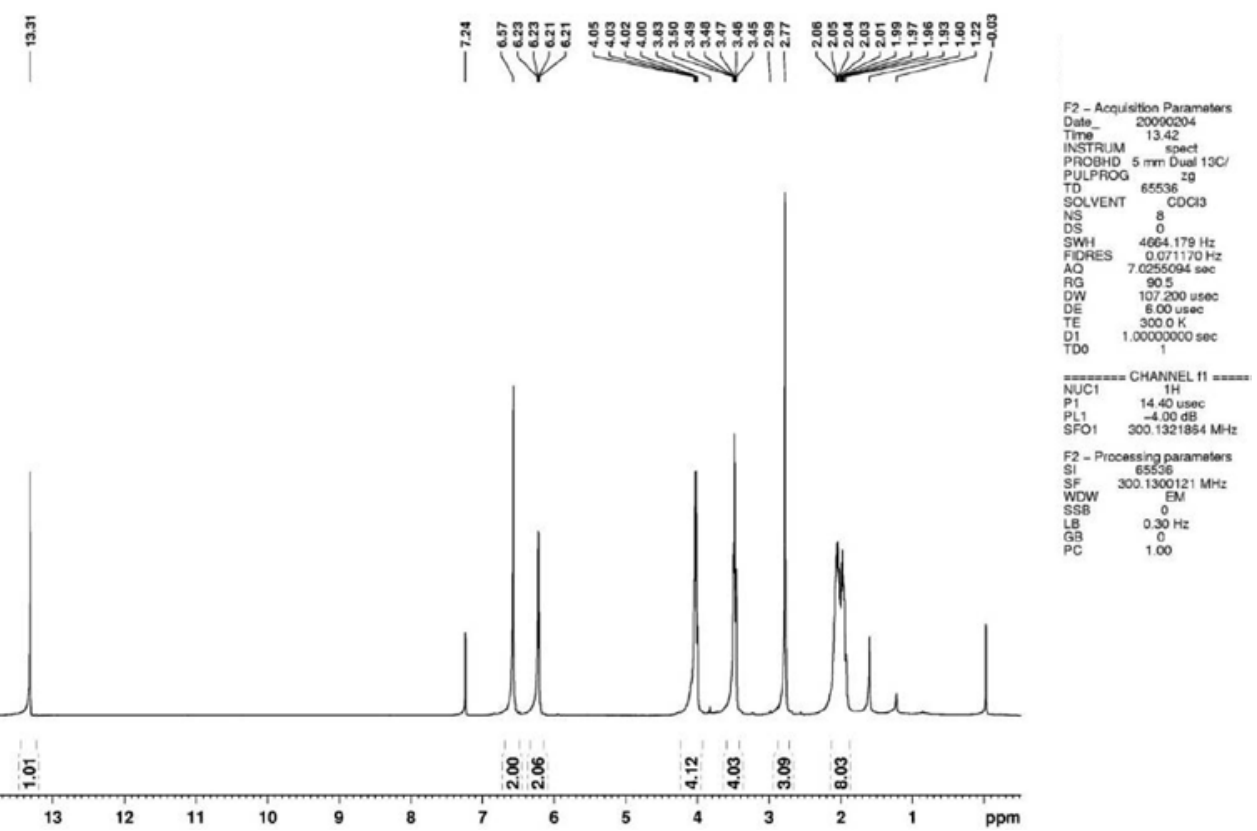

Figure 4S. ${ }^{1} \mathrm{H} N \mathrm{NR}$ spectrum of (4), $300 \mathrm{MHz}, \mathrm{CDCl}_{3}$ 


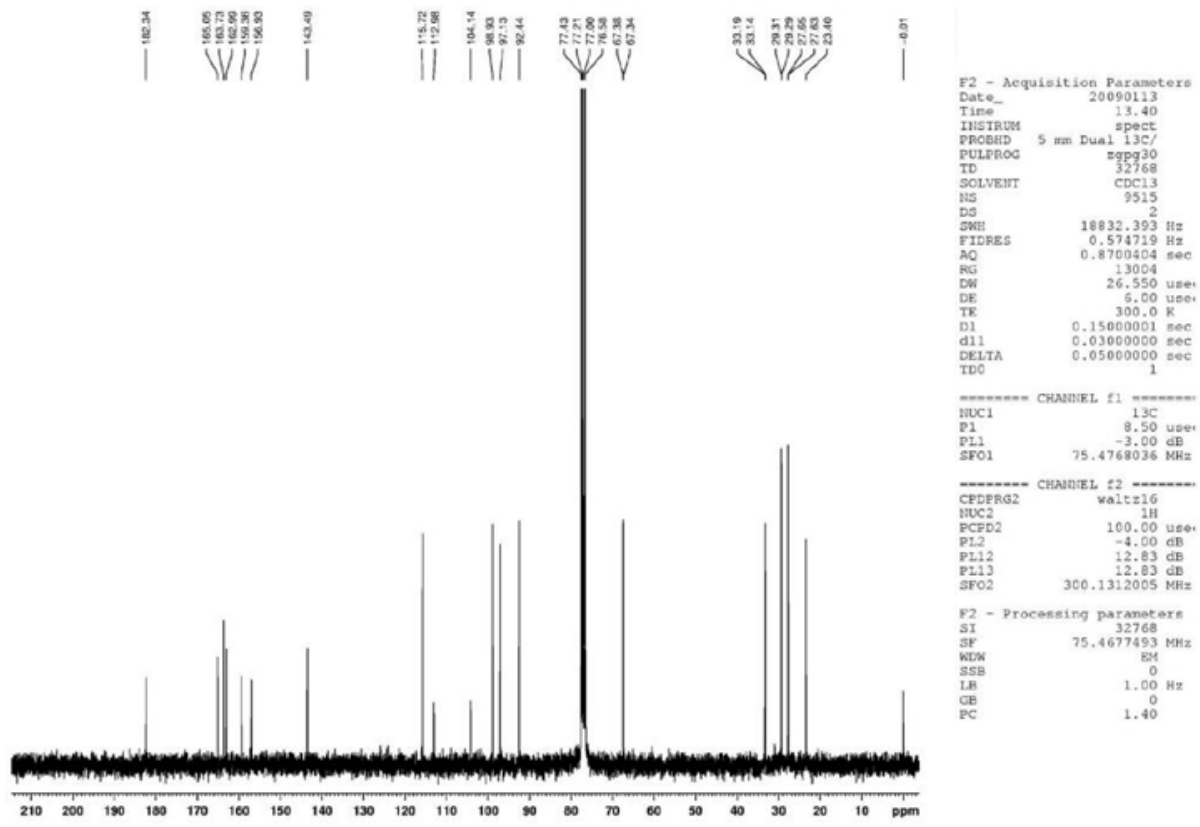

Figure 5S. ${ }^{13} \mathrm{C}$ NMR spectrum of (4), $75 \mathrm{MHz}, \mathrm{CDCl}_{3}$

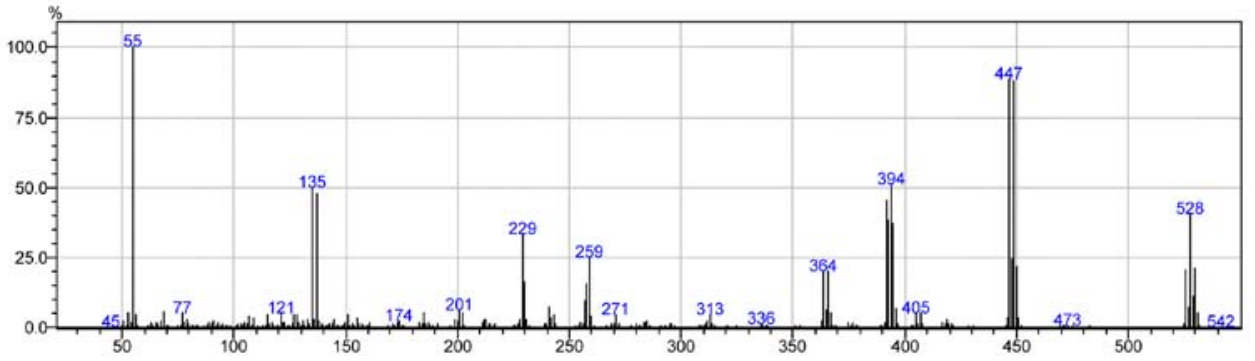

Figure 6S. EI/MS spectrum of (4)

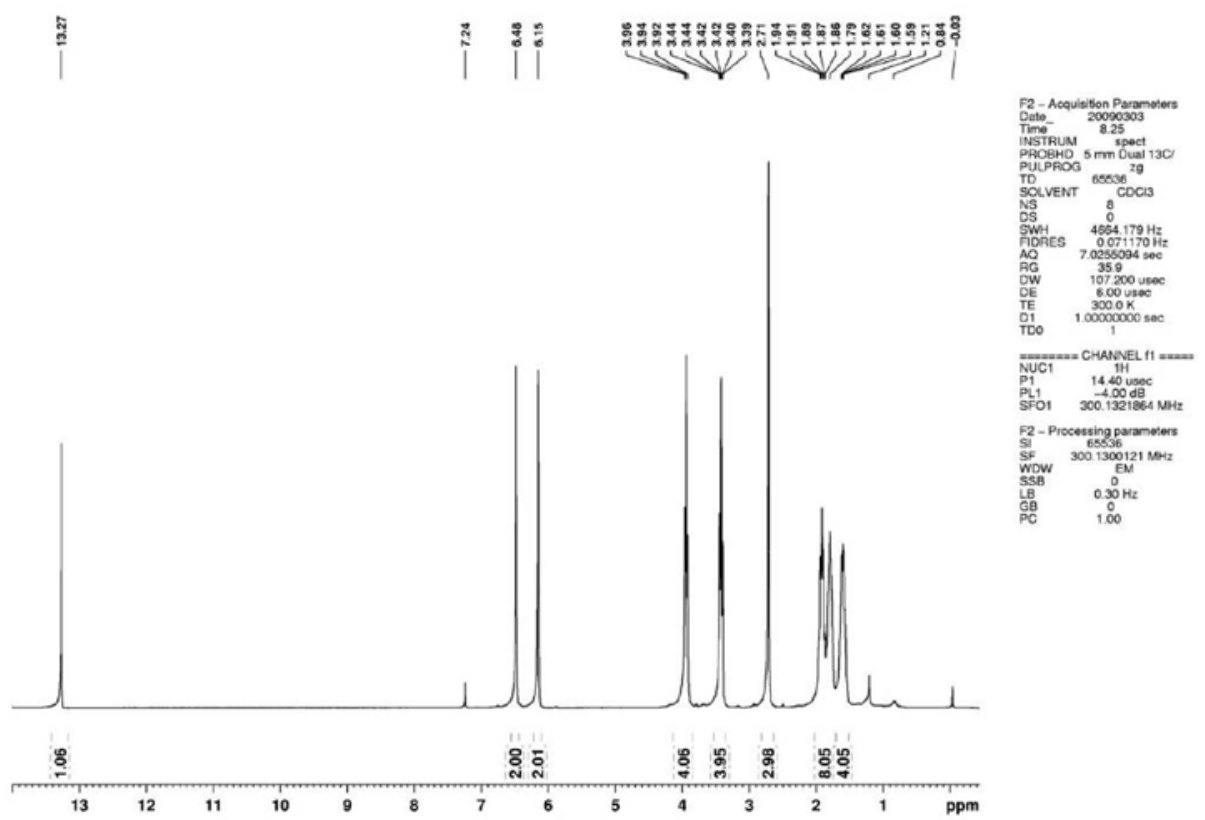

Figure 7S. ${ }^{1} \mathrm{H} \mathrm{NMR}$ spectrum of (5), $300 \mathrm{MHz}, \mathrm{CDCl}_{3}$ 


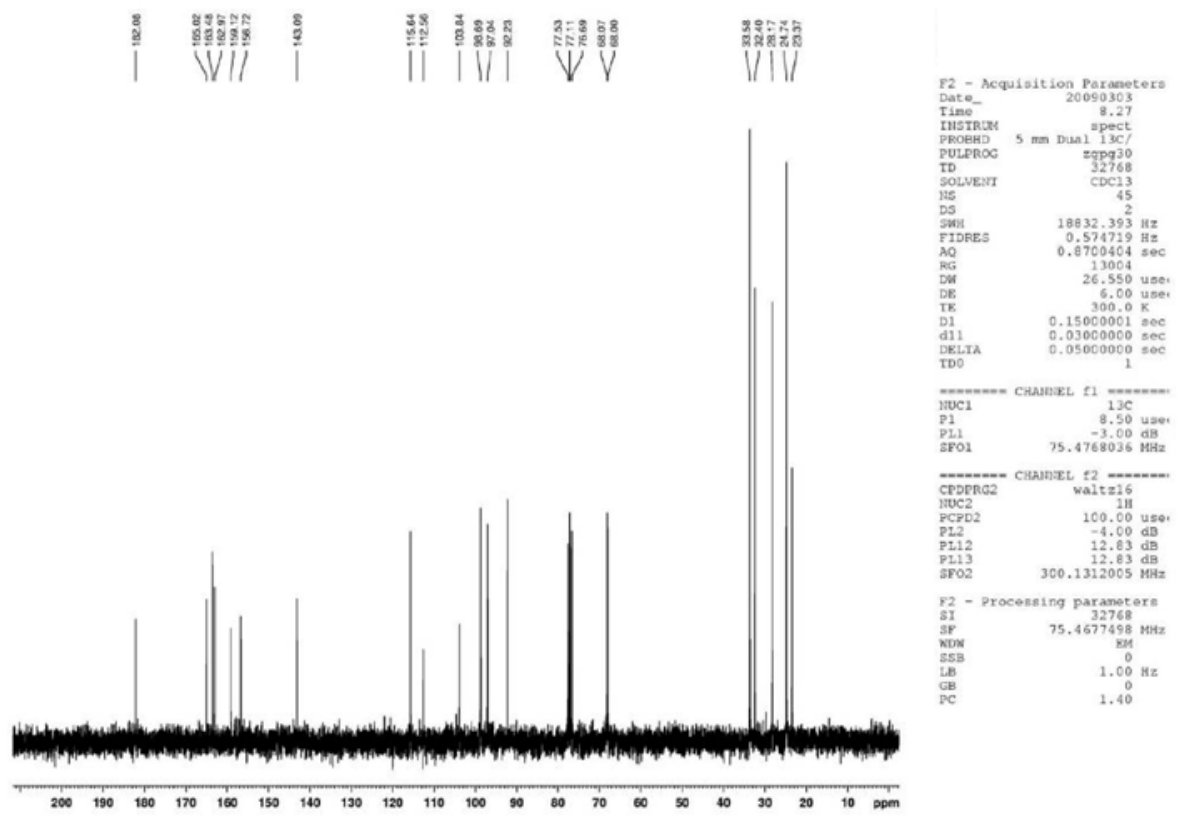

Figure 8S. ${ }^{13} \mathrm{C}$ NMR spectrum of (5), $75 \mathrm{MHz}, \mathrm{CDCl}_{3}$

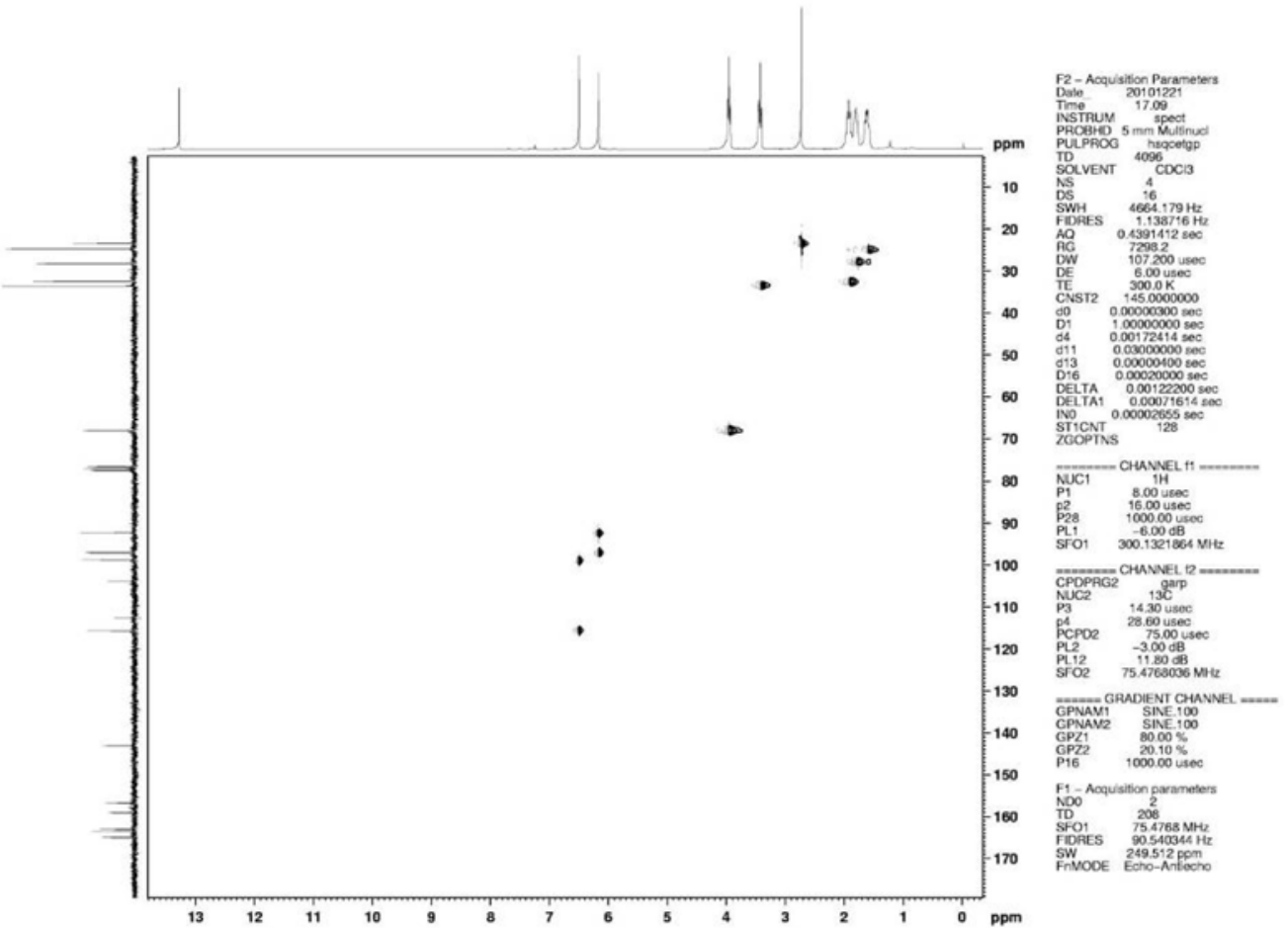

Figure 9S. HSQC spectrum of (5), $\mathrm{CDCl}_{3}$ 


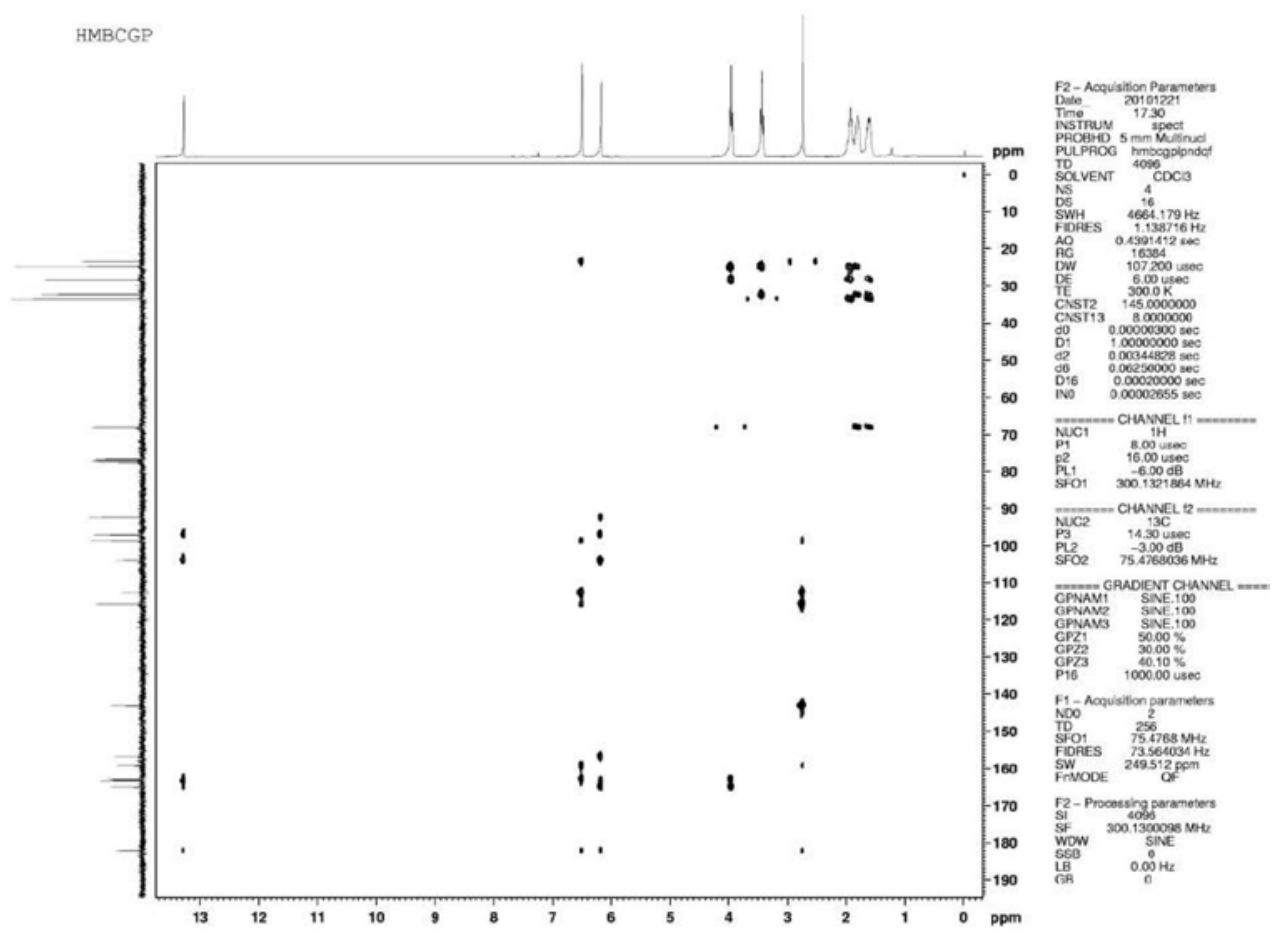

Figure 10S. $\mathrm{HMBC}$ spectrum of (5), $\mathrm{CDCl}_{3}$

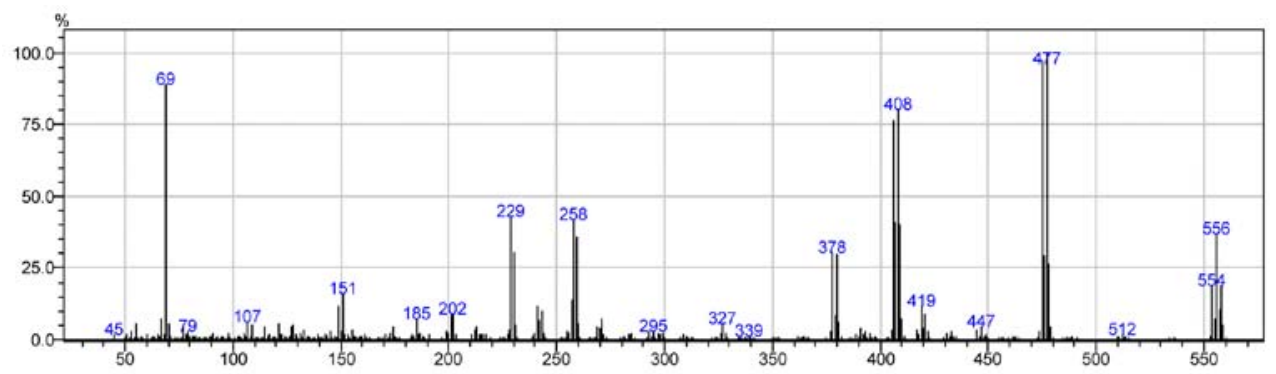

Figure 11S. EI/MS spectrum of (5)

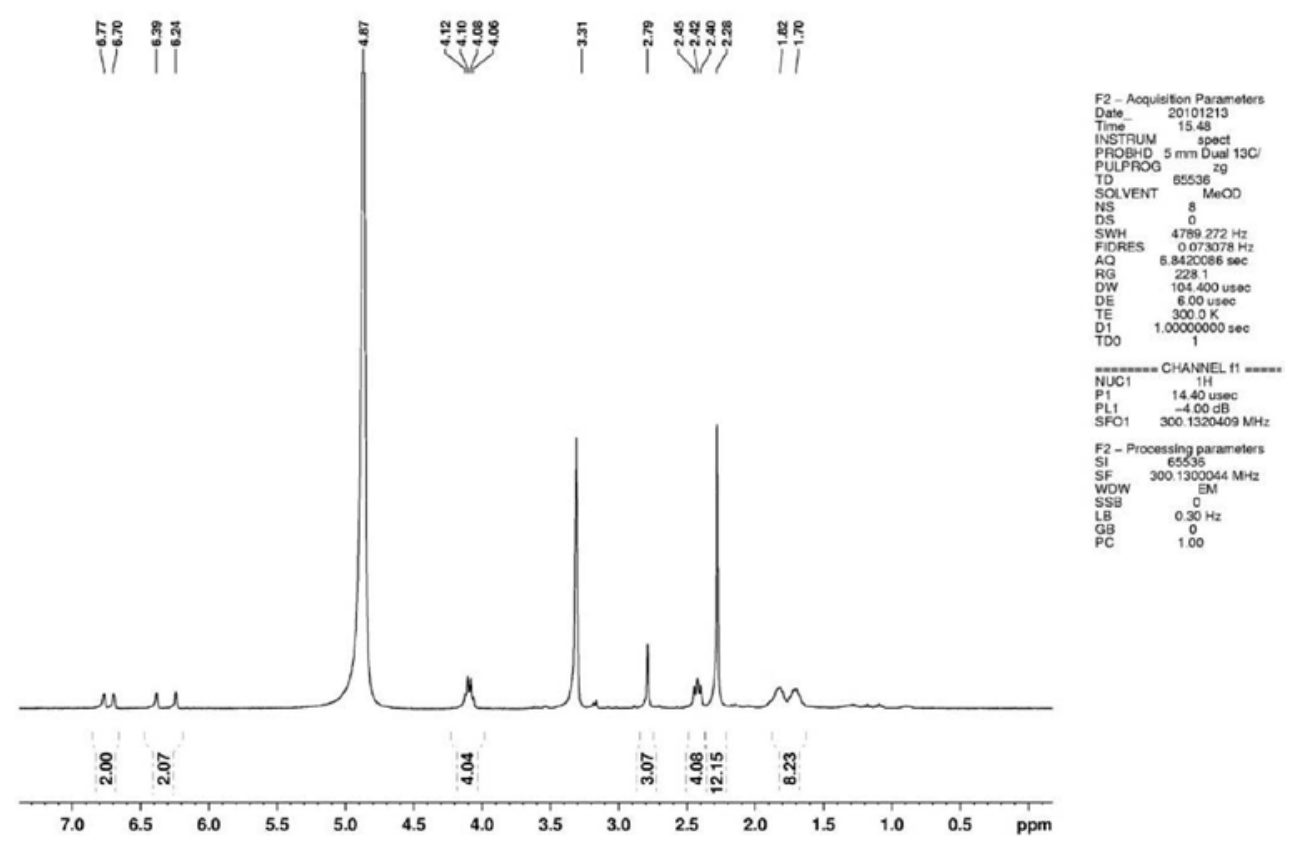

Figure 12S. ${ }^{1} \mathrm{H}$ NMR spectrum of (7), $300 \mathrm{MHz}$, methanol- $d_{4}$ 


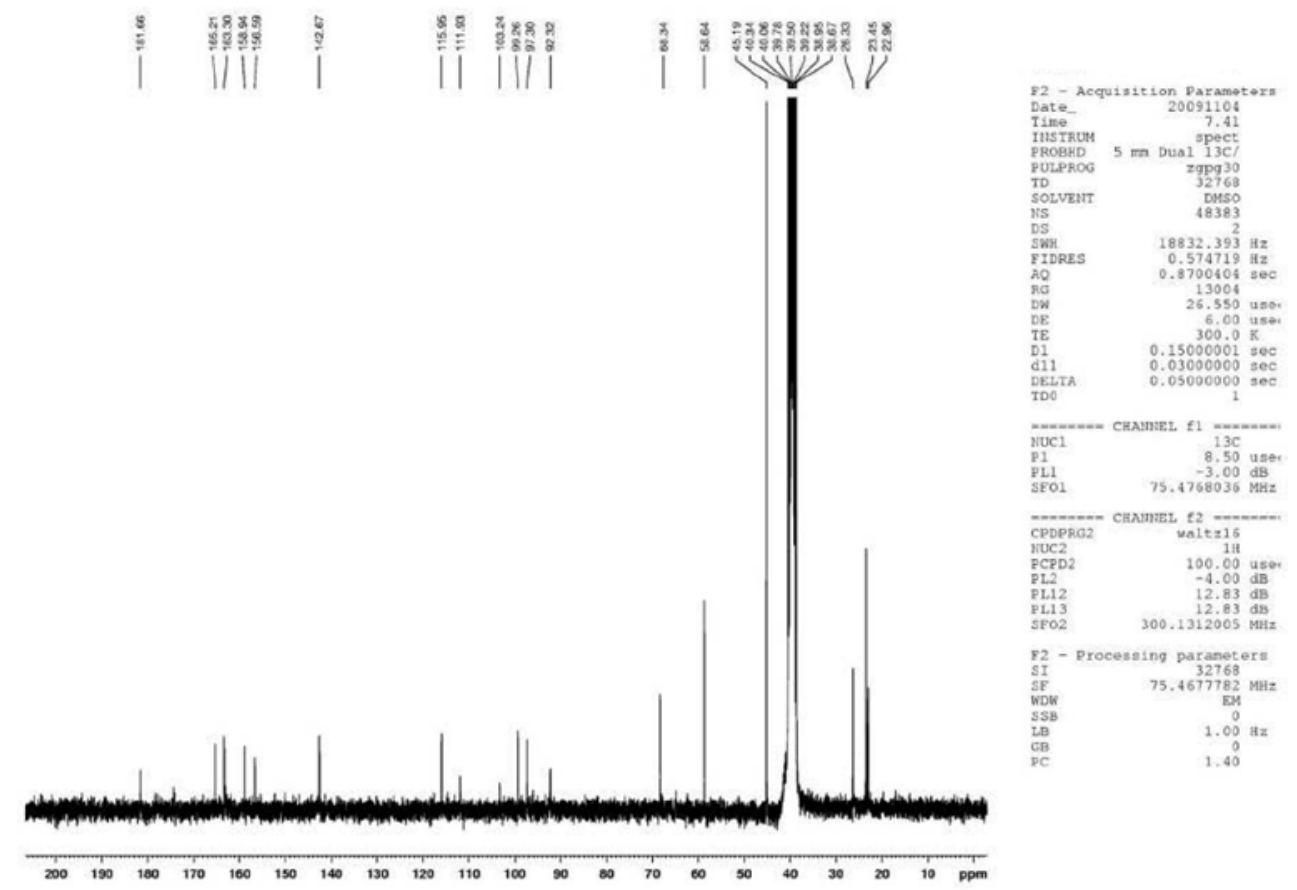

Figure 13S. ${ }^{13} \mathrm{C} M N R$ spectrum of (7), $75 \mathrm{MHz}, \mathrm{DMSO}-\mathrm{d}_{6}$

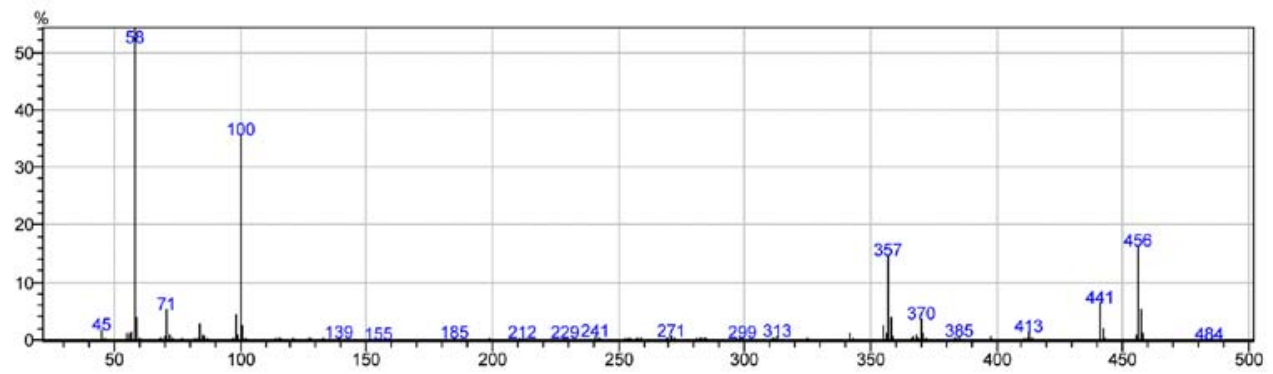

Figure 14S. EI/MS spectrum of (7)

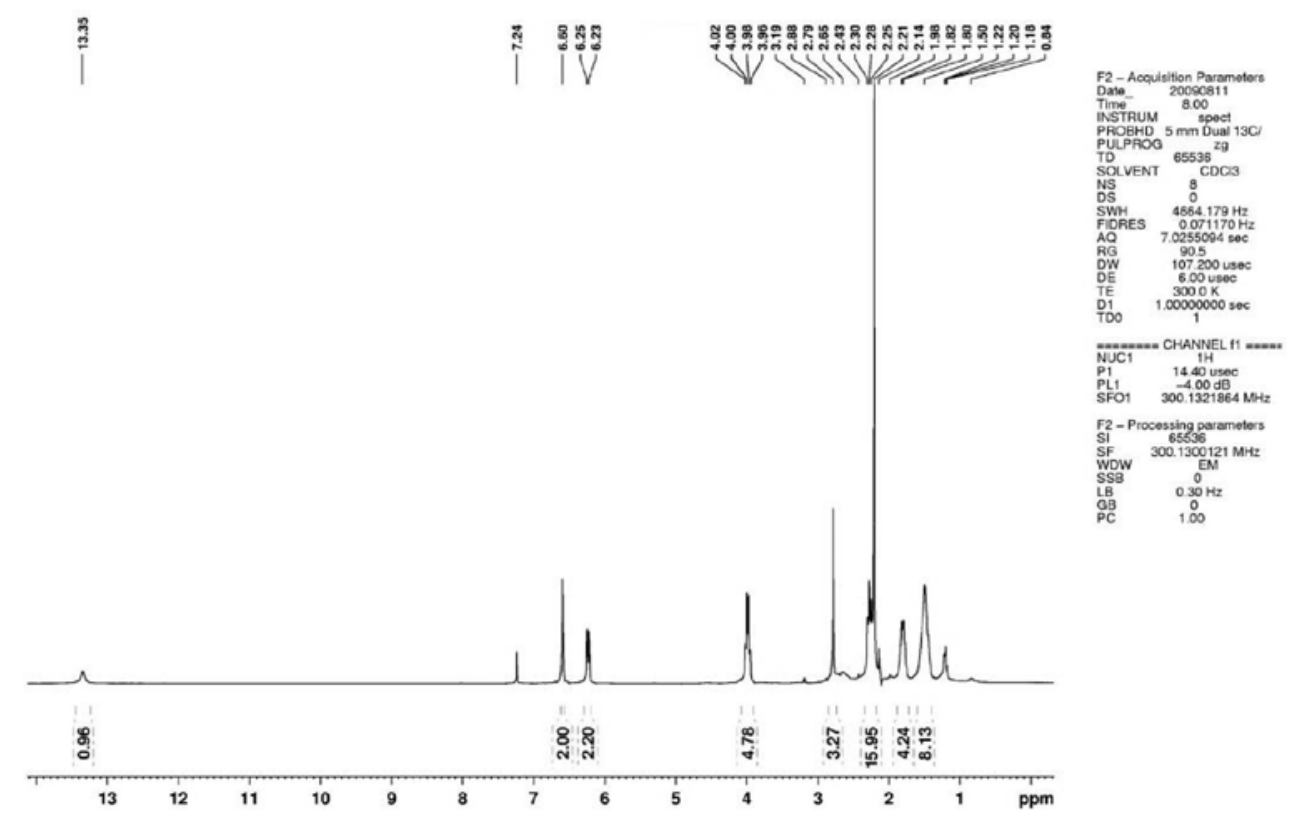

Figure 15S. ${ }^{l} \mathrm{H} \mathrm{NMR}$ spectrum of $(\mathbf{8}), 300 \mathrm{MHz}, \mathrm{CDCl}_{3}$ 


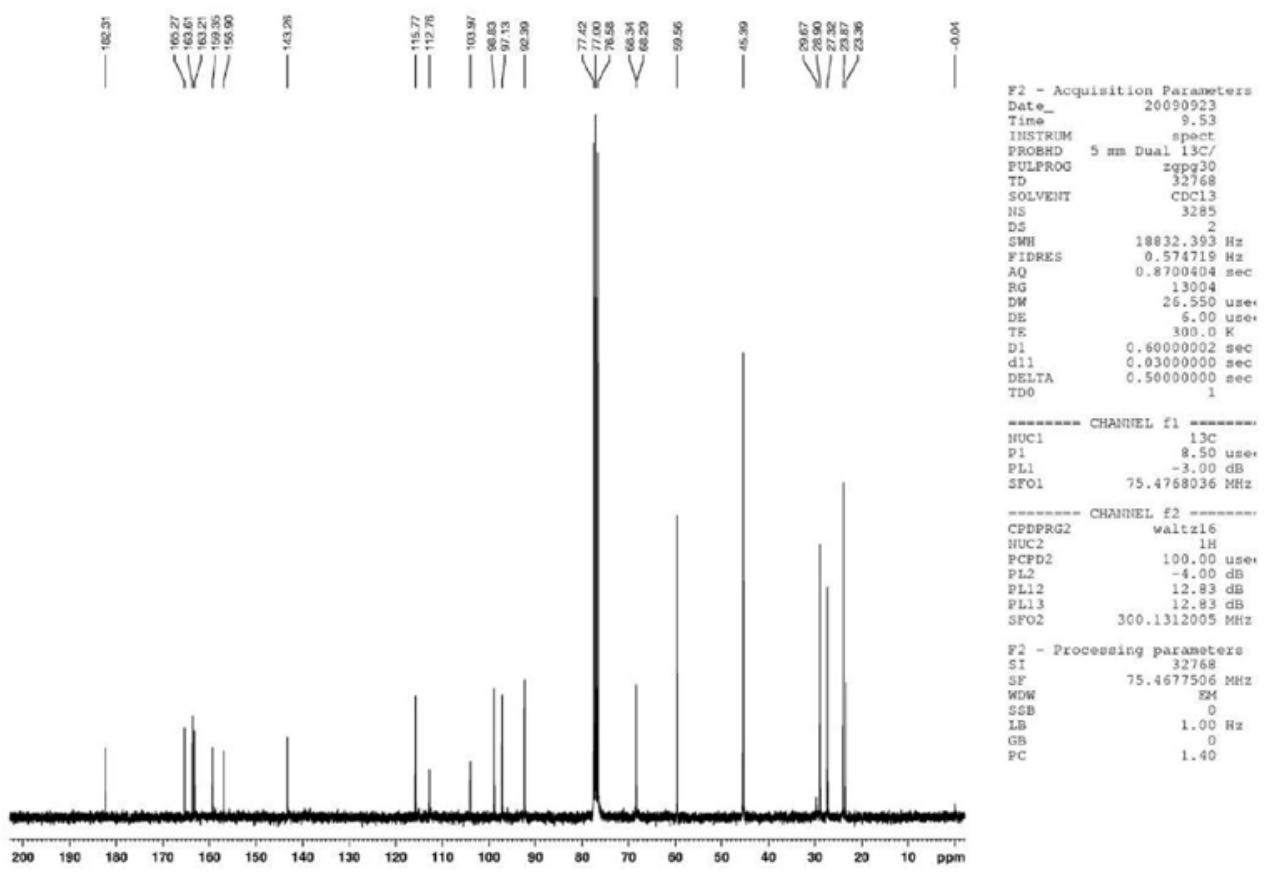

Figure 16S. ${ }^{13} \mathrm{C}$ NMR spectrum of $(\mathbf{8}), 75 \mathrm{MHz}, \mathrm{CDCl}_{3}$

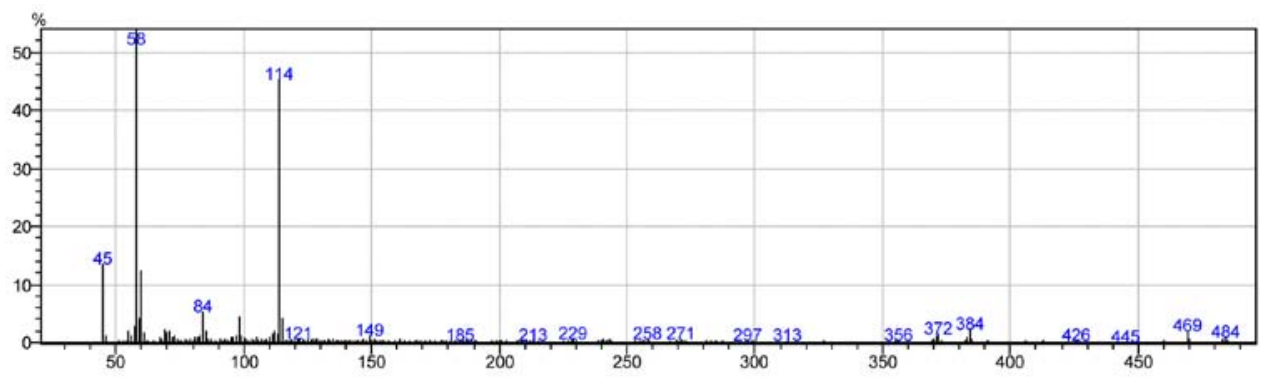

Figure 17S. EI/MS spectrum of $(\mathbf{8})$

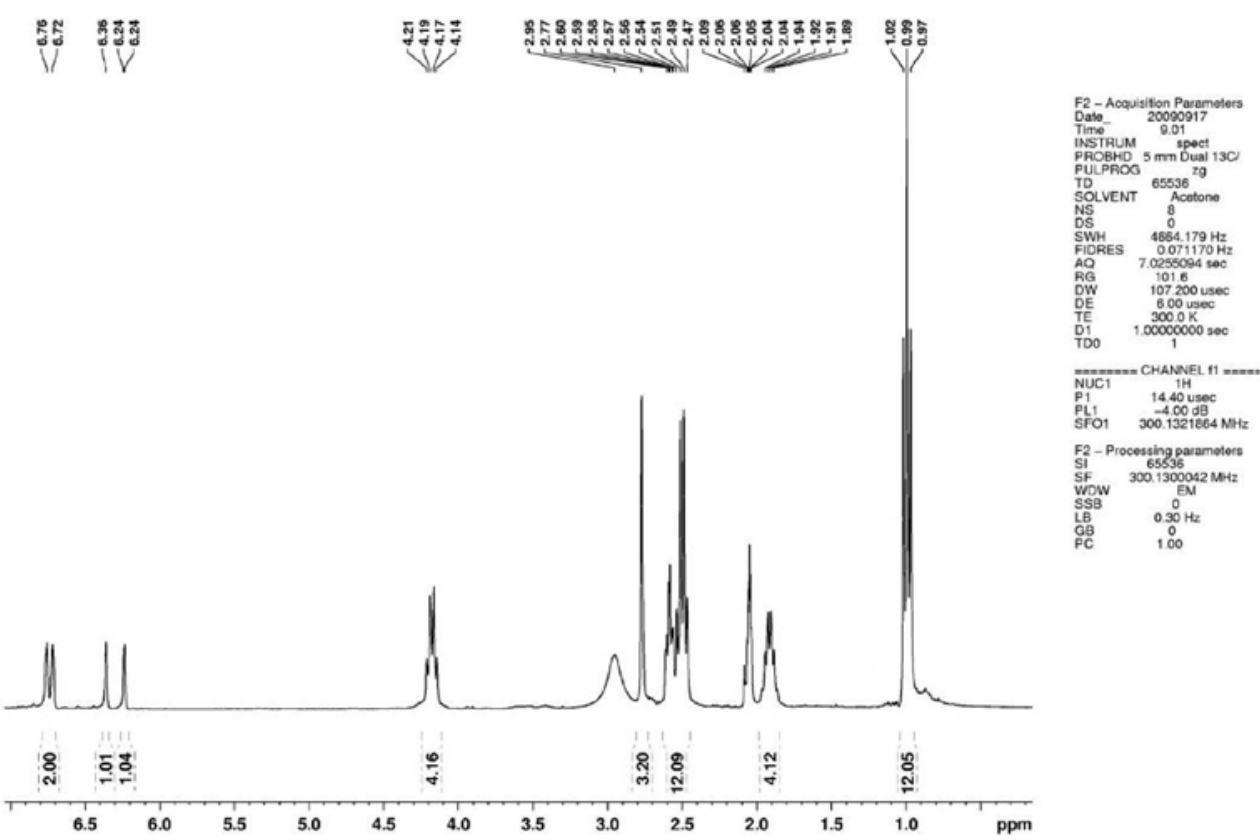

Figure 18S. ${ }^{1} \mathrm{H}$ NMR spectrum of $(\mathbf{9}), 300 \mathrm{MHz}$, acetone- $d_{6}$ 


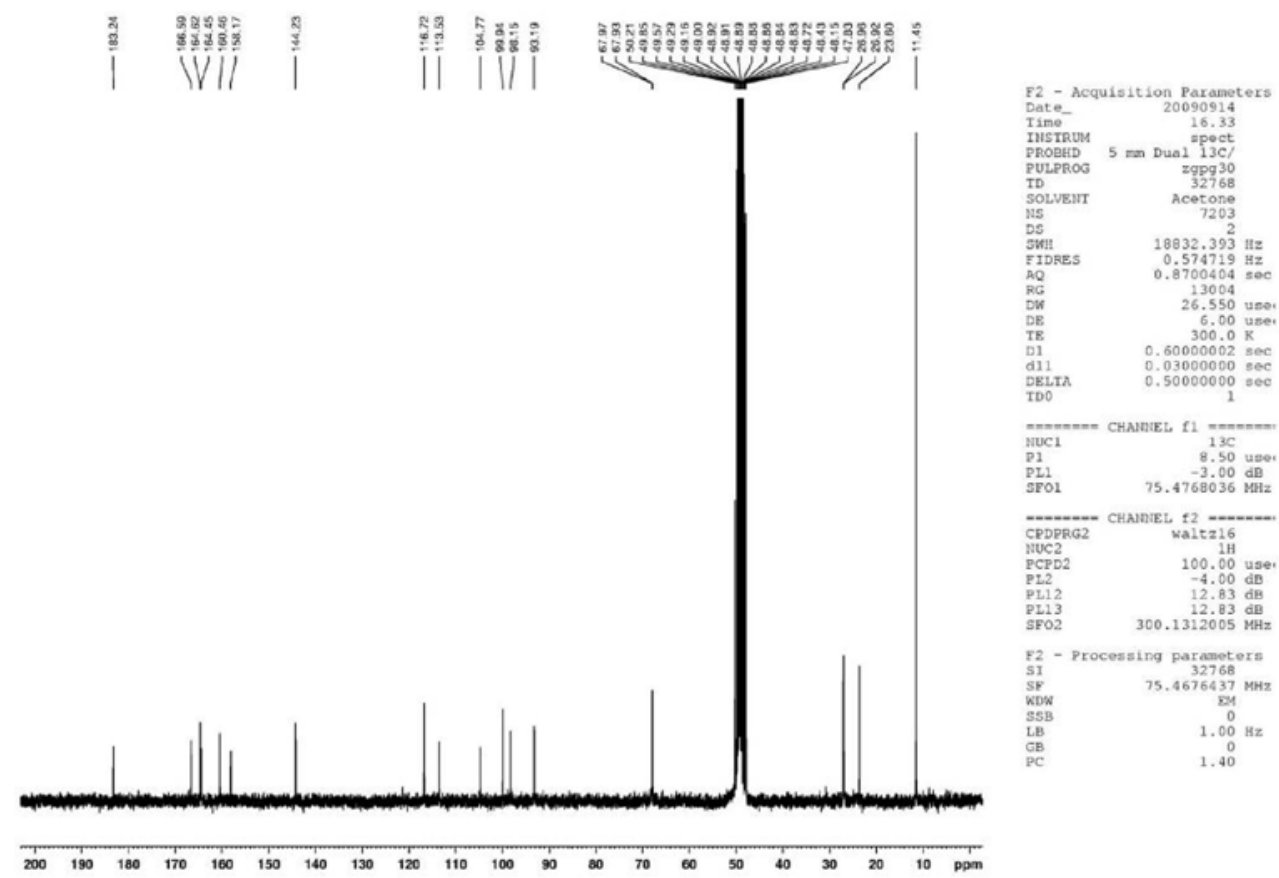

Figure 19S. ${ }^{13} \mathrm{C}$ NMR spectrum of (9), $75 \mathrm{MHz}$, methanol- $d_{4}$

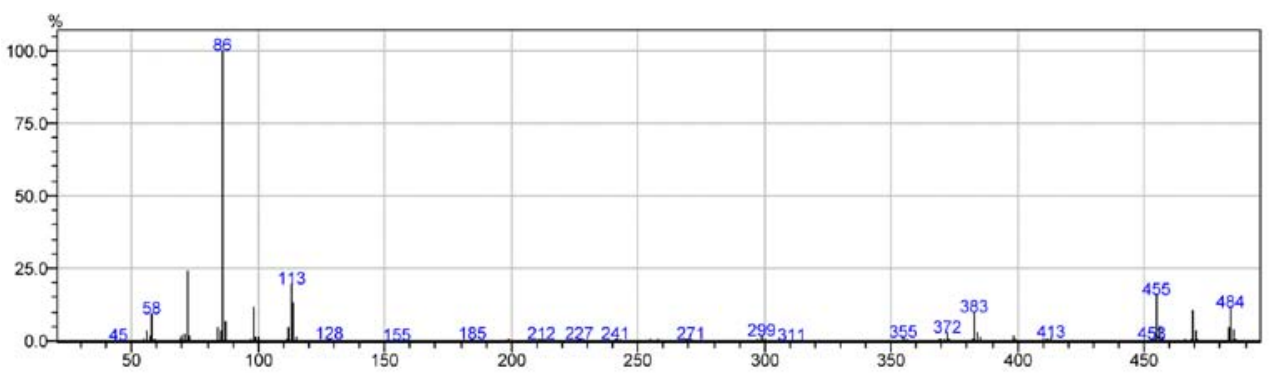

Figure 20S. EI/MS spectrum of (9)

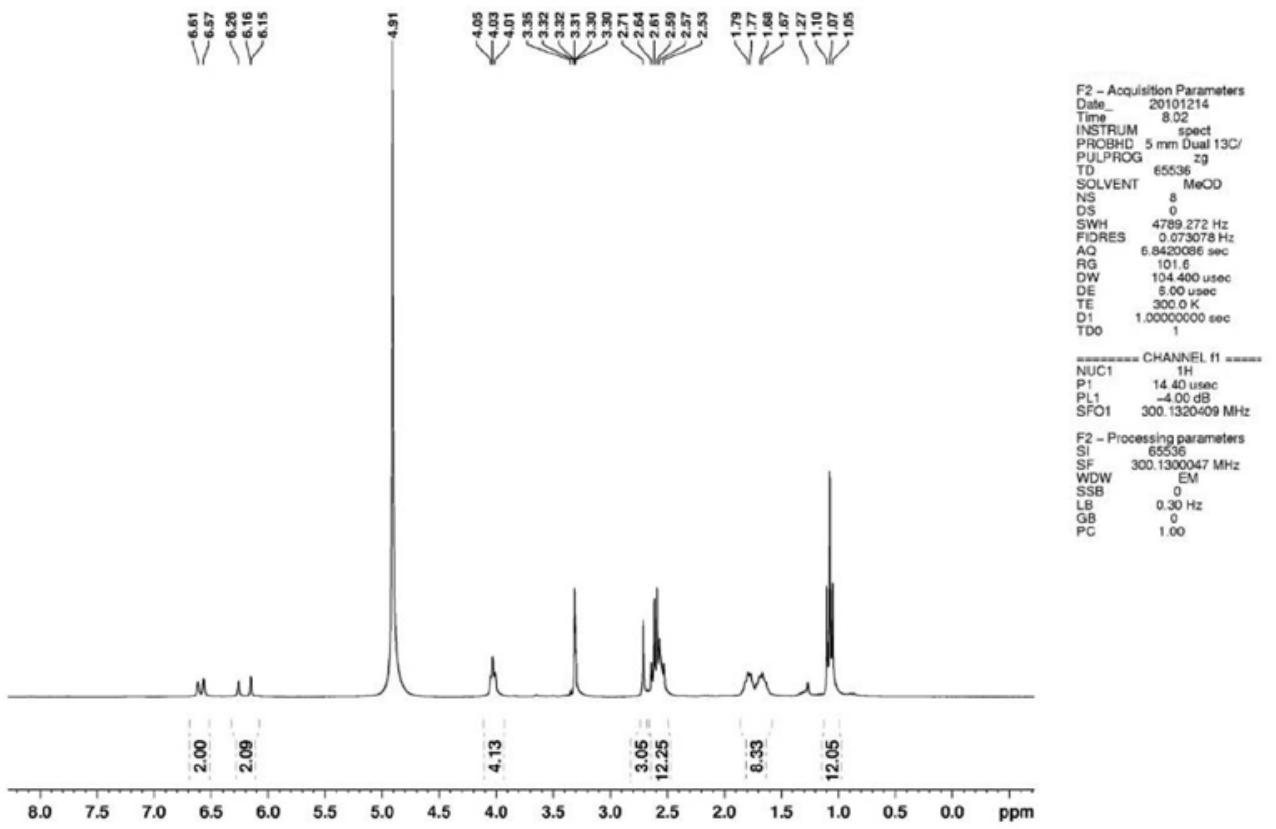

Figure $21 \mathrm{~S} .{ }^{1} \mathrm{H}$ spectrum of $(\mathbf{1 0}), 300 \mathrm{MHz}$, methanol- $\mathrm{d}_{4}$ 

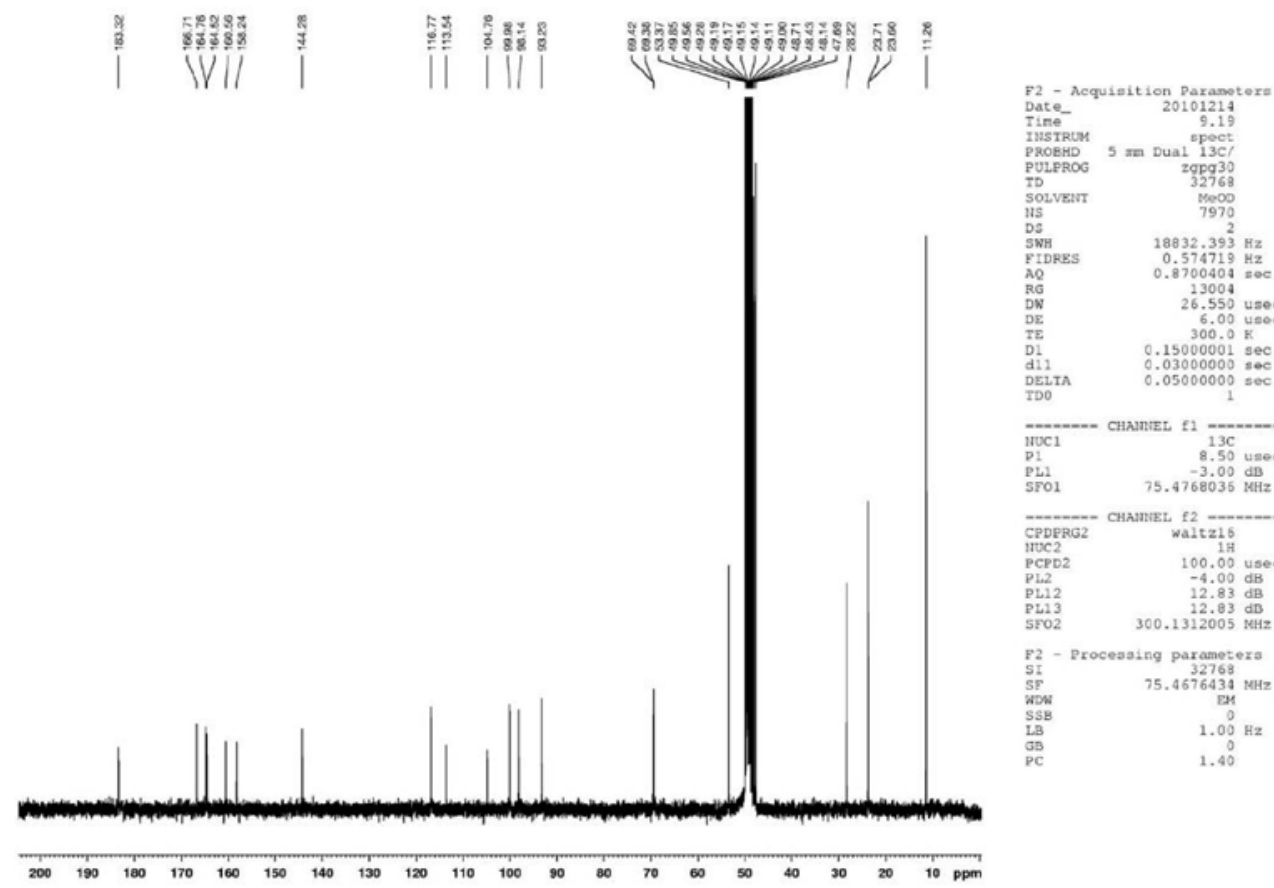

Figure $22 S .{ }^{13} \mathrm{C}$ NMR spectrum of $(\mathbf{1 0}), 75 \mathrm{MHz}$, methanol- $d_{4}$

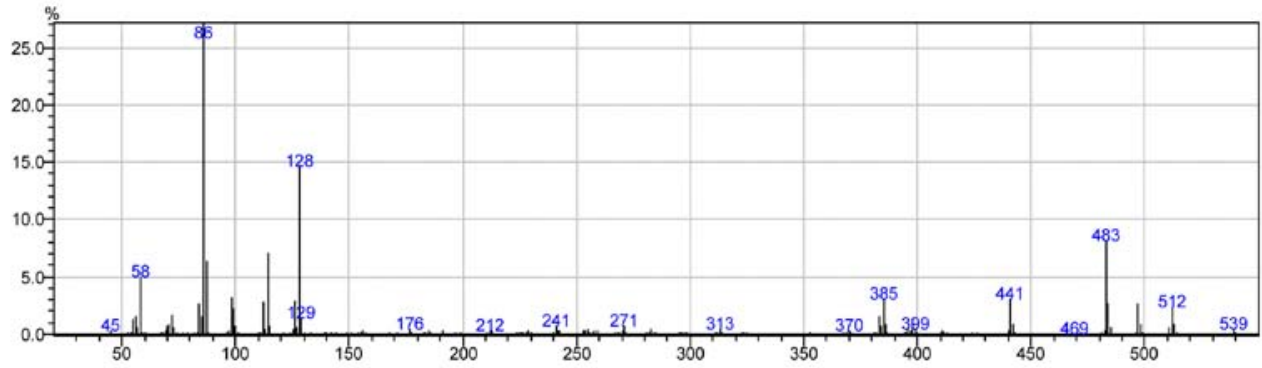

Figure 23S. EI/MS spectrum of (10)

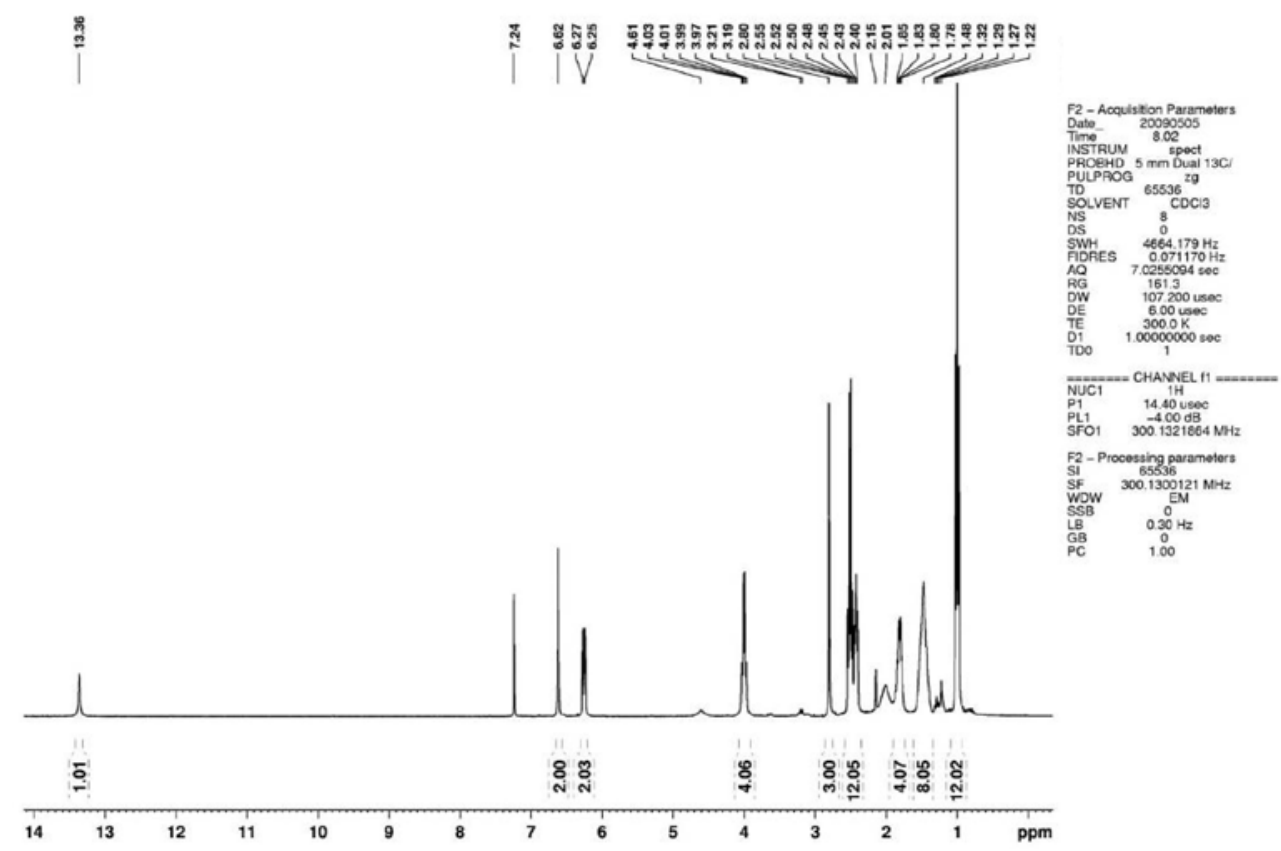

Figure 24S. ${ }^{1} \mathrm{H}$ NMR spectrum of (11), $300 \mathrm{MHz}, \mathrm{CDCl}_{3}$ 

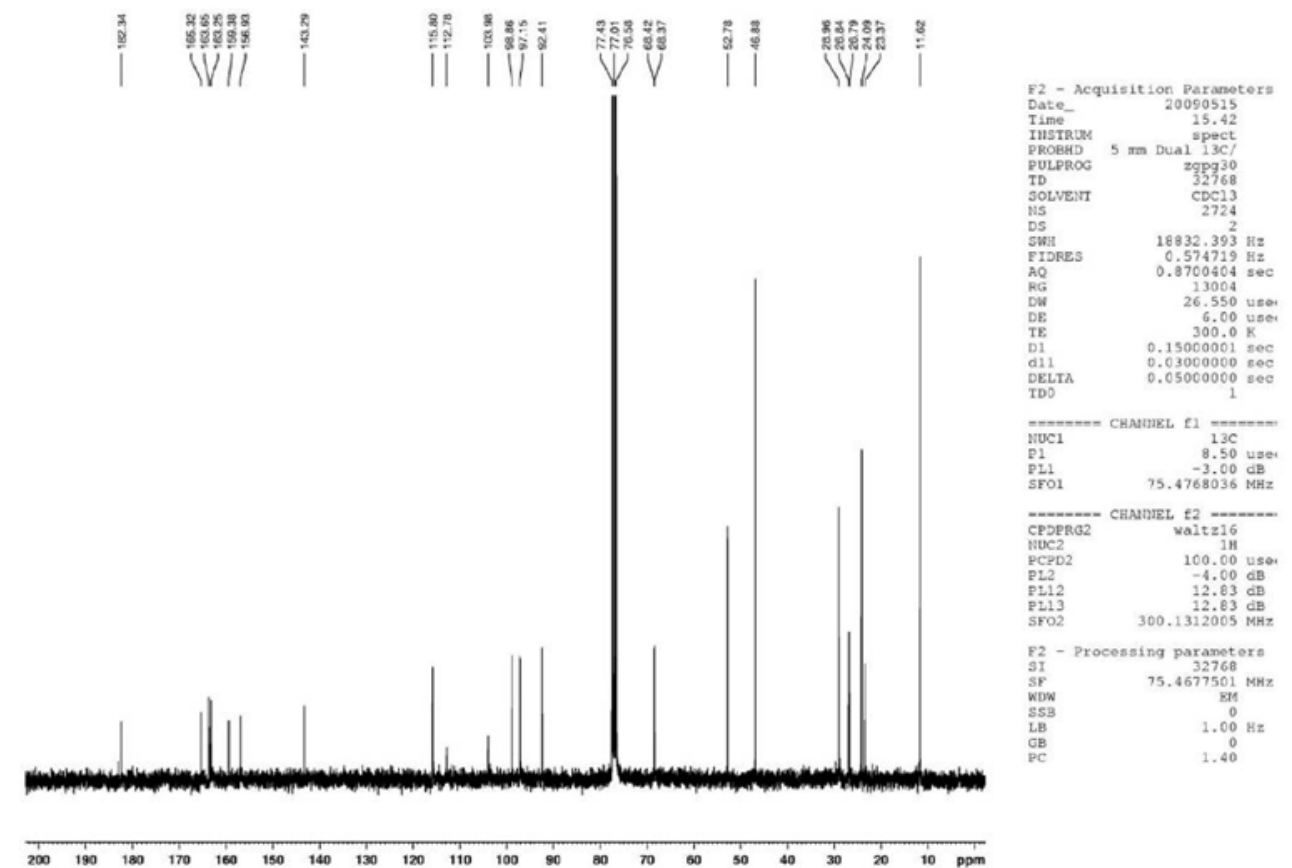

Figure 25S. ${ }^{13} \mathrm{C}$ NMR spectrum of (11), $75 \mathrm{MHz}, \mathrm{CDCl}_{3}$

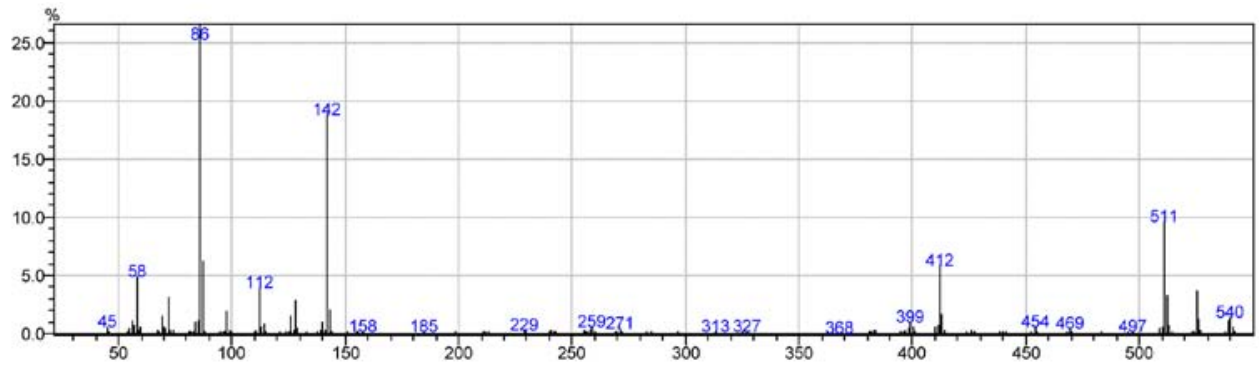

Figure 26S. EI/MS spectrum of (11)

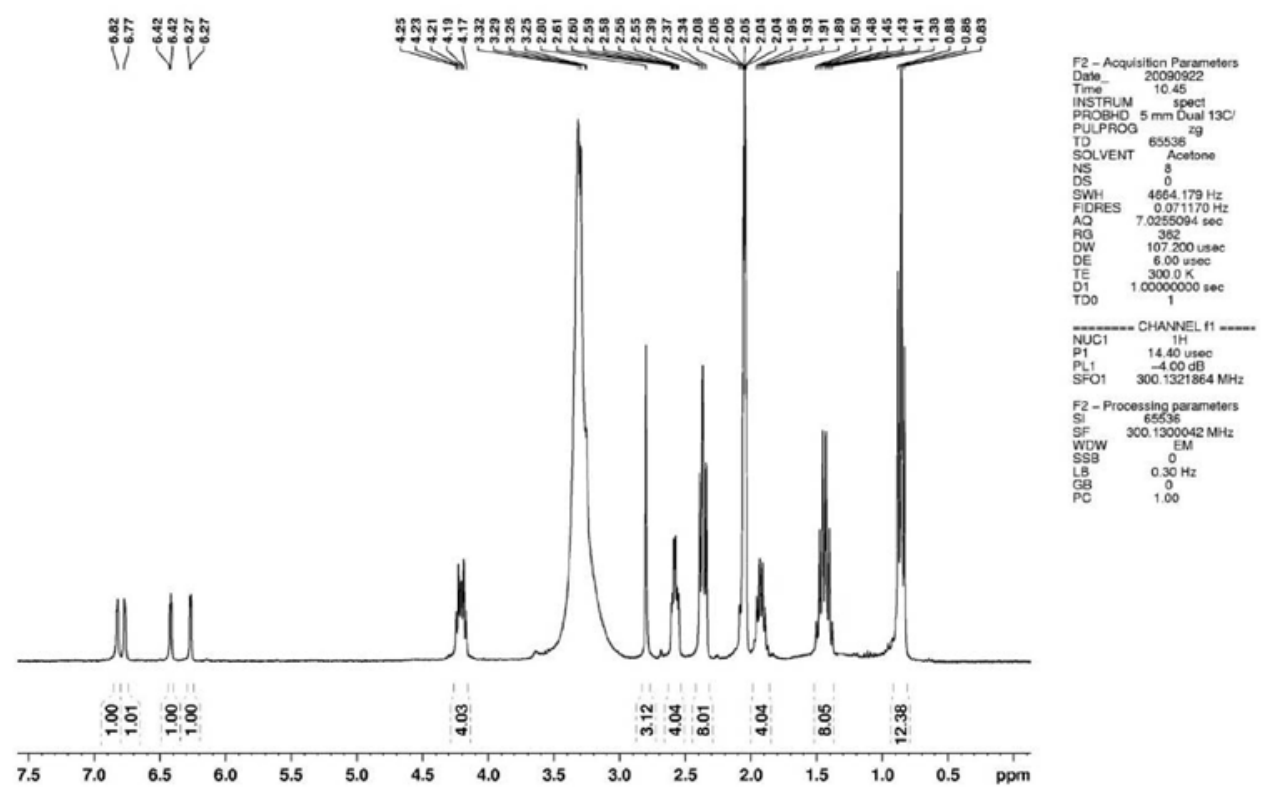

Figure 27S. ${ }^{1} \mathrm{H}$ NMR spectrum of (12), $300 \mathrm{MHz}$, acetone- $d_{6} /{\text { methanol- } d_{4}}$ 

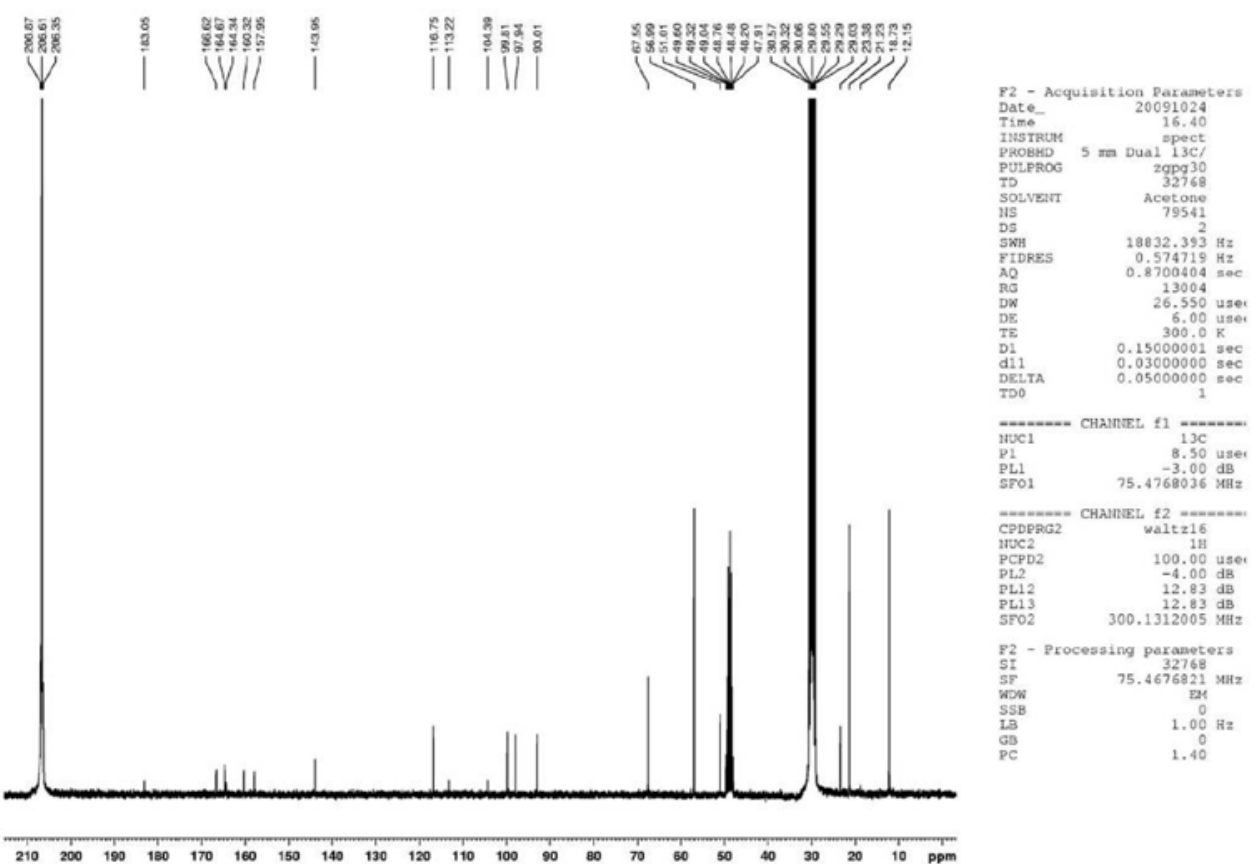

Figure 28S. ${ }^{13} \mathrm{C}$ NMR spectrum of (12), $75 \mathrm{MHz}$, acetone- $d_{6} /$ methanol- $d_{4}$

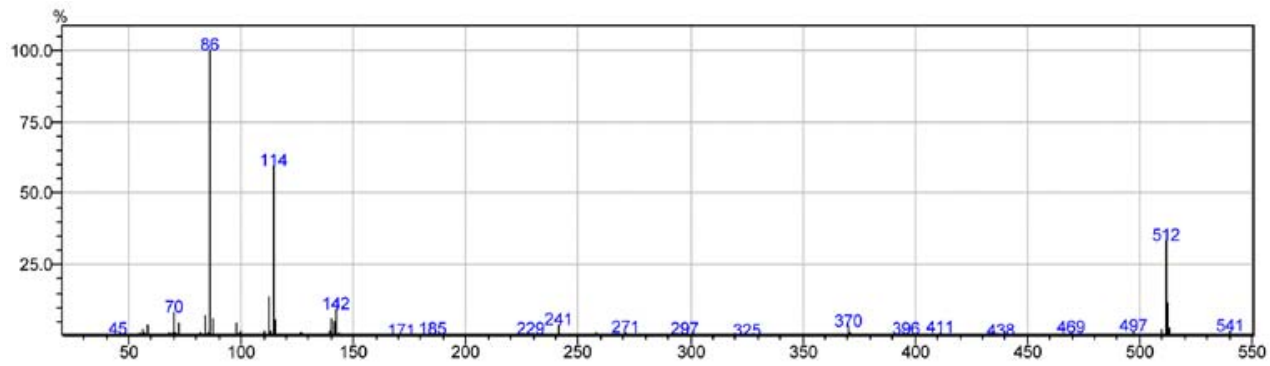

Figure 29S. EI/MS spectrum of (12)
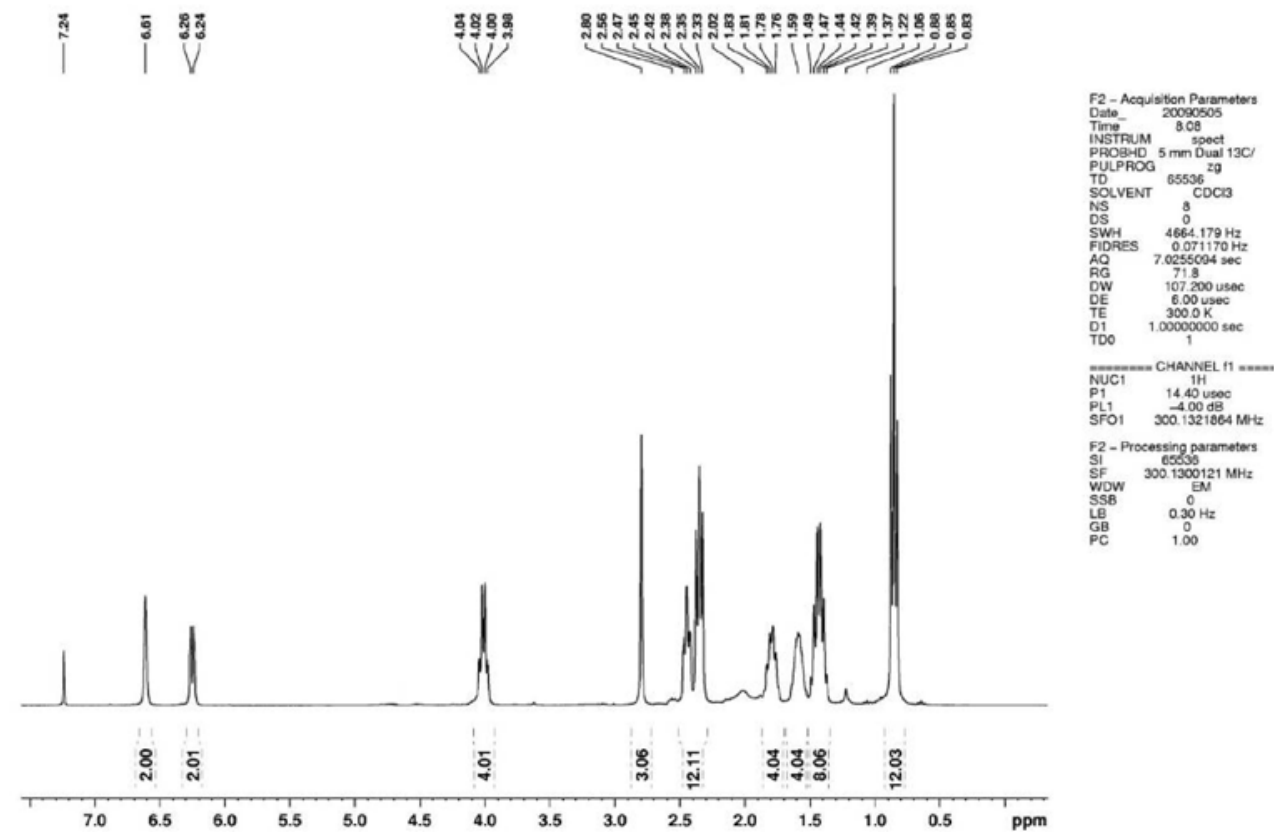

Figure 30S. ${ }^{l} \mathrm{H}$ NMR spectrum of (13), $300 \mathrm{MHz}, \mathrm{CDCl}_{3}$ 

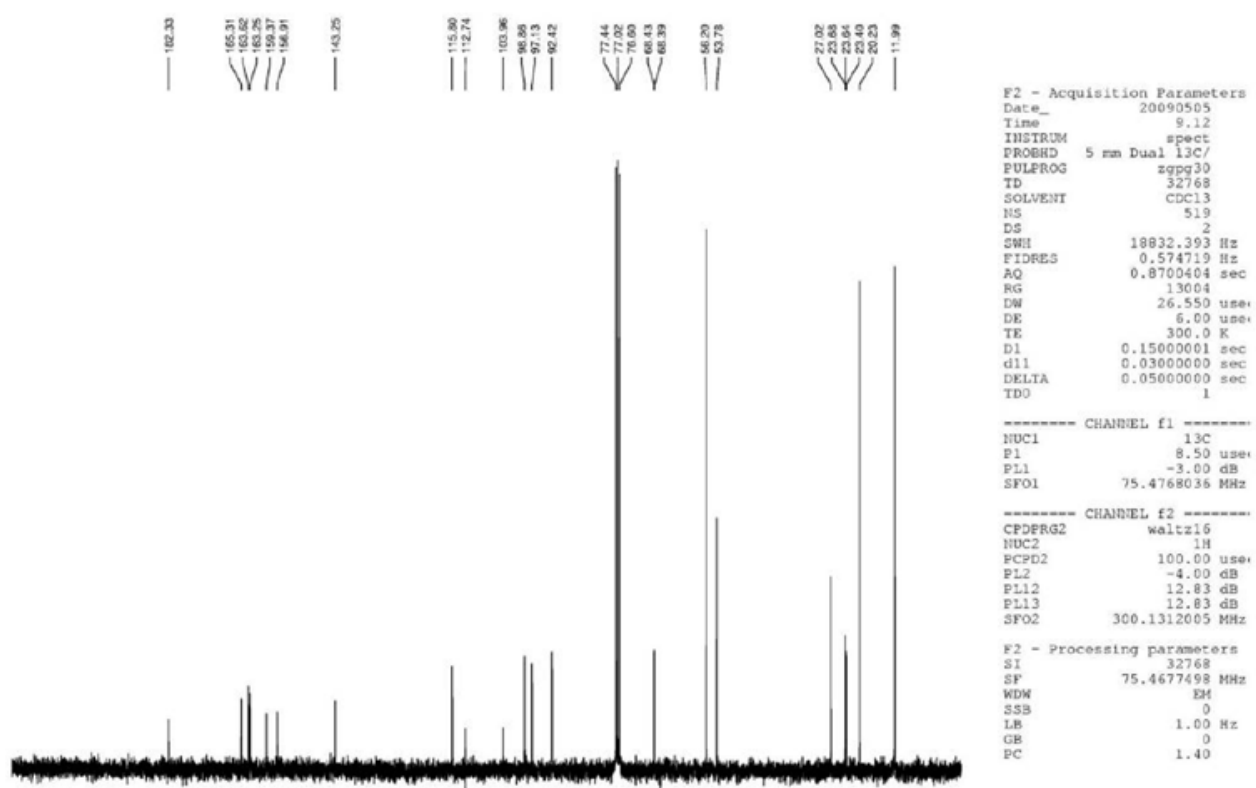

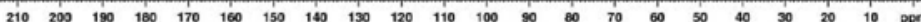

Figure 31S. ${ }^{13} \mathrm{C}$ NMR spectrum of (13), $75 \mathrm{MHz}, \mathrm{CDCl}_{3}$

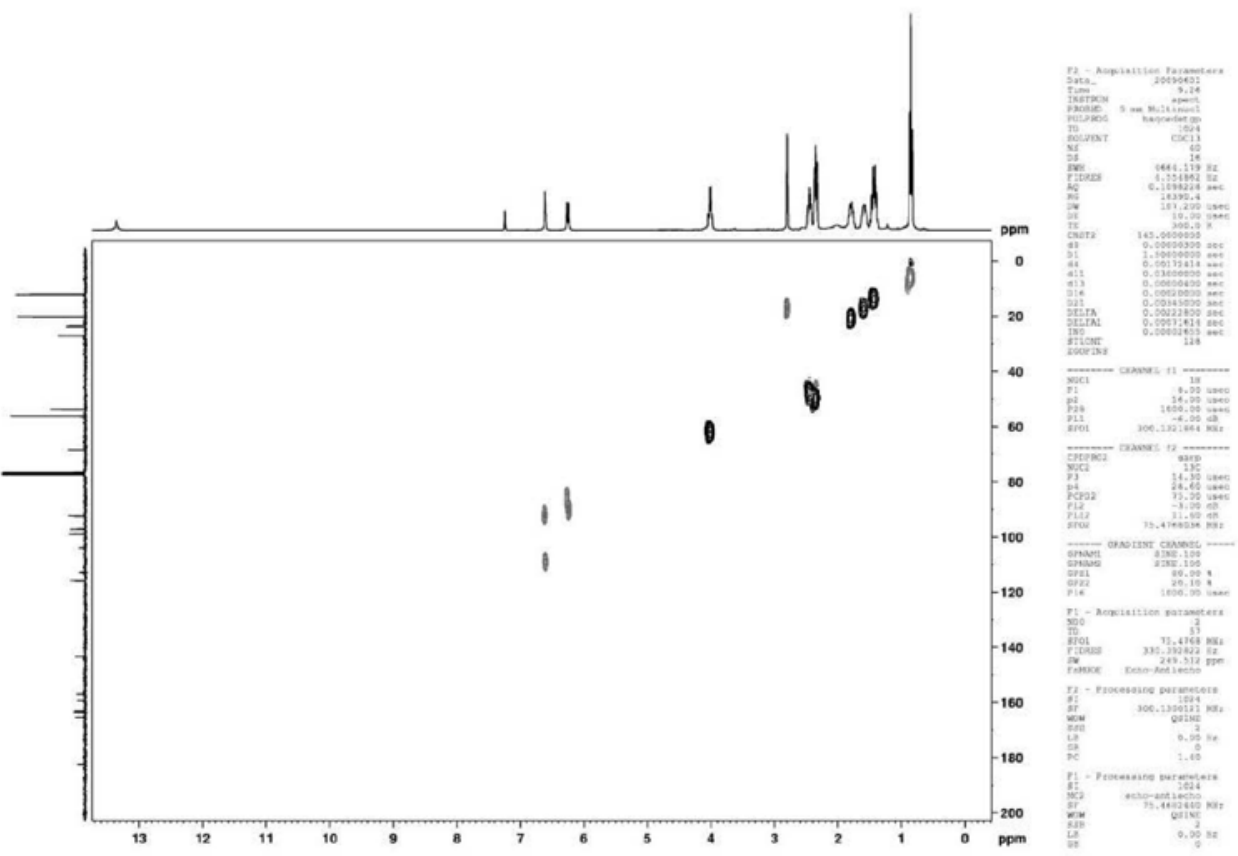

Figure 32S. $\mathrm{HSQC}$ spectrum of (13), $\mathrm{CDCl}_{3}$ 


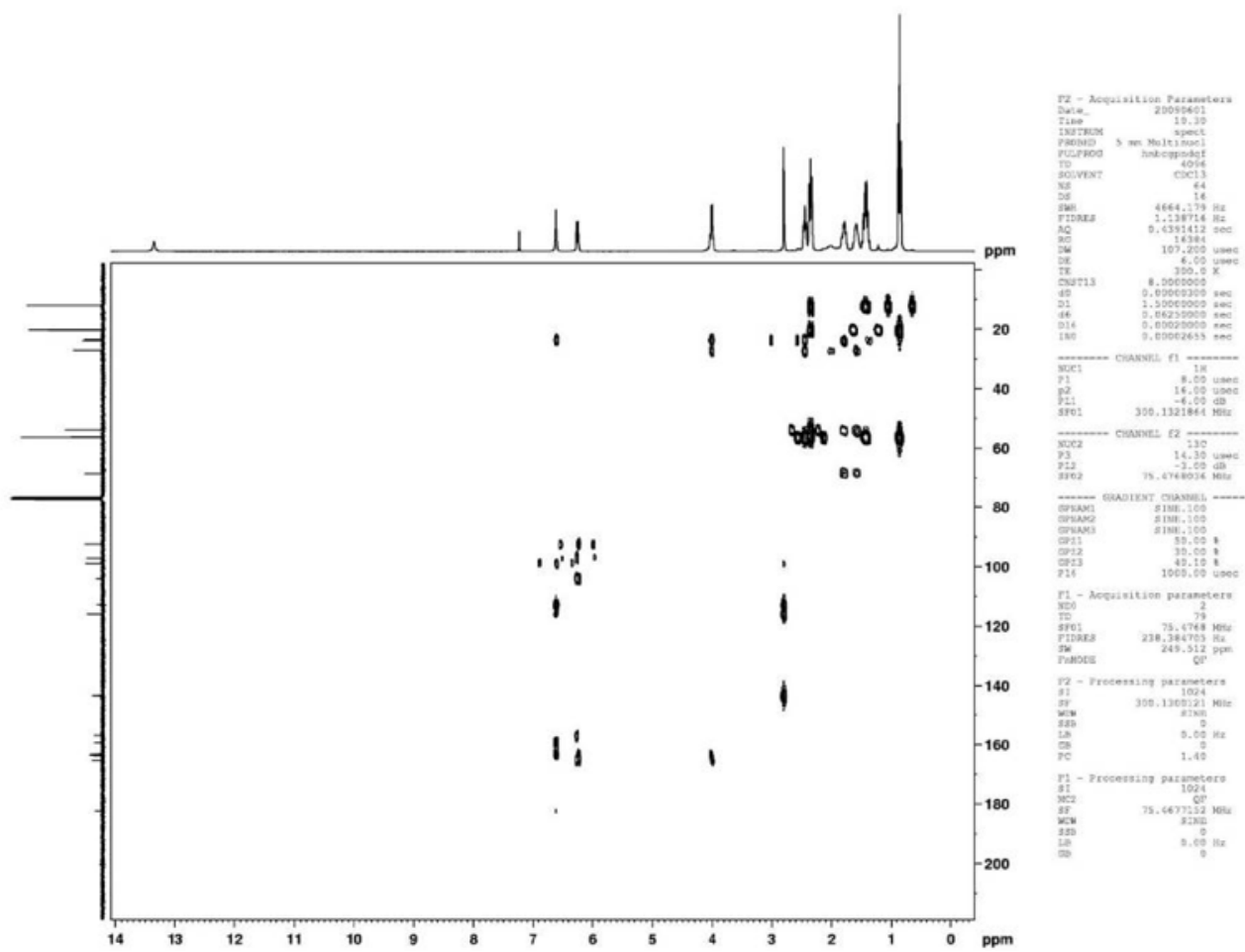

Figure 33S. $\mathrm{HMBC}$ spectrum of $(\mathbf{1 3}), \mathrm{CDCl}_{3}$

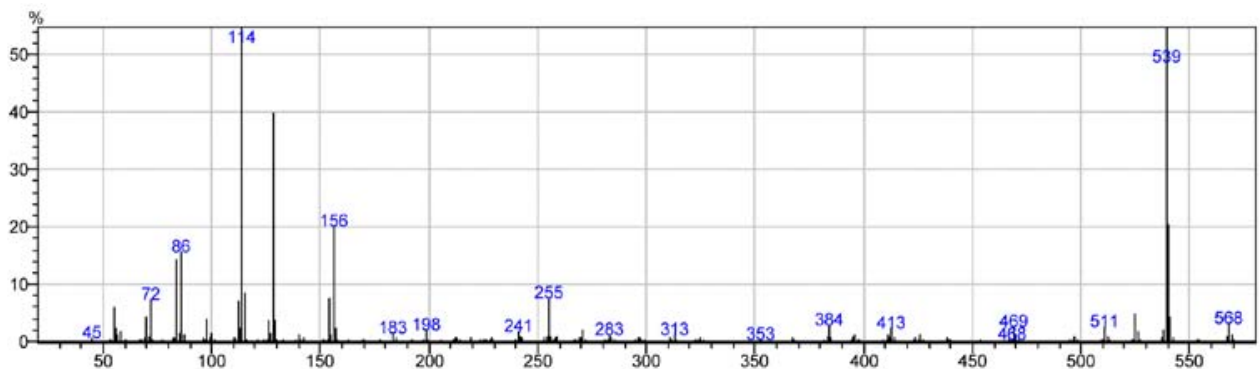

Figure 34S. EI/MS spectrum of (13)

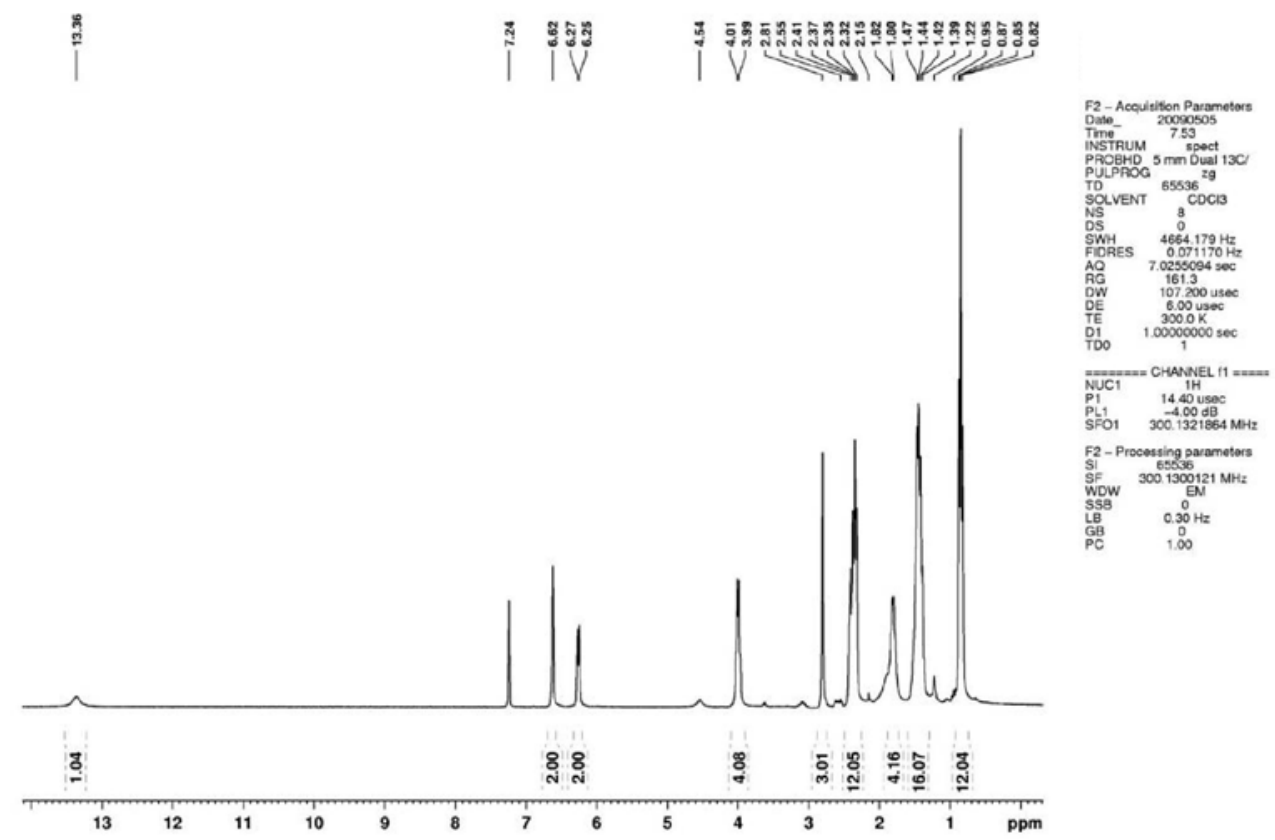

Figure 35S. ${ }^{1} \mathrm{H} \mathrm{NMR}$ spectrum of (14), $300 \mathrm{MHz}, \mathrm{CDCl}_{3}$ 

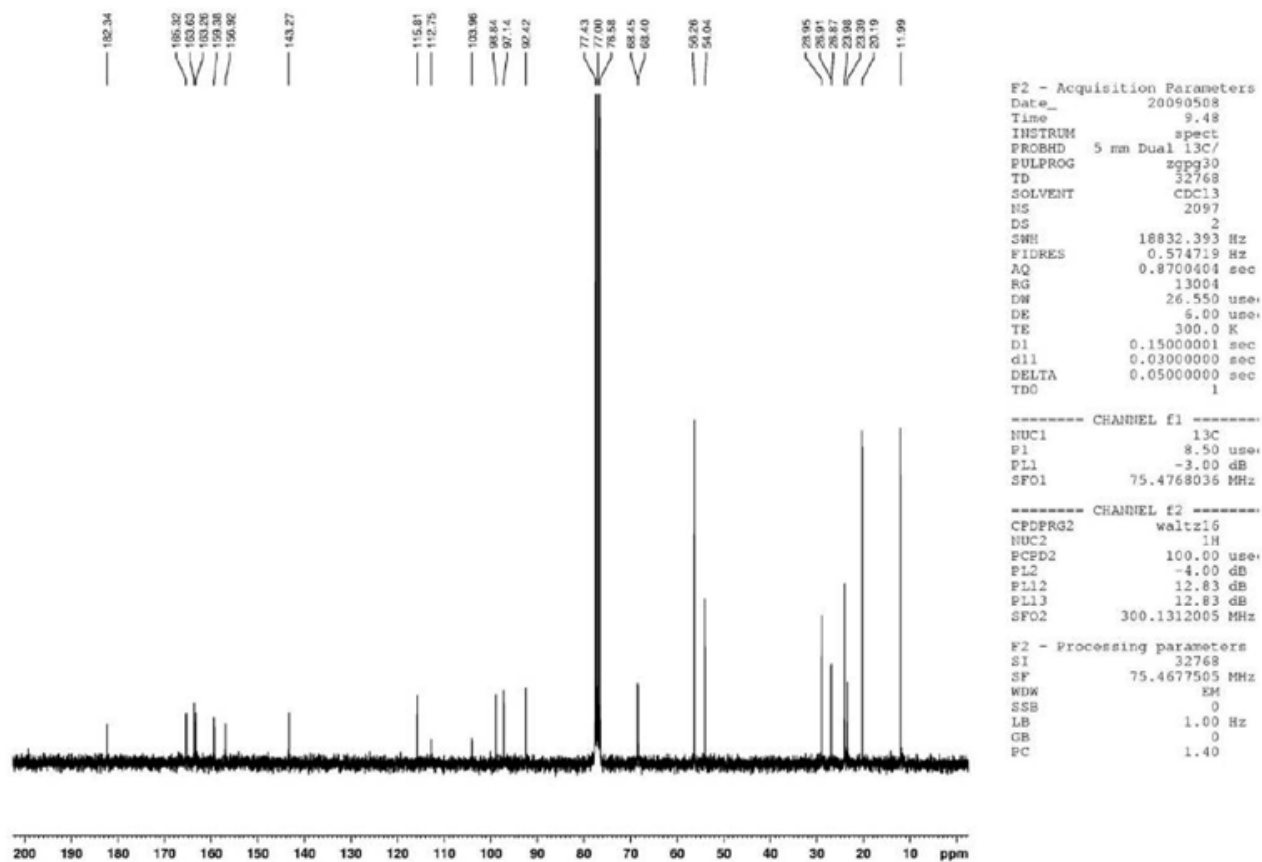

Figure 36S. ${ }^{13} \mathrm{C}$ NMR spectrum of (14), $75 \mathrm{MHz}, \mathrm{CDCl}_{3}$
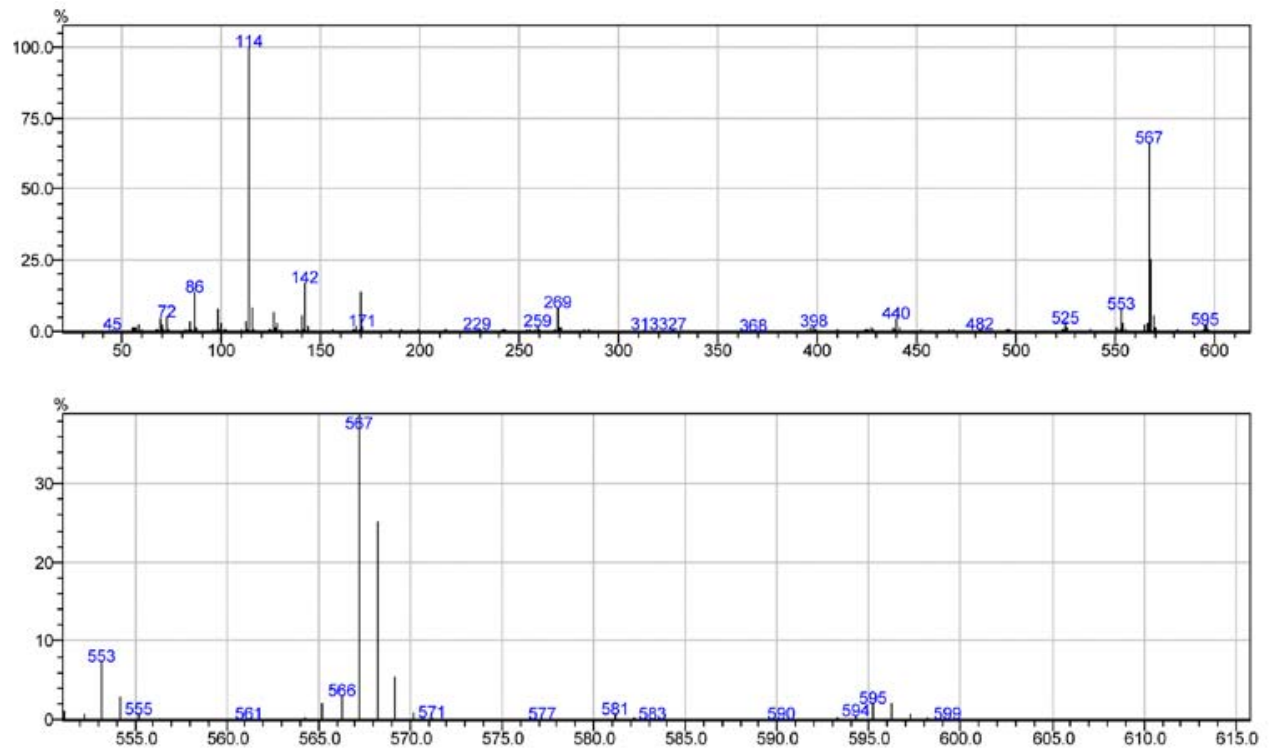

Figure 37S. EI/MS spectrum of (14) 


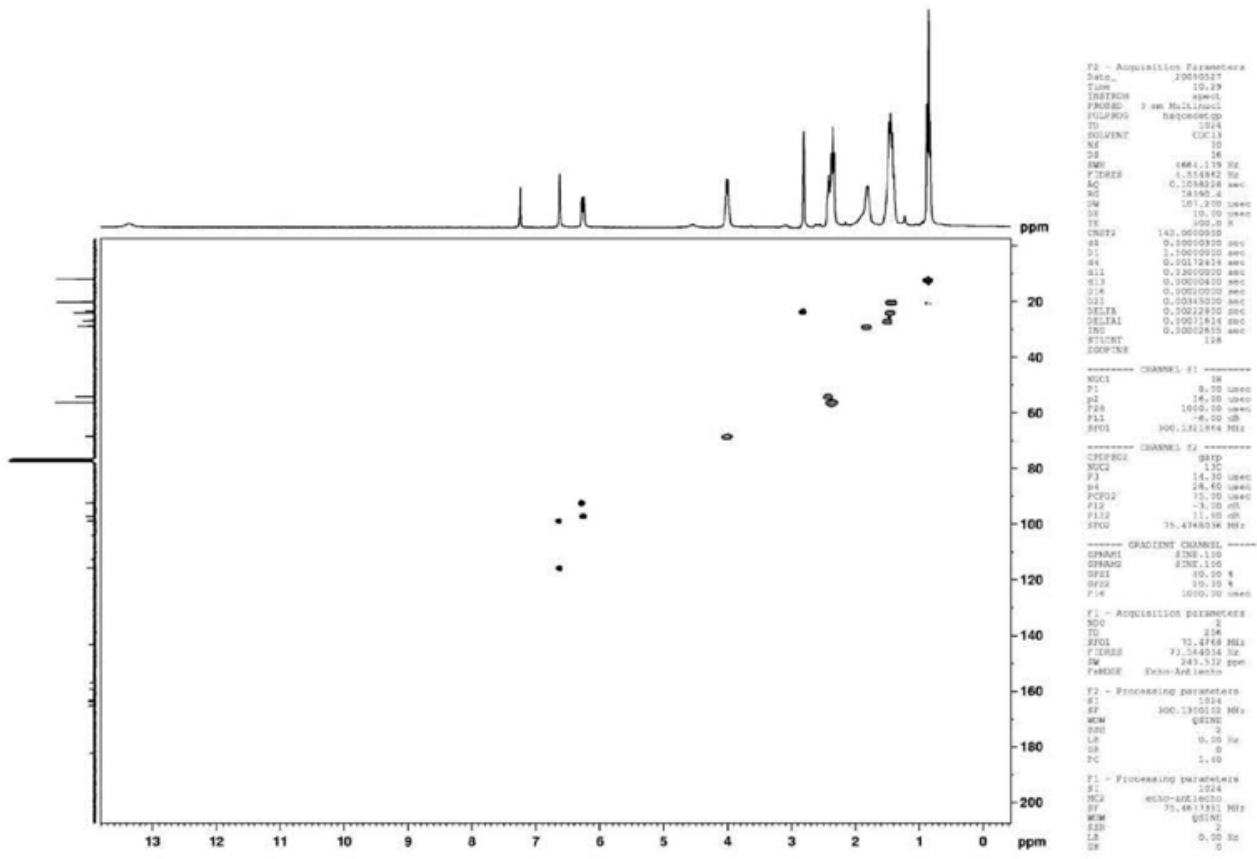

Figure 38S. HSQC spectrum of (14), $\mathrm{CDCl}_{3}$

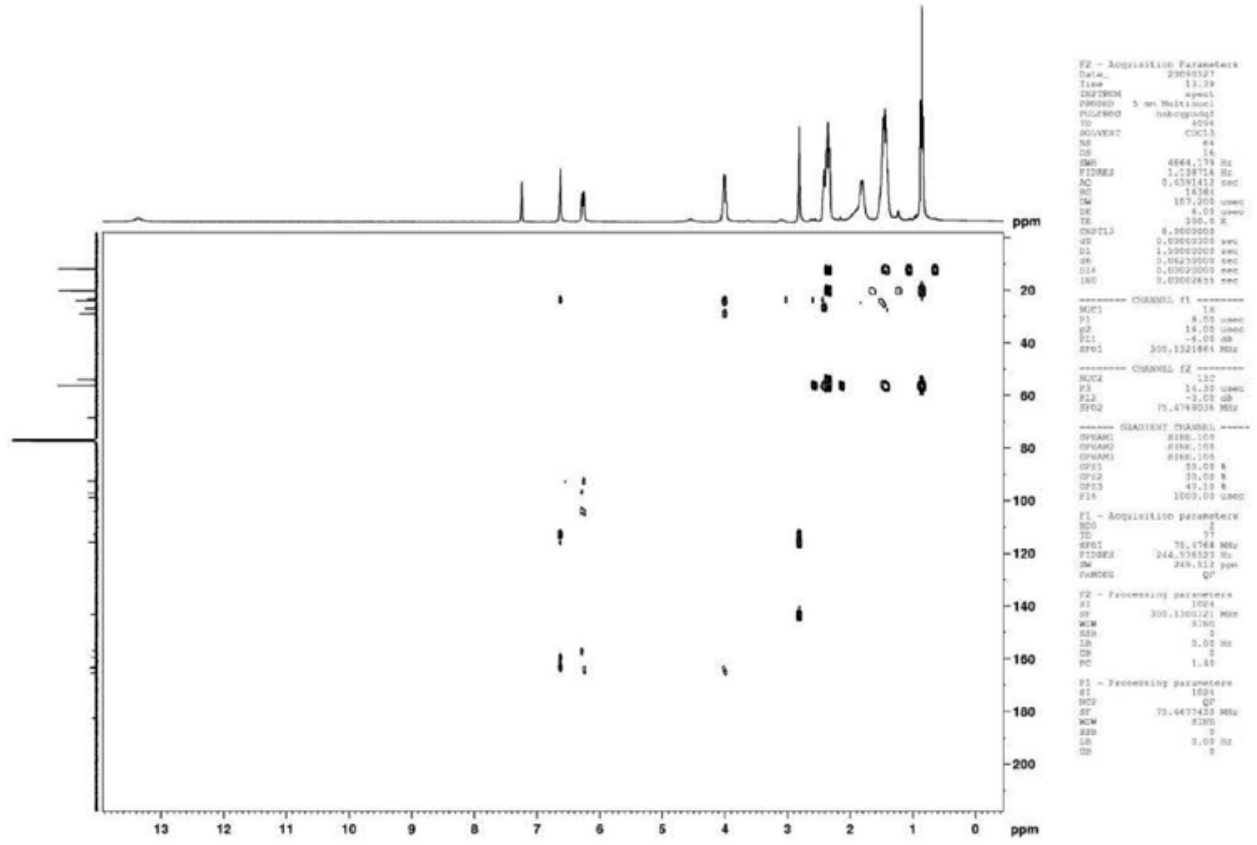

Figure 39S. $\mathrm{HMBC}$ spectrum of (14), $\mathrm{CDCl}_{3}$ 


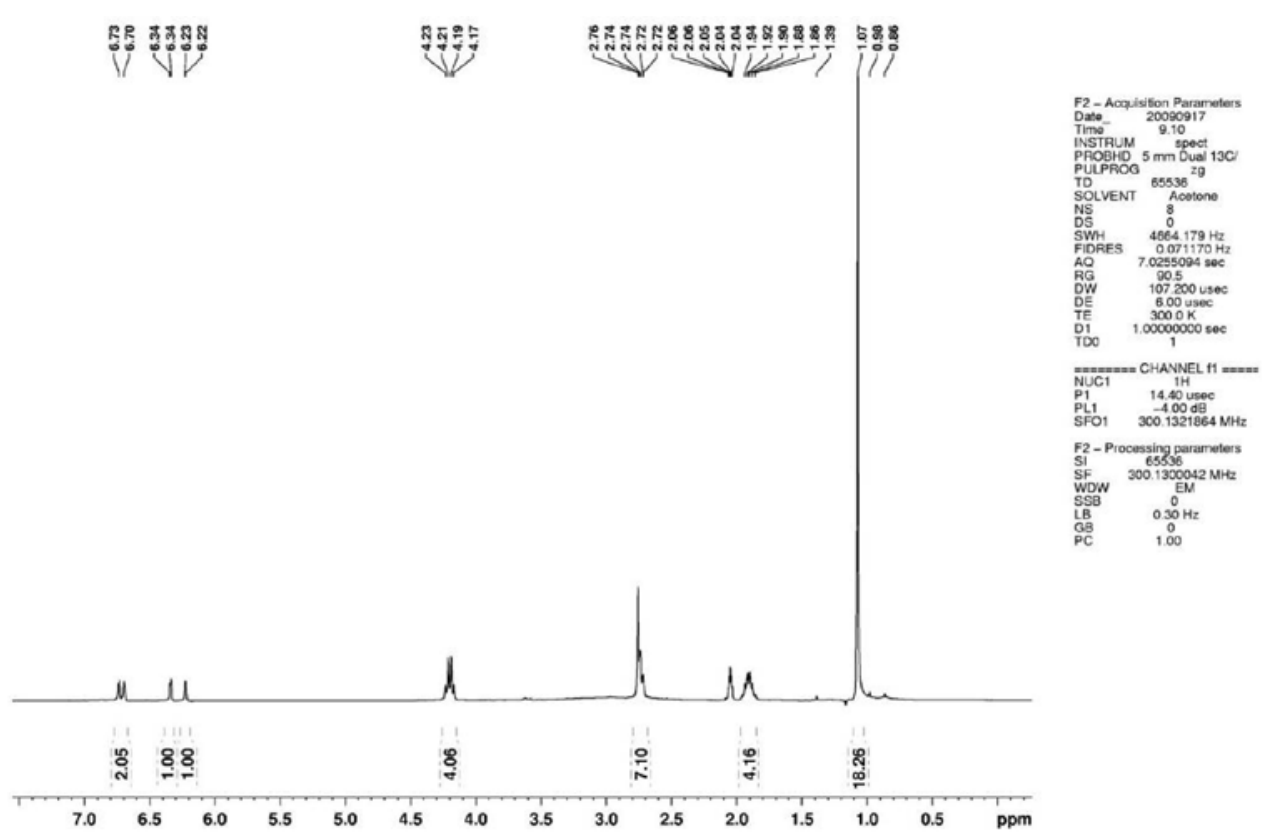

Figure 40S. ${ }^{l} \mathrm{H}$ NMR spectrum of (15), $300 \mathrm{MHz}$, acetone- $d_{6}$
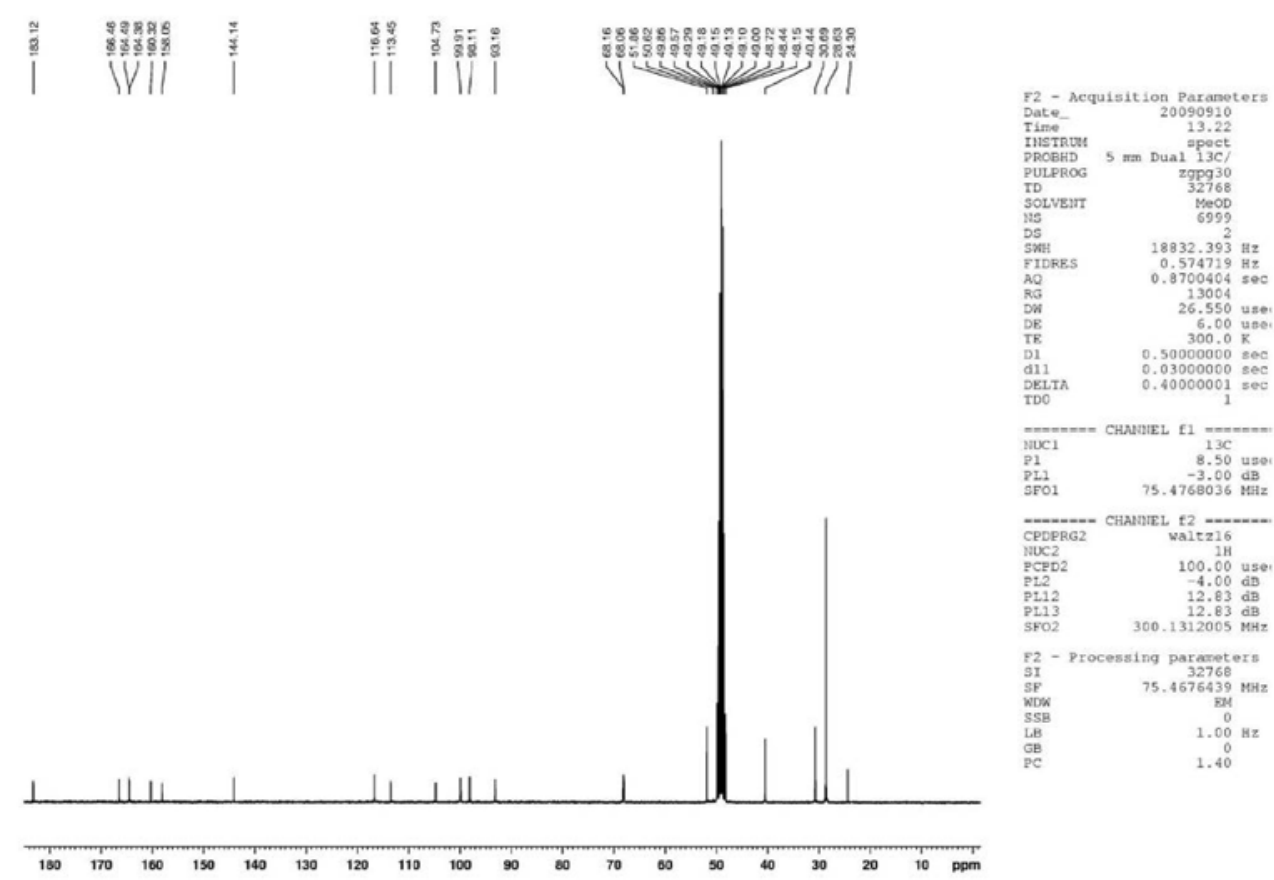

Figure 41S. ${ }^{13} \mathrm{C}$ NMR spectrum of $(\mathbf{1 5}), 75 \mathrm{MHz}$, methanol- $d_{4}$ 

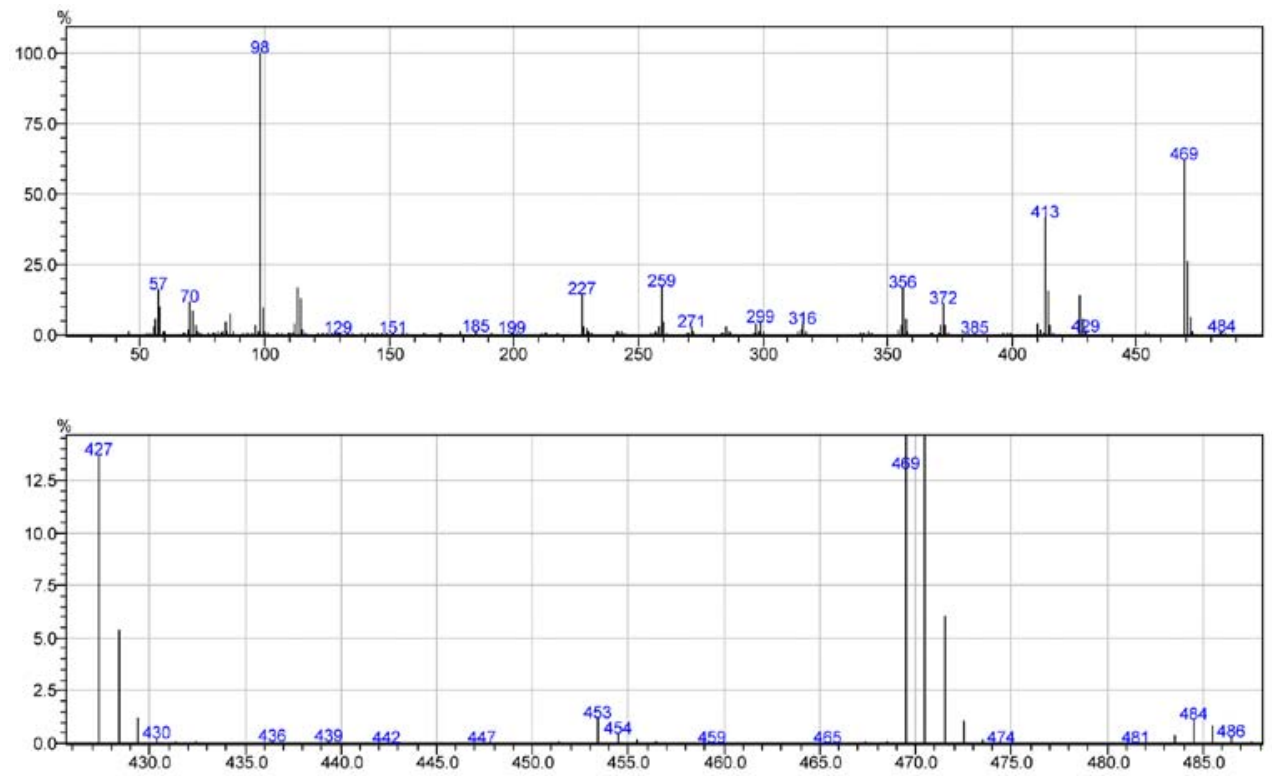

Figure 42S. EI/MS spectrum of (15)

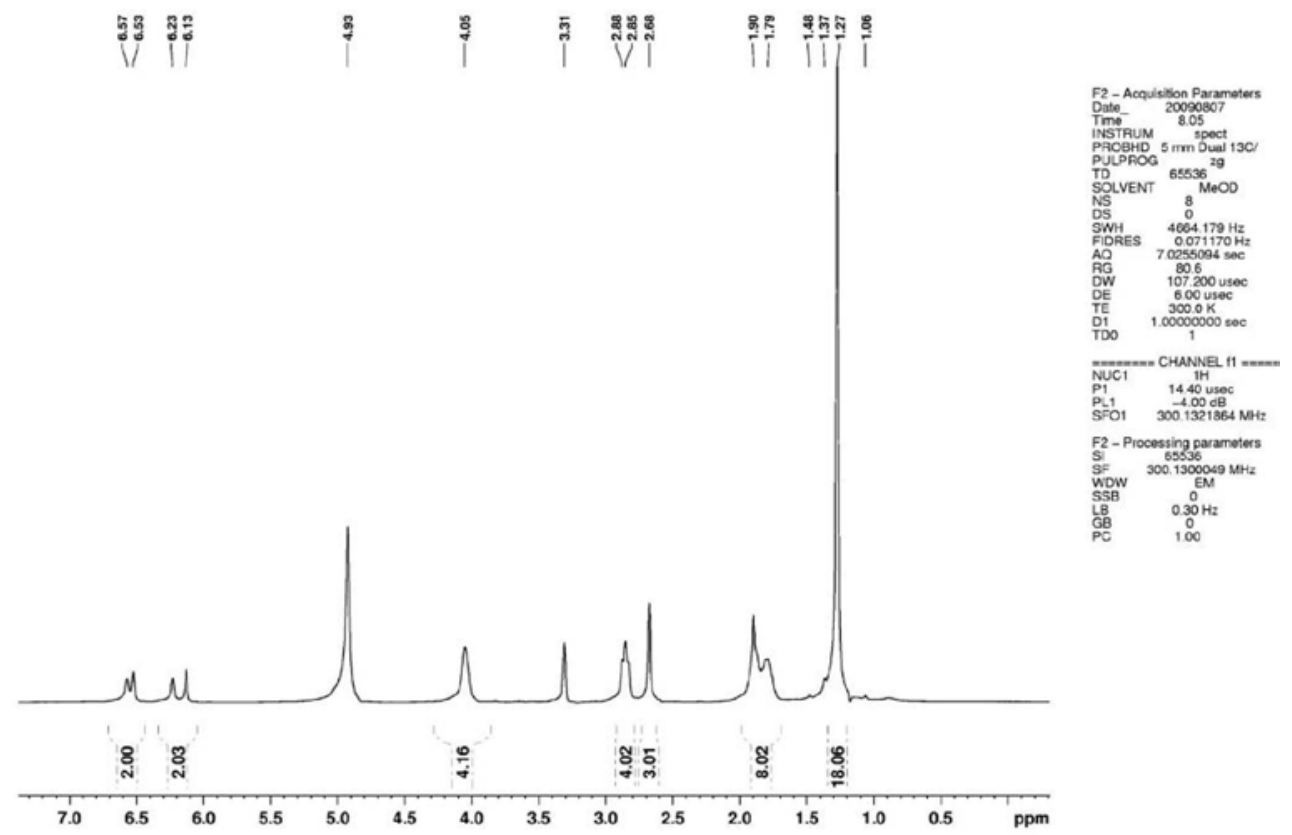

Figure 43S. ${ }^{1} \mathrm{H}$ NMR spectrum of (16), $300 \mathrm{MHz}$, methanol- $d_{4}$ 


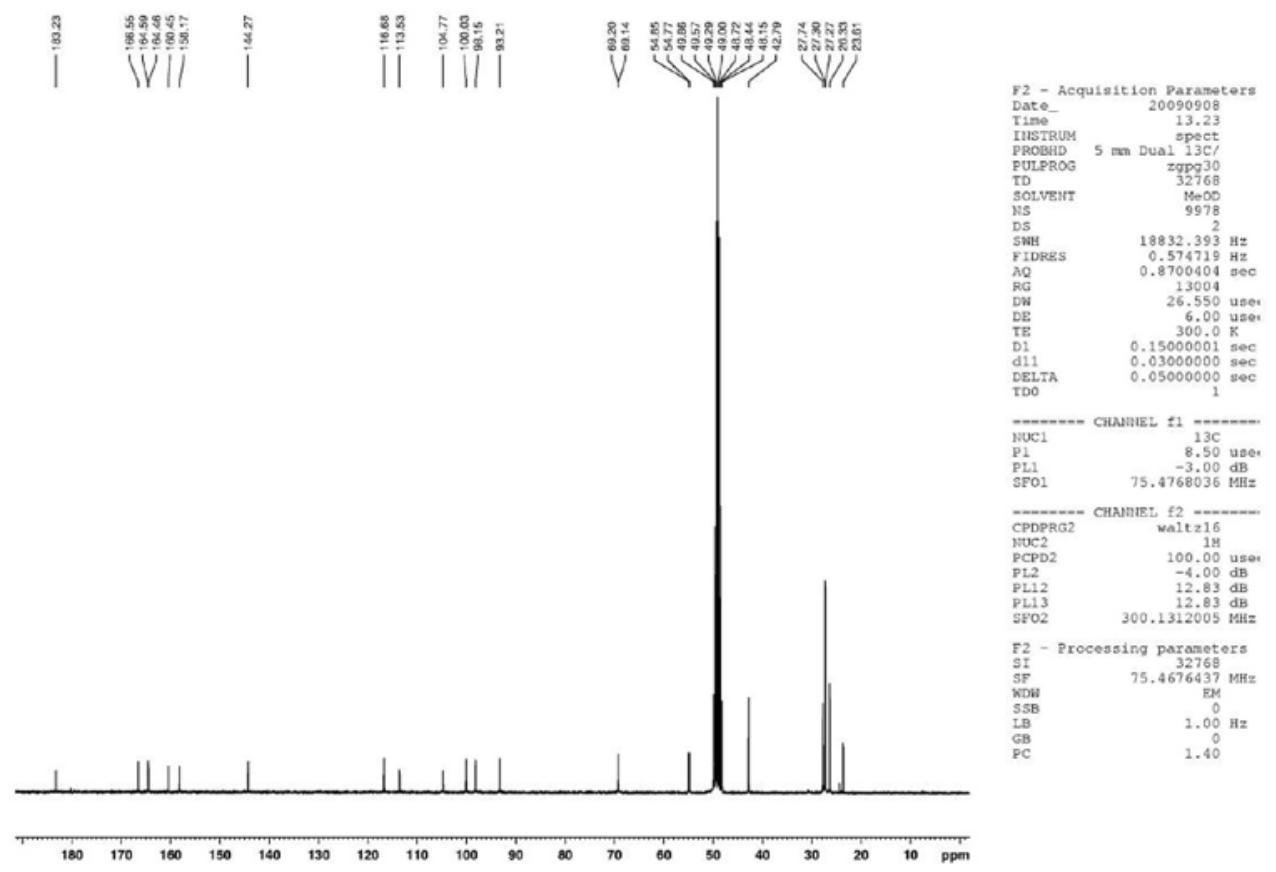

Figure 44S. ${ }^{13} \mathrm{C}$ NMR spectrum of (16), $75 \mathrm{MHz}$, methanol- $d_{4}$

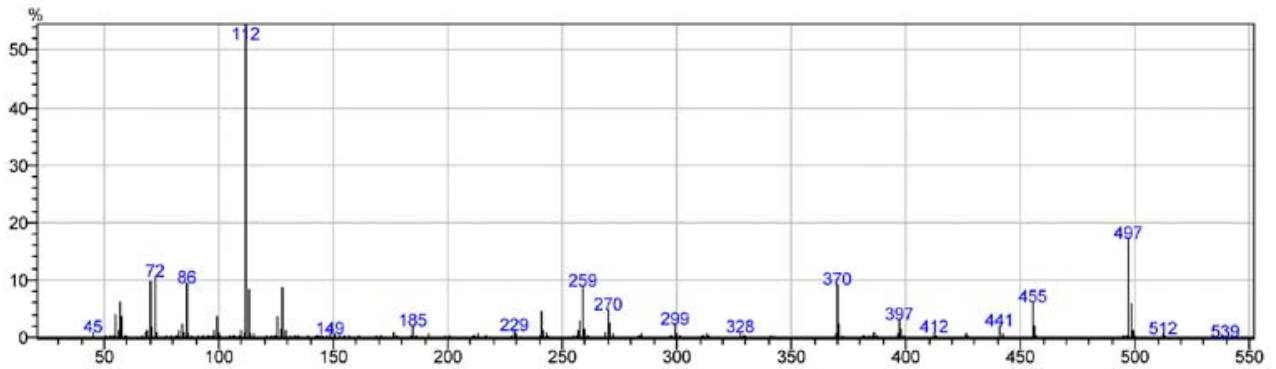

Figure 45S. EI/MS spectrum of (16)

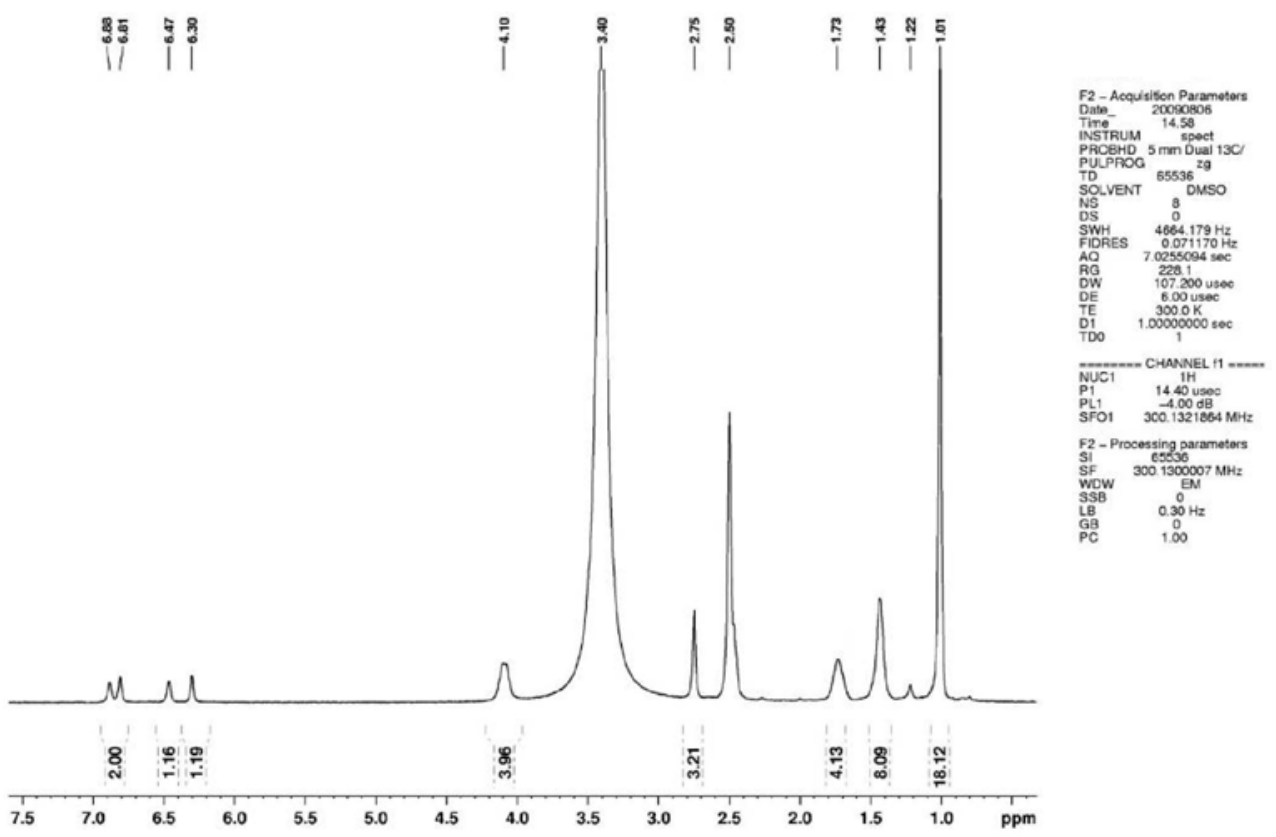

Figure 46S. ${ }^{1} \mathrm{H}$ NMR spectrum of (17), $300 \mathrm{MHz}, \mathrm{DMSO}-\mathrm{d}_{6}$ 

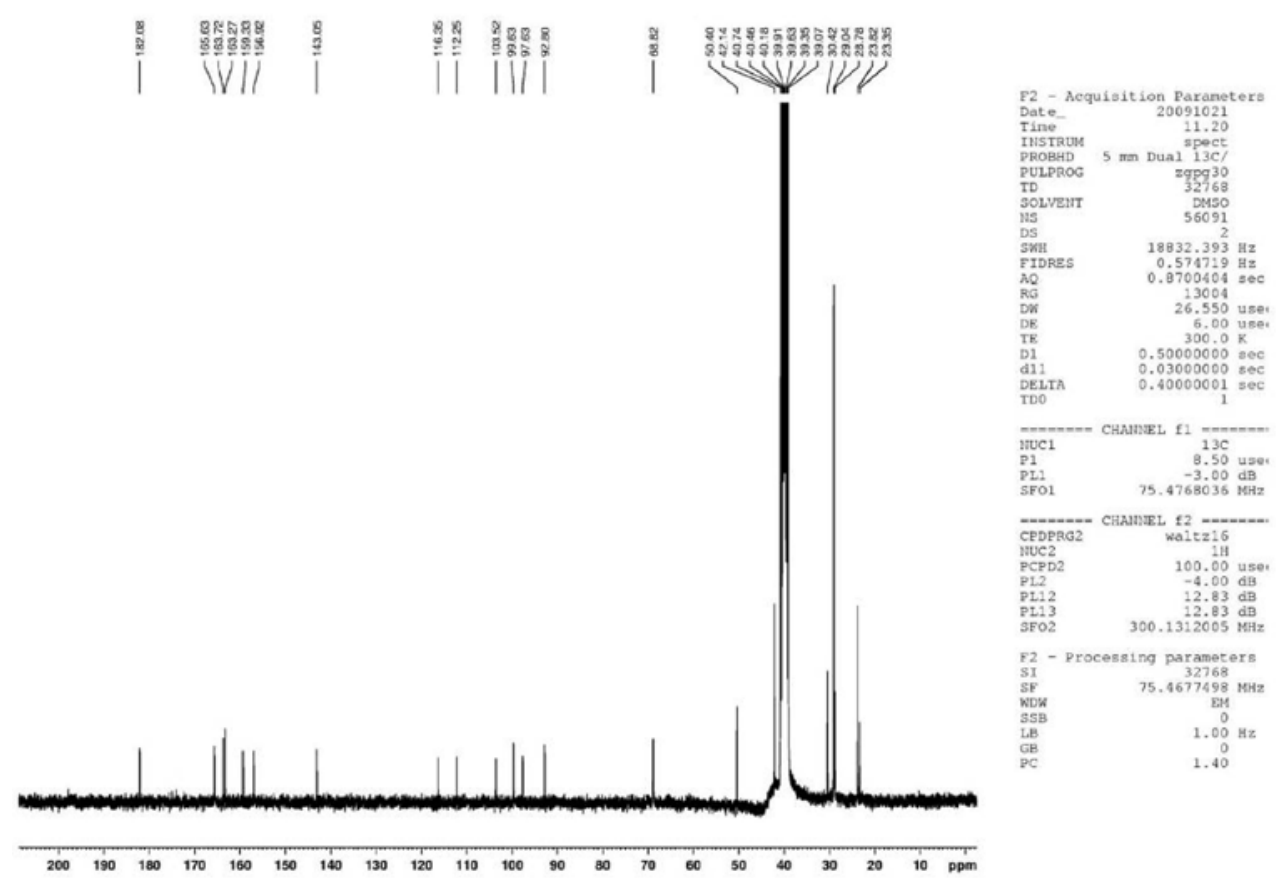

Figure 47S. ${ }^{13} \mathrm{C}$ NMR spectrum of (17), $75 \mathrm{MHz}, \mathrm{DMSO}-\mathrm{d}_{6}$
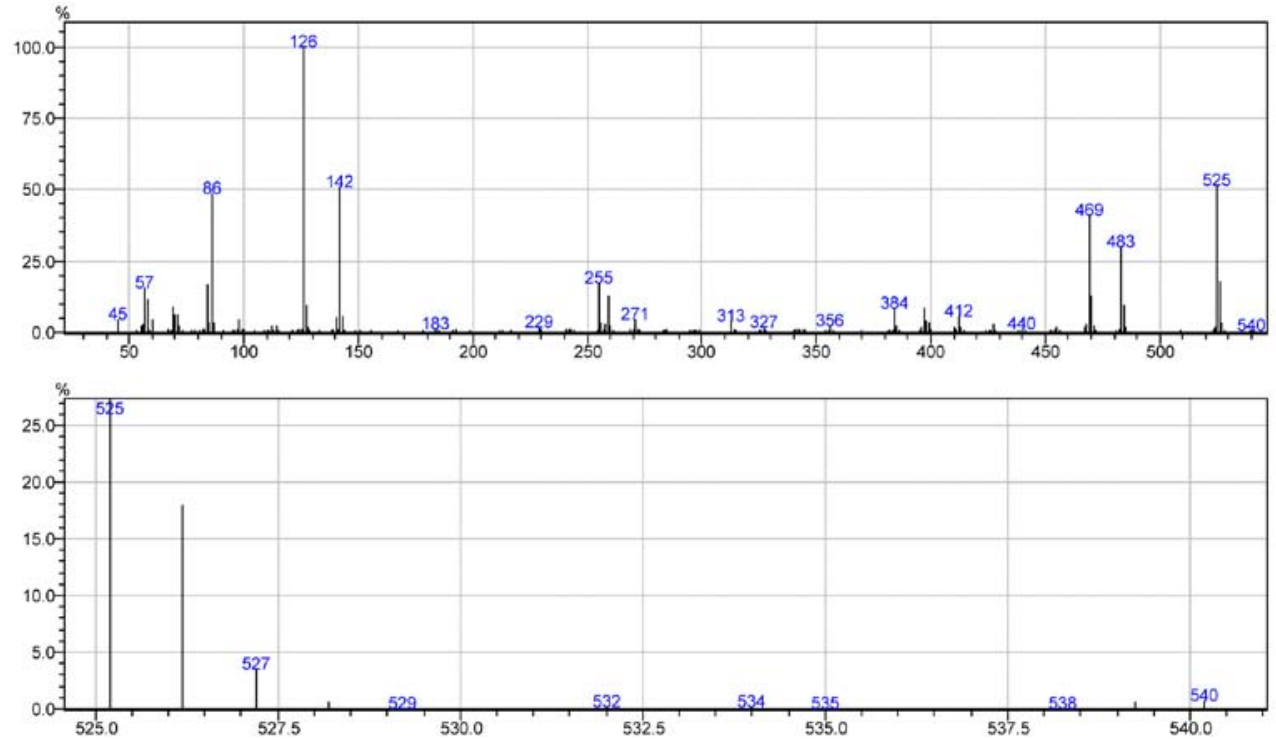

Figure 48S. EI/MS spectrum of $(\mathbf{1 7})$ 


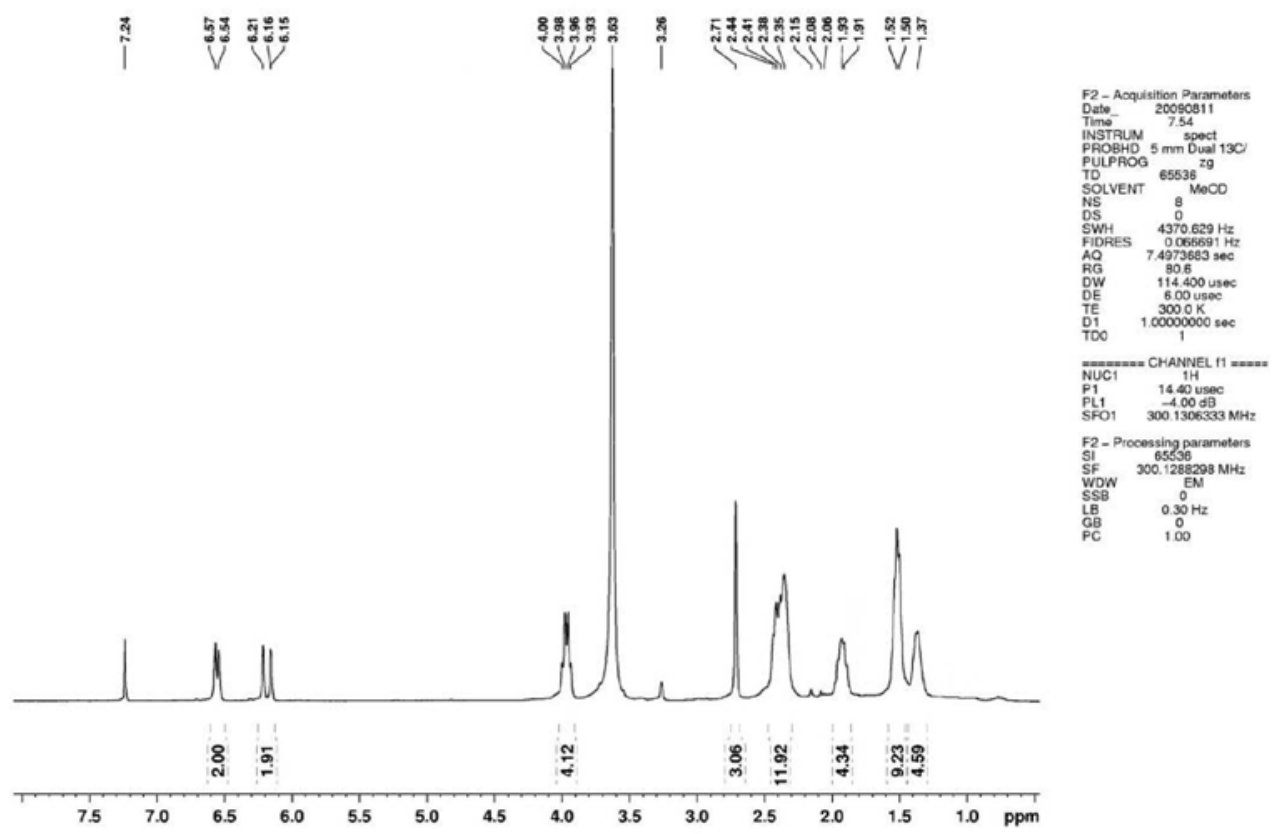

Figure 49S. ${ }^{1} \mathrm{H} \mathrm{NMR}$ spectrum of (18), $300 \mathrm{MHz}, \mathrm{CDCl}_{3} /$ methanol- $_{4}$

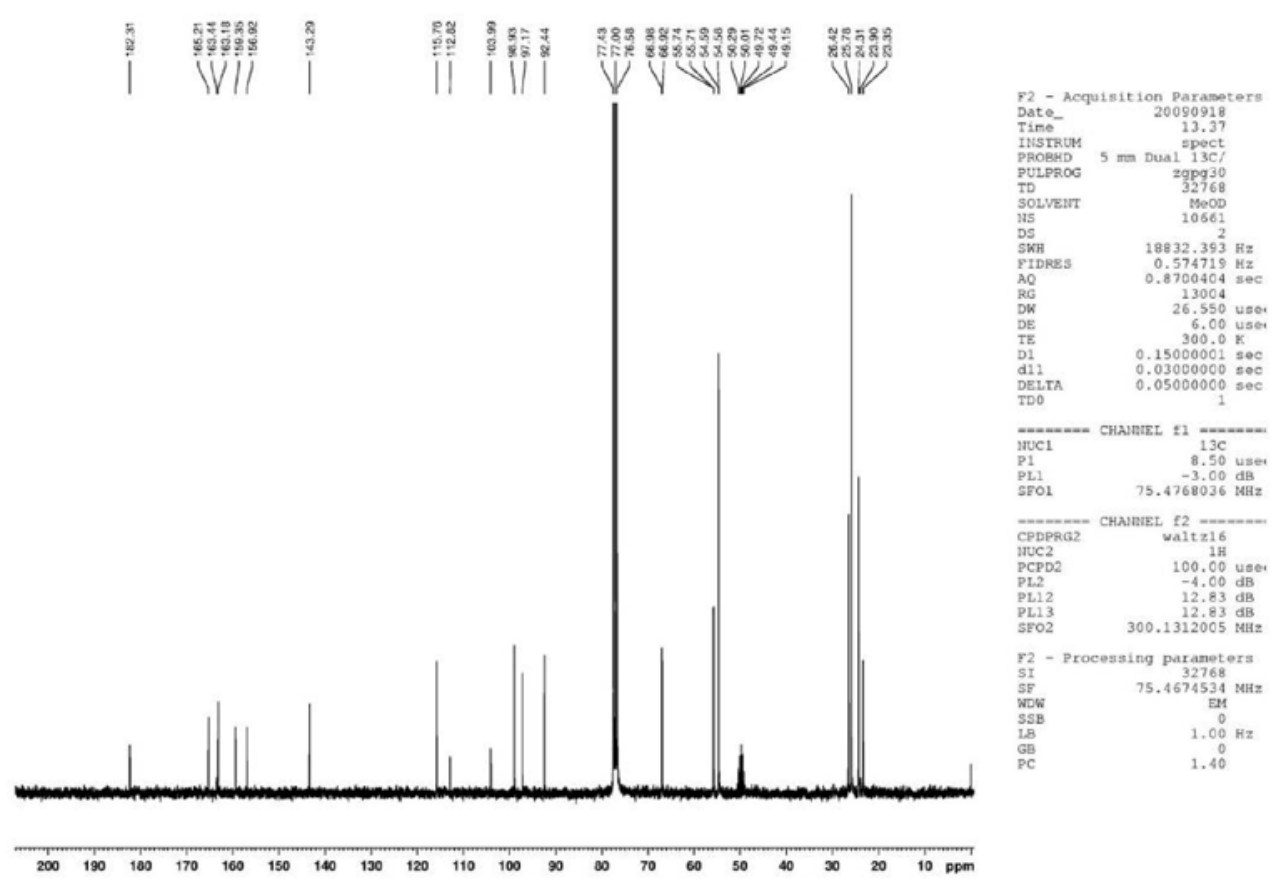

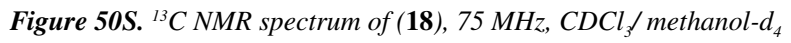




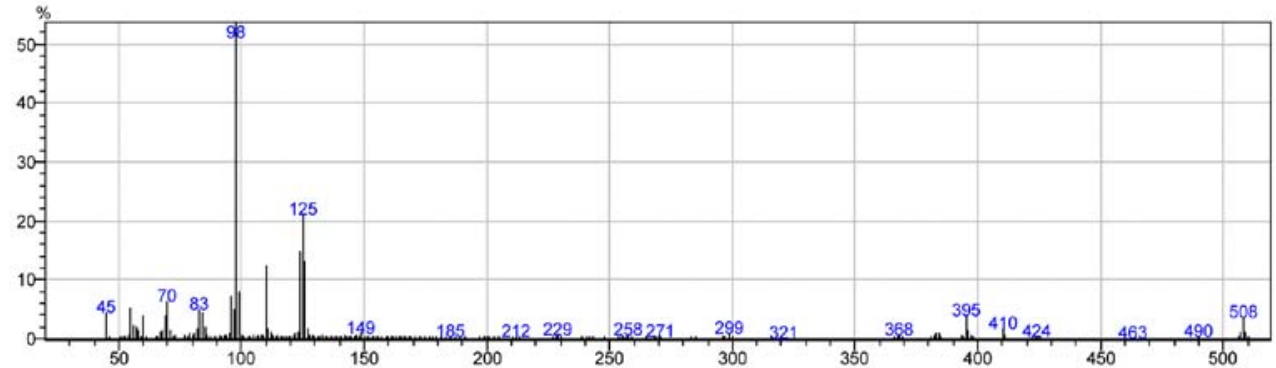

Figure 51S. EI/MS spectrum of (18)

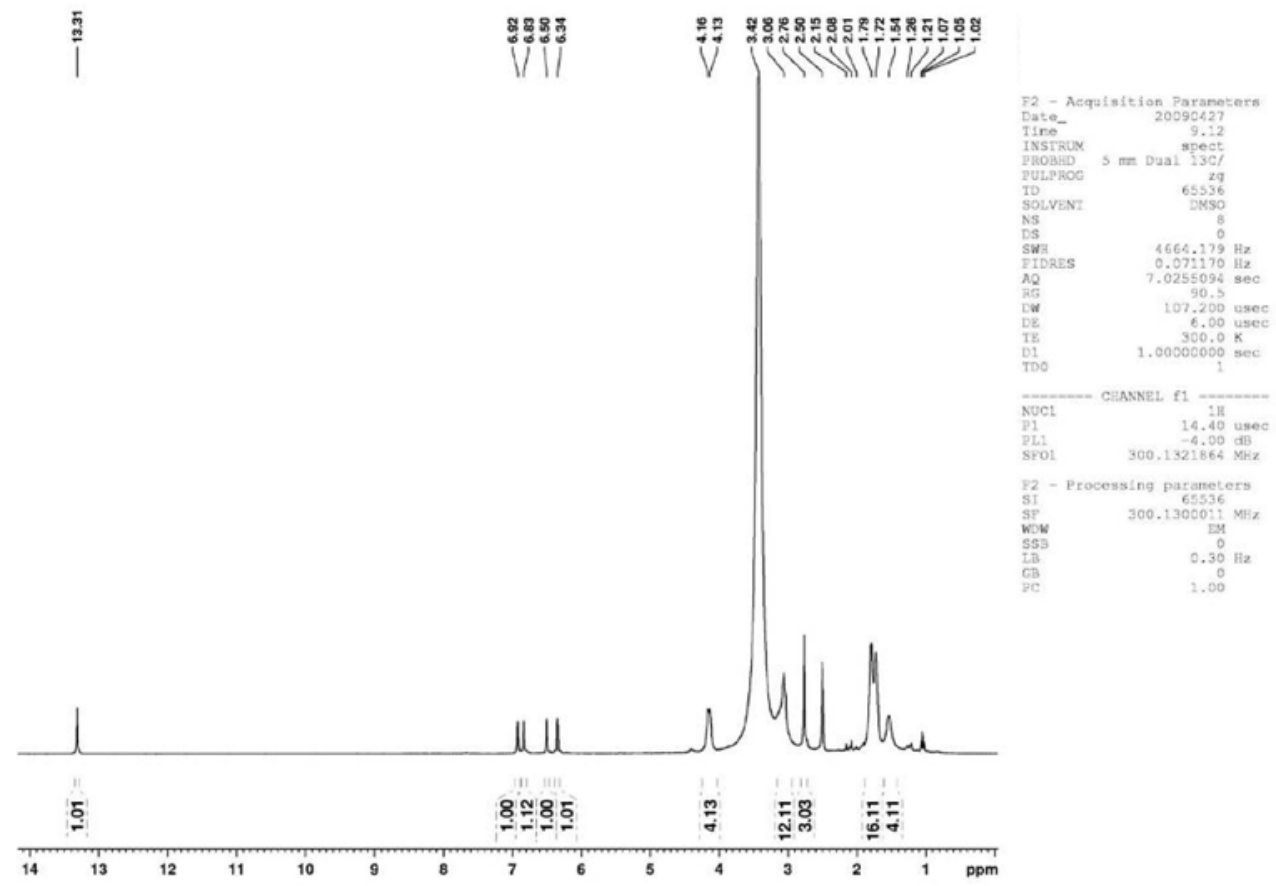

Figure 52S. ${ }^{1} \mathrm{H}$ NMR spectrum of (19), $300 \mathrm{MHz}$, DMSO- $d_{6}$

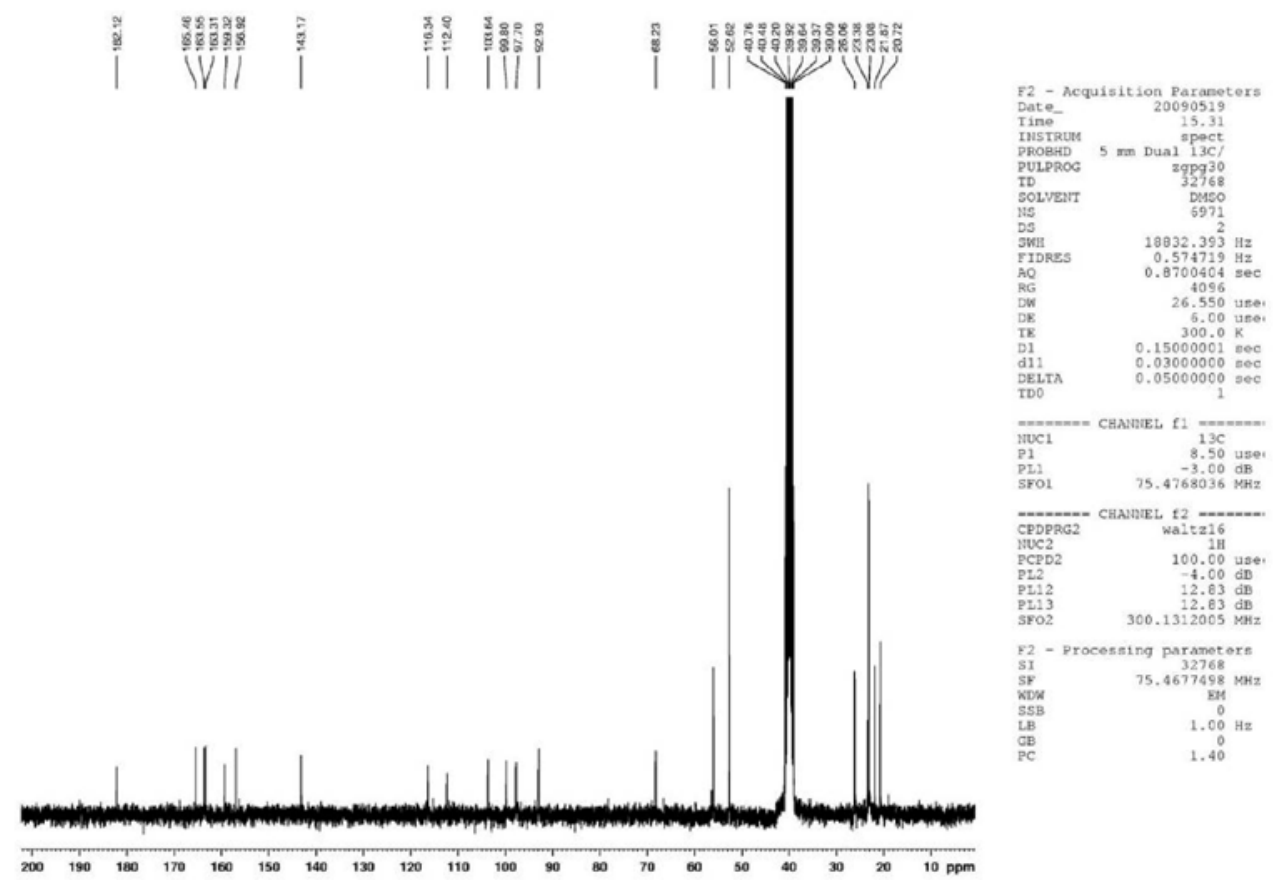

Figure 53S. ${ }^{13} \mathrm{C} N M R$ spectrum of (19), $75 \mathrm{MHz}, \mathrm{DMSO}-d_{6}$ 
$\mathrm{S} 22$

Micheletti et al.

Quim. Nova

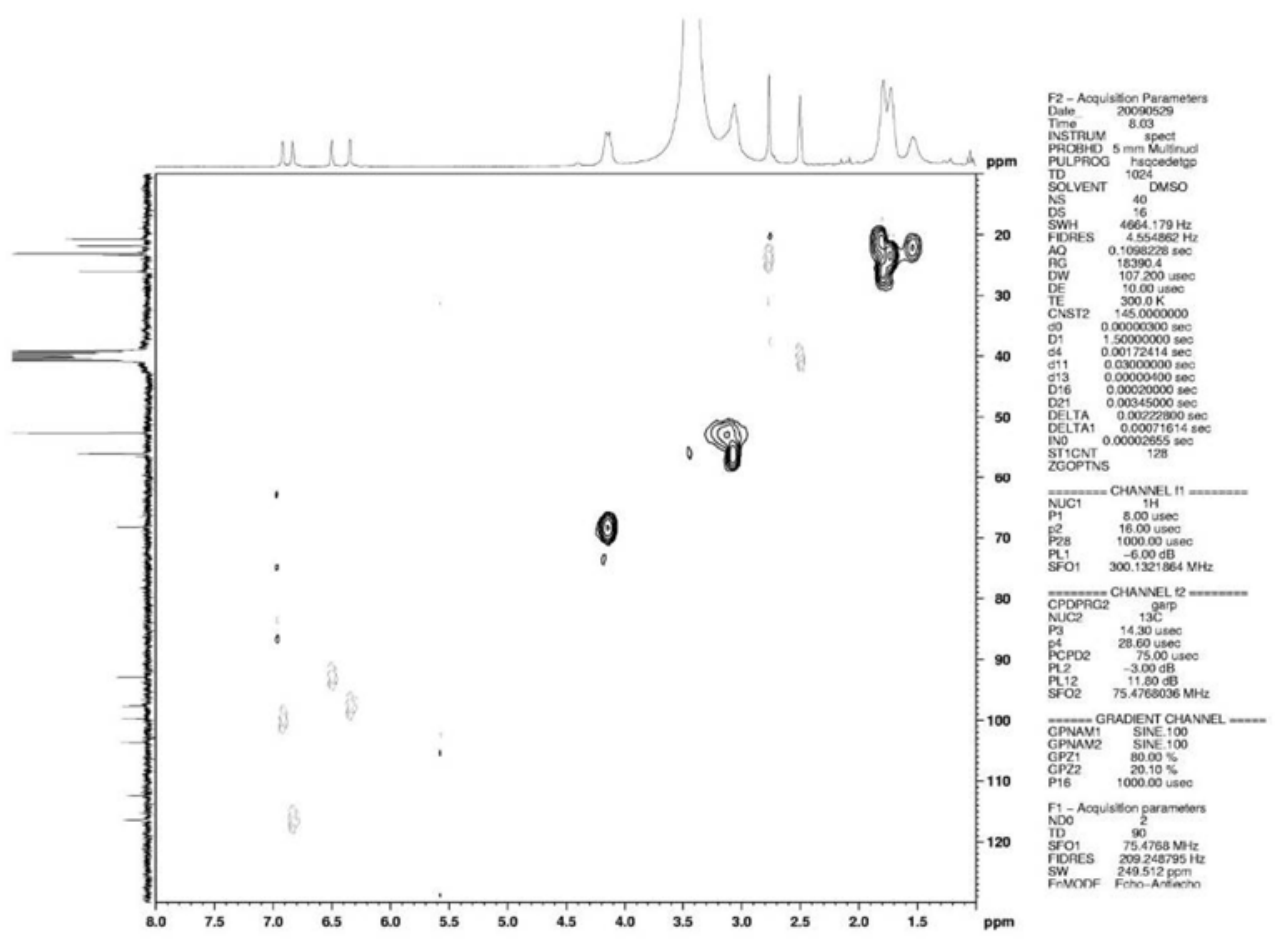

Figure 54S. HSQC spectrum of (19), DMSO-d ${ }_{6}$

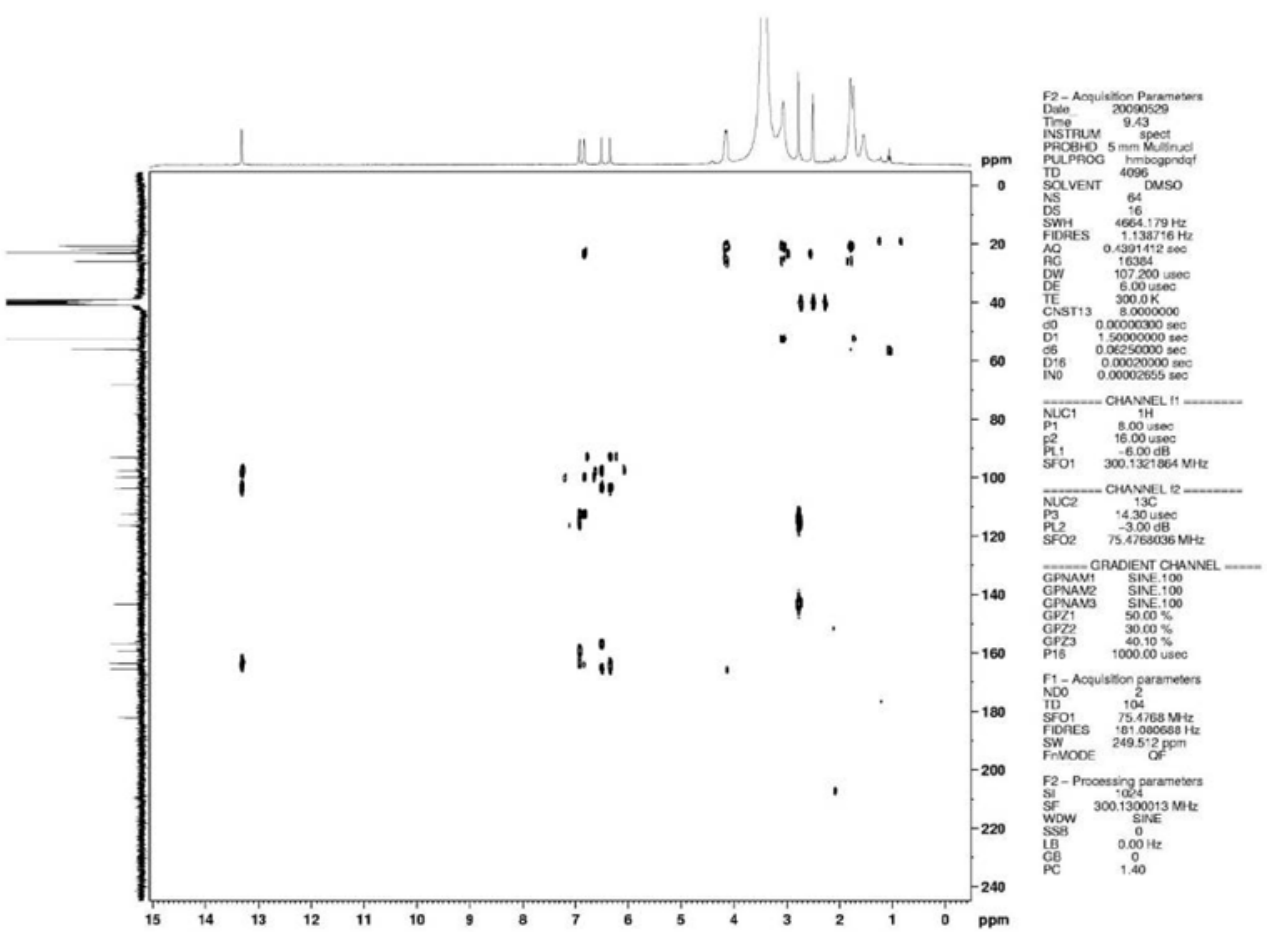

Figure 55S. HMBC spectrum of (19), DMSO- $d_{6}$ 


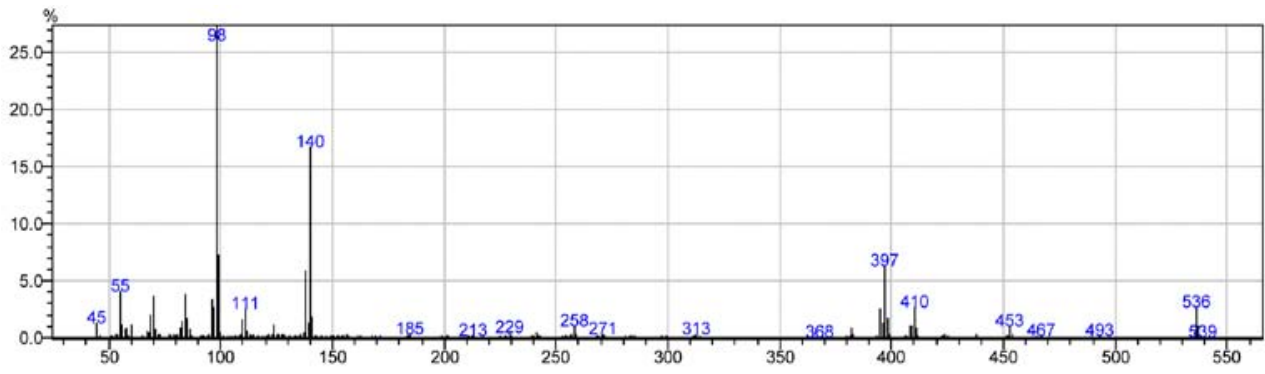

Figure 56S. EI/MS spectrum of (19)

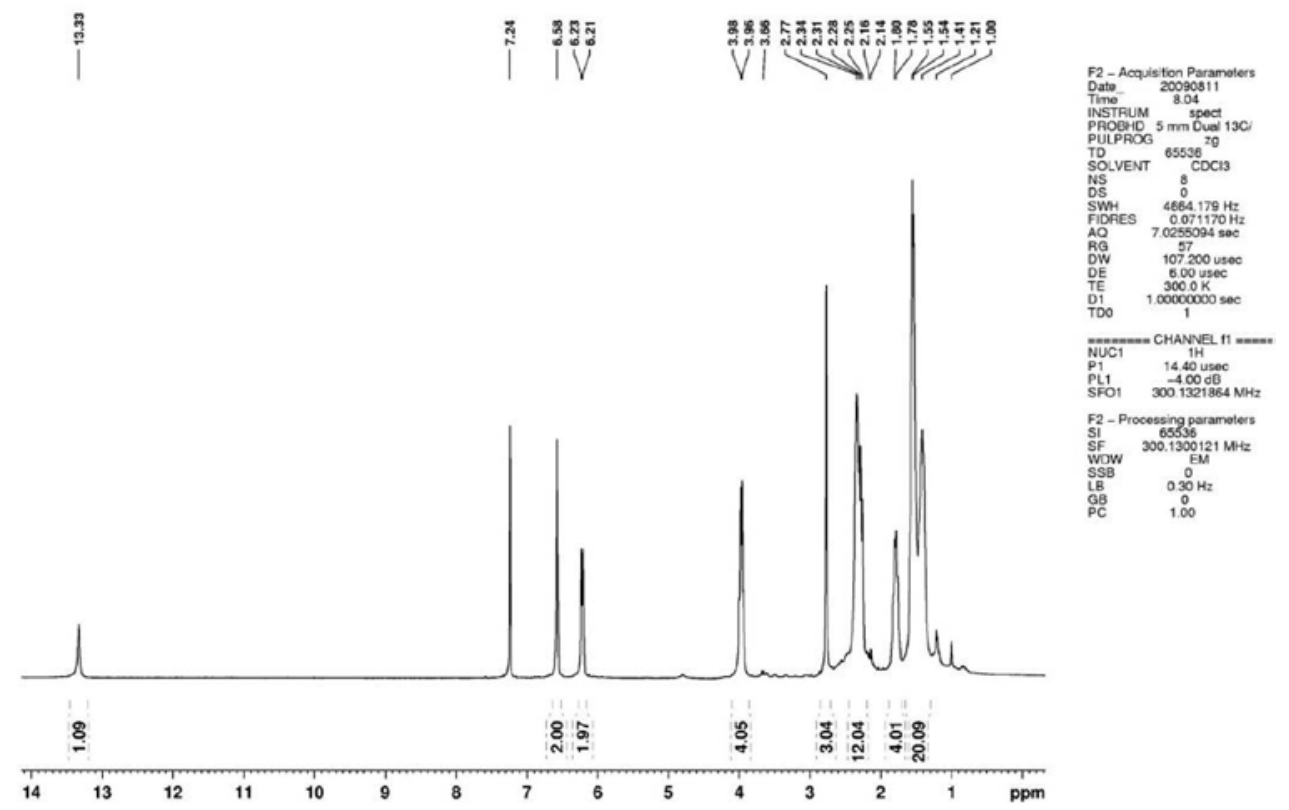

Figure $57 \mathrm{~S} .{ }^{1} \mathrm{H} \mathrm{NMR}$ spectrum of $(\mathbf{2 0}), 300 \mathrm{MHz}, \mathrm{CDCl}_{3}$
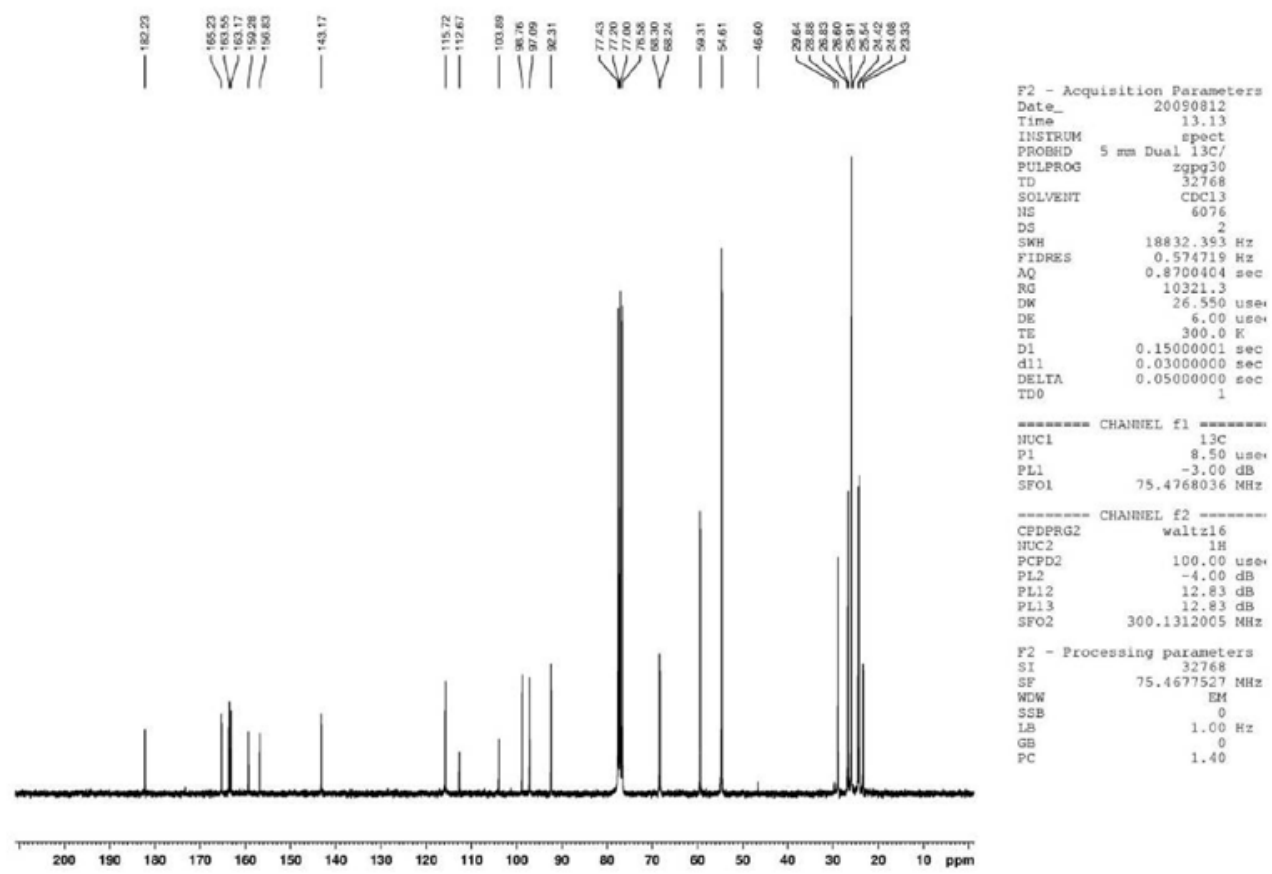

Figure 58S. ${ }^{13} \mathrm{C}$ NMR spectrum of (20), $75 \mathrm{MHz}, \mathrm{CDCl}_{3}$ 

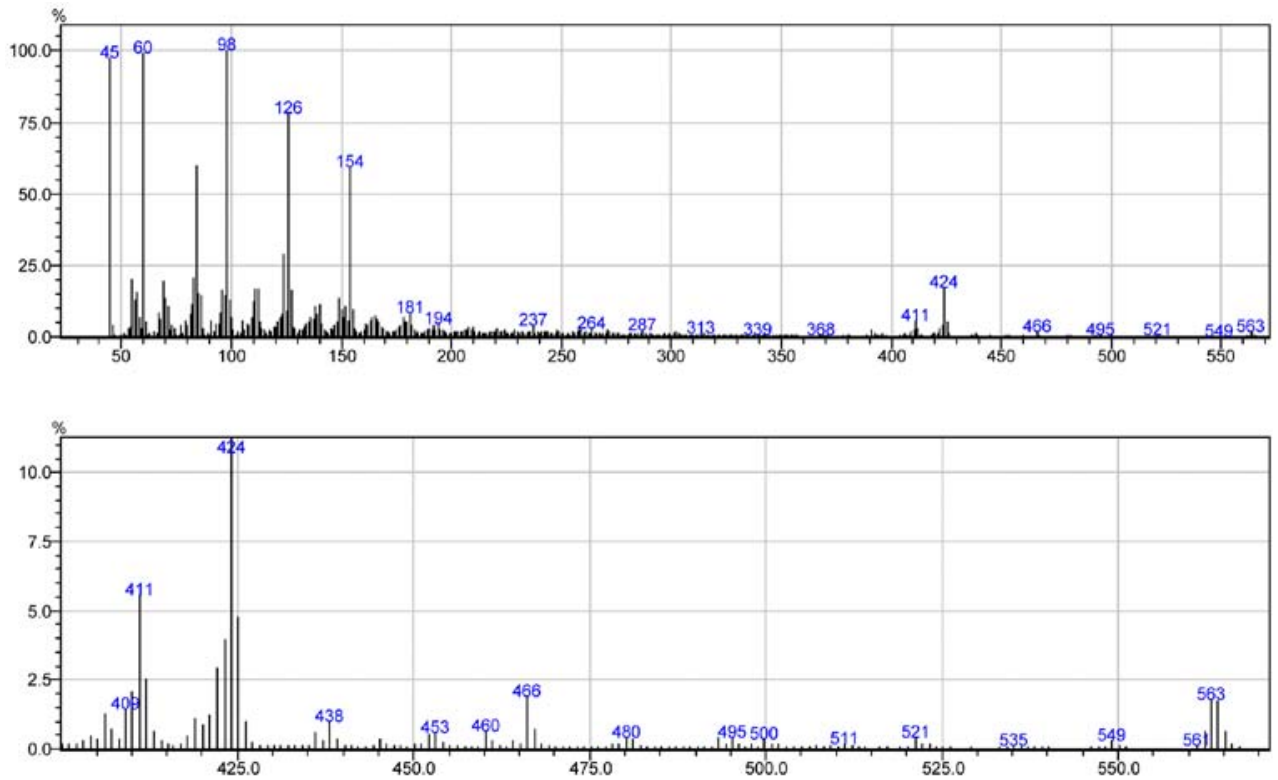

Figure 59S. EI/MS spectrum of (20) 